\title{
Hydrogen and the environment
}

\section{Schultz, M.; Markert, F.; Pilegaard, K.}

Published in:

Risø energy report 3. Hydrogen and its competitors

Publication date:

2004

Document Version

Publisher's PDF, also known as Version of record

Link back to DTU Orbit

\section{Citation (APA):}

Schultz, M., Markert, F., \& Pilegaard, K. (2004). Hydrogen and the environment. In H. Larsen, R. Feidenhans'l, \& L. Sønderberg Petersen (Eds.), Risø energy report 3. Hydrogen and its competitors (pp. 58-62). Denmark. Forskningscenter Risoe. Risoe-R No. 1469(EN)

\section{General rights}

Copyright and moral rights for the publications made accessible in the public portal are retained by the authors and/or other copyright owners and it is a condition of accessing publications that users recognise and abide by the legal requirements associated with these rights.

- Users may download and print one copy of any publication from the public portal for the purpose of private study or research.

- You may not further distribute the material or use it for any profit-making activity or commercial gain

- You may freely distribute the URL identifying the publication in the public portal

If you believe that this document breaches copyright please contact us providing details, and we will remove access to the work immediately and investigate your claim 


\section{Rise Energy Report 3}

\section{Hydrogen and its}

\section{competitors}

Edited by Hans Larsen, Robert Feidenhans'l and Leif Sønderberg Petersen 
Risø Energy Report 3

Edited by Hans Larsen, Robert Feidenhans'l and Leif Sønderberg Petersen

Reviewed by Professor Mildred Dresselhaus, Physics and Electrical Engineering, MIT, USA

Dipl.-Math. Jürgen-Friedrich Hake, Systemforschung und Technologische Entwicklung, Forschungszentrum Jülich

Professor Thorsteinn I. Sigfusson, Science Institute, University of Iceland

Design and production: Rumfang ApS 04183-29

Printing: Holmen Center-Tryk, Holbæk

Risø-R-1469(EN)

ISBN 87-550-3349-0

ISBN 87-550-3350-4(Internet)

ISSN 0106-2840 


\section{Risø Energy Report 3}

\section{Hydrogen and its competitors}

Edited by Hans Larsen, Robert Feidenhans'l and Leif Sønderberg Petersen

Risø National Laboratory

Reviewed by

Professor Mildred Dresselhaus Physics and Electrical Engineering, MIT

Dipl.-Math. Jürgen-Friedrich Hake Systemforschung und Technologische Entwicklung

Forschungszentrum Jülich

Professor Thorsteinn I. Sigfusson Science Institute, University of Iceland

Consultant Charles Butcher Science Journalist 
2. Summary, conclusions and recommendations

$\begin{array}{lr}3 . & \text { Hydrogen in European and global energy systems }\end{array}$

$\begin{array}{ll}\text { 4. Hydrogen in the Danish energy system } & 17\end{array}$

5. Hydrogen system energy technologies in global, European and Danish perspective 23

$\begin{array}{ll}5.1 \text { Technologies for producing hydrogen } & 24\end{array}$

$\begin{array}{ll}5.2 \text { Hydrogen storage } & 31\end{array}$

$\begin{array}{ll}5.3 \text { Hydrogen conversion technologies } & 37\end{array}$

$\begin{array}{ll}5.4 \text { Hydrogen for transport } & 42\end{array}$

$\begin{array}{ll}5.5 \text { Hydrogen in portable devices } & 47\end{array}$

$\begin{array}{ll}5.6 \text { Hydrogen infrastructure } & 52\end{array}$

6. Hydrogen - Environmental and safety aspects $\quad 57$

$\begin{array}{ll}6.1 \text { Hydrogen and the environment } & 58\end{array}$

$\begin{array}{ll}6.2 \text { Hydrogen safety } & 63\end{array}$

$\begin{array}{lll}7 . & \text { Index } & 67\end{array}$

\begin{tabular}{lr} 
8. & References \\
\hline
\end{tabular} 


\section{Preface}

HANS LARSEN, ROBERT FEIDENHANS'L AND LEIF SØNDERBERG PETERSEN, RIS $\varnothing$ NATIONAL LABORATORY

Interest in the hydrogen economy has grown rapidly in recent years. Those countries with long traditions of activity in hydrogen research and development have now been joined by a large number of newcomers. The main reason for this surge of interest is that the hydrogen economy may be an answer to the two main challenges facing the world in the years to come: climate change and the need for security of energy supplies. Both these challenges require the development of new, highly-efficient energy technologies that are either carbon-neutral or low emitting technologies.

Another reason for the growing interest in hydrogen is the strong need for alternative fuels, especially in the transport sector. Alternative fuels could serve as links between the different energy sectors, especially between the power system and the transport sector, to facilitate the uptake of emerging technologies and increase the flexibility and robustness of the energy system as a whole.

This is the background for this Risø Energy Report, the third in a series that provides a perspective on energy issues at global, regional and national levels. The following pages provide a critical examination of the hydrogen economy and its alternatives. The Report explains the current R\&D situation, addresses the challenges facing the large-scale use of hydrogen, and makes some predictions for the future.

The Report explores the current and future role of hydrogen in energy systems at Danish, European and global levels. It discusses the technologies for producing, storing and converting hydrogen, the role of hydrogen in the transport sector and in portable electronics, hydrogen infrastructure and distribution systems, and environmental and safety aspects of the hydrogen economy.

Individual chapters of the Report have been written by Risø staff members and leading Danish and international experts. The Report is based on internationally recognised scientific material, and is fully referenced and refereed by an international panel of independent experts. Information on current developments is taken from the most up-to-date and authoritative sources available.

Our target groups have colleagues, collaborating partners, customers, funding organisations, the Danish government and international organisations including the European Union, the International Energy Agency and the United Nations. 



\section{Summary, conclusions and recommendations}

HANS LARSEN, ROBERT FEIDENHANS'L AND LEIF SØNDERBERG PETERSEN, RISØ NATIONAL LABORATORY

Interest in the hydrogen economy and in fuel cells has increased dramatically in recent years. The main reason is that a hydrogen economy may be an answer to the two major challenges facing the future global economy: climate change and the security of energy supplies.

Both these challenges call for development of new, highly-efficient technologies that are either carbonneutral or low emitting technologies. The commercial introduction of such technologies has huge potential to create economic growth and new high-tech jobs.

The need for new and sustainable energy technologies is particularly urgent in the transport sector, where energy demand keeps growing, especially in China and other developing countries. It will be a major challenge for the transport sector to convert to carbon-neutral fuels, in terms of both technology and infrastructure. Hydrogen could link the power system to the transport sector, increasing the flexibility and robustness of the total energy system. Hydrogen could also be used to store energy produced from renewable, intermittent energy sources, and hence open the way for their large-scale penetration into the total energy system.

Unlike coal or oil, hydrogen is not a primary energy source. Instead, it is an energy carrier comparable to the electricity grid or a district heating network, and as such it needs to be converted from other sources of energy. Most hydrogen produced today is used in the chemical industry. The dominant method of production is steam reforming of natural gas, which is currently used to make more than $90 \%$ of all hydrogen.

Alternative production methods include gasification and reforming of other fuels, electrolysis, and biological methods. Biogas can be reformed directly to yield hydrogen. Solid fuels such as coal and biomass can be gasified, followed by reforming of the resulting gas. Electrolysis is a 200-year-old method, and is presently, and for the forseeable future the most straightforward way to make hydrogen from water using electricity, though it is not economically competitive at the moment.

Biological routes to hydrogen, including biotechnology and "bio-inspired" methods, have excellent long-term potential as sustainable energy sources, but basic science breakthroughs are needed, however, to make such methods commercially viable.

Renewable energy sources can be used to produce methane, methanol and other hydrocarbon fuels that deserve careful consideration as alternatives to "renewable" hydrogen.

A serious challenge, and potentially a complete obstacle, to the hydrogen economy is the need for cost-effective ways to store hydrogen. The low energy density of hydrogen makes it difficult to store in a cost-effective way smaller amounts in cars and portable devices. Possible answers are to store hydrogen in solid form, as metal hydrides, or as synthetic hydrocarbons, but in each case breakthroughs in basic science will be essential. Although pressurised storage of gaseous hydrogen is a well-known technology used in large scale, new lightweight storage vessels will be needed to make the hydrogen economy practical. Very large quantities of hydrogen could be stored in underground caverns similar to those now used for natural gas.

Existing fuel cells can convert hydrogen efficiently into electric power. Emerging fuel cell technologies can do the same for other hydrogen-rich fuels, while generating little pollution. Fuel cells are already close to market introduction in niche areas such as portable electronic devices and small power units, which do not require a large hydrogen infrastructure. Applications like this could pave the way to a future hydrogen economy based on hydrogen-rich fuels.

If large amounts of hydrogen are to be used across the world, a comprehensive hydrogen infrastructure will have to be developed. Hydrogen grids could become a fourth backbone in the energy supply system, alongside the existing electricity and natural gas grids and district heating systems. Because hydrogen can be interconverted between electricity and fuel, however, hydrogen grids could also link the other energy backbones to an extent that is not possible today.

Developing robust solutions for a hydrogen infrastructure in road transport is particularly urgent. Prototype hydrogen-based fuel cell vehicles are already in operation, and hydrogen vehicles could enter the market in 15-20 years' time.

Hydrogen as a fuel has a low environmental impact at the point of use, with no emissions of greenhouse gases or of most other pollutants. The amounts of hydrogen entering and leaving the atmosphere, and the routes by which this happens, are still very uncertain, but our current knowledge suggests that the widespread use of hydrogen would bring little environmental risk.

Hydrogen is no more hazardous than conventional fuels, but its safety-related properties are significantly different from those of conventional fuels. Thus, detailed risk assessments are needed for every element in the hydrogen supply chain.

International hydrogen research and development is comprehensive. Japan is one of the most ambitious countries in its hydrogen programme. The USA has 
recently launched an extensive research and development strategy to develop hydrogen vehicles and a hydrogen infrastructure. Iceland plans a national hydrogen infrastructure for transport and fishery.

2003 saw the launch of the International Partnership for the Hydrogen Economy (IPHE), the largest global effort so far aimed at harmonising progress towards a global hydrogen infrastructure. The IPHE partners are Australia, Brazil, Canada, China, the European Commission, France, Germany, Iceland, India, Italy, Japan, Norway, Russia, South Korea, the UK and the USA.

The European Commission in 2002 set up a High Level Group on Hydrogen and Fuel Cells.

Hydrogen R\&D in Denmark related to the whole value chain of the hydrogen economy, and Danish research communities have a strong position in European R\&D projects, especially in fuel cells.

The development of hydrogen systems is in line with the current trend towards decentralised and distributed energy systems. These are high on EU's agenda, and are expanding rapidly in the USA.

\section{Driving forces}

The development of a hydrogen economy is driven by several forces related to the environment and security of energy supply. The most important of these forces are:

- A hydrogen-based energy system will increase the opportunity to use renewable energy in the transport sector. This will increase the diversity of energy sources and reduce overall greenhouse gas emissions.

- Hydrogen in the transport sector can reduce local pollution, which is a high priority in many large cities.

- Government targets for reducing vehicle noise may be met by replacing conventional engines with hydrogen powered fuel cells.

- The robustness and flexibility of the energy system will be increased by the introduction of hydrogen as a strong new energy carrier that can interconnect different parts of the energy system.

- Fuel cells for battery replacement and backup power systems are niche markets in which price and efficiency are relatively unimportant. Sales in this market will drive the technology forward towards the point at which fuel cells will become economic for the introduction into the energy sector.

- Hydrogen electrolysers/fuel cells connected directly to wind turbines are a convenient way to balance out local fluctuations in the availability of wind power. With its strong position in wind turbines, Denmark could do very well in this market.

- The development of fuel cells and a hydrogen economy will provide new market opportunities and new jobs in Denmark as well as elsewhere.

- Present knowledge indicates that hydrogen as an energy carrier will involve little environmental risk.

\section{Barriers}

A hydrogen-based society will require fundamental breakthroughs in both basic science and technology. There is a huge performance gap between what today's technologies can deliver and what a market-driven hydrogen economy will need. Most studies agree that key hydrogen technologies are still too inefficient and too expensive to meet our energy demands in the near future. Most importantly:

- More efficient and cheaper ways to make hydrogen must be developed.

- Better storage systems for hydrogen in the transport sector are critically important.

- Fuel cell prices must fall, and their operating lifetime must be increased.

- A prerequisite for the introduction of fuel cell vehicles is an adequate hydrogen distribution infrastructure.

\section{Conclusions}

Long-term challenges such as climate change and security of energy supply require long-term solutions. A combination of fuel cells, which will reach commercial maturity in 10-20 years, and a hydrogen infrastructure, could be a way forward if the technological barriers can be overcome. This combination has the potential to create an efficient, clean and sustainable energy system within the next $20-40$ years.

Present knowledge indicates that large-scale use of hydrogen will pose no major environmental risk. Hydrogen is also no more hazardous than conventional fuels, as long as the proper technical standards and safety rules are used.

The challenge for Danish R \& D communities is to develop critical mass in selected areas of fuel cell and hydrogen $\mathrm{R} \& \mathrm{D}$, and to exploit these areas both academically and economically.

The most pressing technical issue is to develop better storage systems for hydrogen, especially in the transport sector. Failure to do this could jeopardise the entire hydrogen vision.

In the long term, hydrogen could be a key element in highly diversified, robust, environmentally-benign and affordable energy systems.

\section{Recommendations}

Denmark has the potential to become a key international player in selected areas of research, innovation and product development related to the hydrogen economy, since Danish R\&D in hydrogen and fuel cells is already significantly engaged in European research platforms in this area. This, in turn, would allow Danish industry to play a major role in the new market opportunities. For this potential to become reality, it is important to act quickly. Unless the right political decisions are taken within the next few years, Denmark will miss the hydrogen high-speed train. 
We see possibilities for Danish commercial breakthroughs in several areas of the hydrogen economy. As we have pointed out, Denmark is internationally recognized for its work in fuel cells, a key element in the hydrogen economy. Danish expertise and know-how in sustainable energy technologies is unique. As a result, Danish companies could become internationally competitive in the development of new technologies, consultancy and services for the production, storage, distribution, conversion and end-use of hydrogen. And as we see it, this market will undoubtedly grow over the next few decades.

A prerequisite is that Danish research, both basic and applied, focuses on carefully selected technology platforms, demonstration projects and Europe-wide projects. Danish researchers should also help to develop the international standards and regulations needed to allow the safe and widespread implementation of new hydrogen technologies.

Research areas that in particular need to be strengthened are:

- Hydrogen production by environmentally-benign routes, including sustainable energy sources such as wind and solar power and biological/biotech methods.
- Fuel cells and electrolysers as key technologies for balancing electricity grids in conjunction with hydrogen storage and distribution systems.

- The environmental effects of hydrogen.

- Storage of hydrogen for use in vehicles, power plants and electronics, including portable applications.

- Infrastructure development, especially in the transport sector.

- International standards and regulations.

As hydrogen technologies mature, there will be a need for large-scale demonstration projects ("lighthouse" projects).

The Copenhagen-Malmö-Gothenburg Øresund metropolitan area could be the setting for a lighthouse project on hydrogen infrastructure involving two countries and both land and sea transport.

In conclusion, focused R\&D push combined with suitable regulation and market incentives could allow Denmark to become a world leader in hydrogen and fuel cell energy systems. Delay, however, is likely to mean that Denmark will be out-manoeuvred by the fastgrowing international competition.

Estimated maximum potential market share for Danish industry in various hydrogen technologies and services, with a timescale for the likely commercial introduction of each. The chart, which is purely qualitative, was drawn up by the editors in co-operation with the authors of the various chapters of this Report.

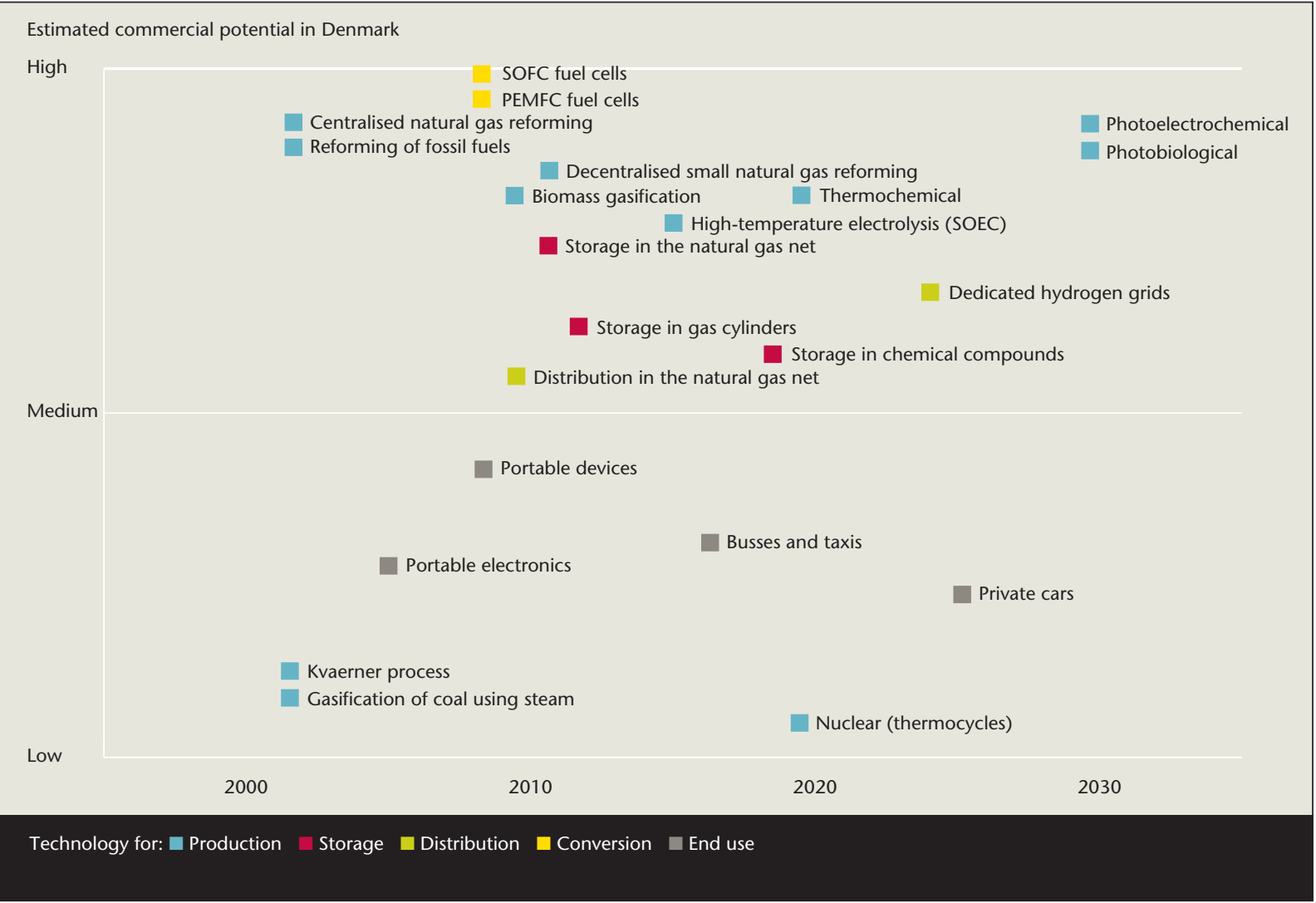





\section{Hydrogen in European and global energy systems}

POUL ERIK MORTHORST, RISØ NATIONAL LABORATORY; ULRICH BÜNGER, LUDWIG-BÖLKOW-SYSTEMTECHNIK, GERMANY; BENT SØRENSEN, RUC, DENMARK

\section{Introduction}

Interest in energy systems based on hydrogen is growing rapidly. Countries including the USA, Japan and Germany have been active in this area for a number of years, but recently a large number of new countries have appeared on the hydrogen scene. These include Australia, Romania, Greece, China and India.

The main reason for this renewed interest is that a future hydrogen society may be one of the solutions to the two major challenges facing the future global economy: climate change and security of energy supply. Both these challenges require the development of new, highly-efficient energy technologies that are either carbon-neutral or emit only small amounts of carbon dioxide.

While demand for oil is expected to keep on growing, the supply of oil is forecasted to peak within the next 10-20 years. In a longer time-perspective, there is thus a strong need for new fuels, especially in the transport sector. Several existing and emerging low-carbon energy technologies, including photovoltaics, wind power, wave power and nuclear plants, yield electricity as their primary output. If these technologies are to contribute significantly to overall energy production, and not just to the electricity grid, we will need ways to link the different energy sectors, especially electricity and transport. This will not only facilitate the adoption of new technologies but will also increase the flexibility and robustness of the whole energy system.

Hydrogen could provide such links, and by providing a way to store energy for longer periods of time, it could also pave the way for the large-scale use of intermittent sources of renewable energy, such as solar, wind and wave power. ${ }^{1}$

\section{Hydrogen and energy systems}

Unlike coal or oil, hydrogen is not a primary source of energy. Hydrogen cannot be collected by mining or harvesting; instead, it has to be manufactured, usually either by electrolysis or by steam reforming of natural gas [7]. This makes hydrogen an "energy carrier" on a par with the electricity grid or a district heating network.

In electrolysis, electrical energy is used to split water molecules into hydrogen and oxygen. This process is well-understood and the energy conversion efficiency is approximately $65-75 \%$, based on the lower heating value (LHV) of the hydrogen. Any source of electricity can be used, though electricity from renewable or nuclear sources is preferable if the hydrogen is to be used to cut carbon dioxide emissions or reduce dependence on fossil fuels.

Steam reforming of natural gas converts methane $\left(\mathrm{CH}_{4}\right)$ to hydrogen $\left(\mathrm{H}_{2}\right)$, carbon monoxide $(\mathrm{CO})$ and carbon dioxide $\left(\mathrm{CO}_{2}\right)$. This process can achieve a practical efficiency of about $80 \%$ based on LHV and is used for more than $90 \%$ of all hydrogen manufactured today.

Hydrogen can be produced in a number of other ways (Figure 1). Fossil fuels such as coal can be gasified and reformed to yield hydrogen, with the option of capturing and sequestering the resulting carbon dioxide. Biomass can be liquefied or gasified and reformed, and biogas can be reformed directly. Efficiencies for hydrogen production from biomass, biogas and coal are similar, and lower than those for steam reforming.

Considerable effort is being put into developing new and environmentally-attractive ways to make hydrogen. Approaches include photobiological, photoelectrochemical and photochemical processes; the aim is to create hydrogen from sunlight and water more directly than is possible from, say, a combination of solar cells and electrolysis. At the moment such processes are in their infancy, and much more research needs to be done before commercial products can be developed [7].

Today a number of countries have quite a substantial production of hydrogen, among these are Germany and the USA. In the Nordic countries most of the production of hydrogen is related to oil refineries. In Denmark the total production of hydrogen is approximately 300 $\mathrm{MNm}^{3}$ per year.

Storage of hydrogen will be an important part of any hydrogen-based energy system. Hydrogen has a high energy density: a kilogramme of hydrogen contains more than three times as much energy as a kilogramme of gasoline or natural gas. On a volume basis, however, hydrogen has only about one-third of the energy content of natural gas, and this makes it difficult to store hydrogen cost-effectively in small quantities [7]. Today, hydrogen is most commonly stored as a highpressure gas, in tanks made from composites or steel. Very large amounts of compressed hydrogen can also be stored in suitable underground caverns, such as mined cavities in salt domes; this is a well-known and relatively cheap technology. Technologies are currently under 
development to store hydrogen as a cryogenic liquid in insulated tanks or within solid materials, including metal hydrides and nanoporous materials such as activated carbon or organometallic compounds.

Applications for hydrogen as a fuel include portable equipment, transport, power generation (centralised or dispersed) and industrial processes. For power generation and industrial applications, hydrogen can be burned as a substitute for natural gas. For transport, hydrogen can be used in a gasoline engine with only minor modifications. High-purity hydrogen, however, is used to best advantage in high-efficiency technologies such as fuel cells. ${ }^{2} \mathrm{~A}$ fuel cell produces electricity, heat and water through an electrochemical process whose inputs are oxygen from the air and a fuel such as hydrogen. Fuel cells have many useful characteristics, including modularity, good loadfollowing ability, almost no noise and, when using hydrogen, almost no emissions.

Fuel cells come in many varieties. Low-temperature designs such as proton exchange membrane fuel cells (PEMFCs, also known as polymer electrolyte membrane fuel cells) are mostly aimed at portable and transport applications. High-temperature designs such as solid oxide fuel cells (SOFCs) are better for stationary power plants.

At the point of use, burning hydrogen as a fuel has very little impact on the environment. There are no emissions of greenhouse gases, nor of most other pollutants. If air is used as the oxygen source, nitrous oxide will be present in the exhaust gases and may need to be controlled, as with any other combustion technology.

The total environmental impact of hydrogen therefore depends almost entirely on the way the hydrogen is produced. Hydrogen energy systems based on renewable energy sources such as wind or solar power are among the most environmentally-benign systems known today. The transport and distribution of hydrogen is an important issue that does not always get the attention it deserves. The use of large amounts of hydrogen worldwide will require a comprehensive and very costly infrastructure, which only can be developed in a long time perspective. To keep costs at a reasonable level, this infrastructure will have to be used at close to full capacity, making the smooth transition to hydrogen an important challenge for society and industry [5].

Once in place, however, a hydrogen infrastructure would have several advantages. Working alongside the existing grids for electricity, natural gas and district heating, a hydrogen grid could act as a fourth "backbone" that would link the other three energy sources as well as providing energy in its own right (figure 1). Hydrogen could be distributed locally, regionally or nationally, and could even be carried by the existing natural gas grid, with some modifications. ${ }^{3}$ Alternatively, a proportion of hydrogen could simply be blended with the supply of natural gas.

Hydrogen is easy to use because of its versatility, in terms of both manufacture and end-use. Hydrogen could provide the link between renewable energy and the transport sector, transforming biomass, solar and wind energy into transport fuel and reducing dependence on oil. A hydrogen economy is expected to substantially improve the security of energy supply for the transport sector.

Besides its potential as a fuel or energy transport medium in the transport and power generation sectors, hydrogen could have an important role as a way to store surplus energy. Fuel cells normally used to produce electricity from hydrogen can be designed to switch into reverse and produce hydrogen from electricity. At periods when electricity is cheap - when the wind is blowing strongly, for instance, so that wind farms are producing more power than the grid requires - this surplus electricity can be used to make hydrogen, which is then stored for future use. This "buffer" principle could be used at all scales, from centralised power stations right down to small fuel cells in private cars.

However, especially with regard to complex energy systems, the overall efficiency from primary energy to end use has to be considered carefully and considerable drawbacks are here identified for a hydrogen system, because of its long energy conversion chain. When hydrogen is produced out of electricity and then reversed back into electricity again, there are great losses and therefore additional advantages and added values should be observed to justify such a system from an energy-efficient point of view.

One of the most important advantages of hydrogen is its potential to replace gasoline and diesel as transport fuels, and thus to eliminate air pollution directly from vehicles. However it is produced, hydrogen cannot at present compete with conventional transport fuels in purely economic terms. However, within 10-20 years the supply of oil is expected to peak, while demand will probably continue to grow, so in the medium to long term the price of oil is expected to increase. Nevertheless, the introduction of a hydrogen system has to be seen as a long-term option. Although hydrogen will become cheaper as technology improves and demand increases, hydrogen is not expected to become cost-competitive as a transport fuel in another 10-30 years time. Even if the development of a hydrogen infrastructure is given a high priority in terms of costs and political willingness, it cannot be expected to be in place before 20-40 years from now.

2. Not all the hydrogen production methods discussed here provide high-purity hydrogen. Expensive purification processes may be needed to purify hydrogen made by reforming processes, for instance. On the other hand, some types of fuel cells do not require high-purity hydrogen.

3. Most conventional natural gas pipelines are able to carry hydrogen, though compressors and valves may have to be adapted or replaced. 


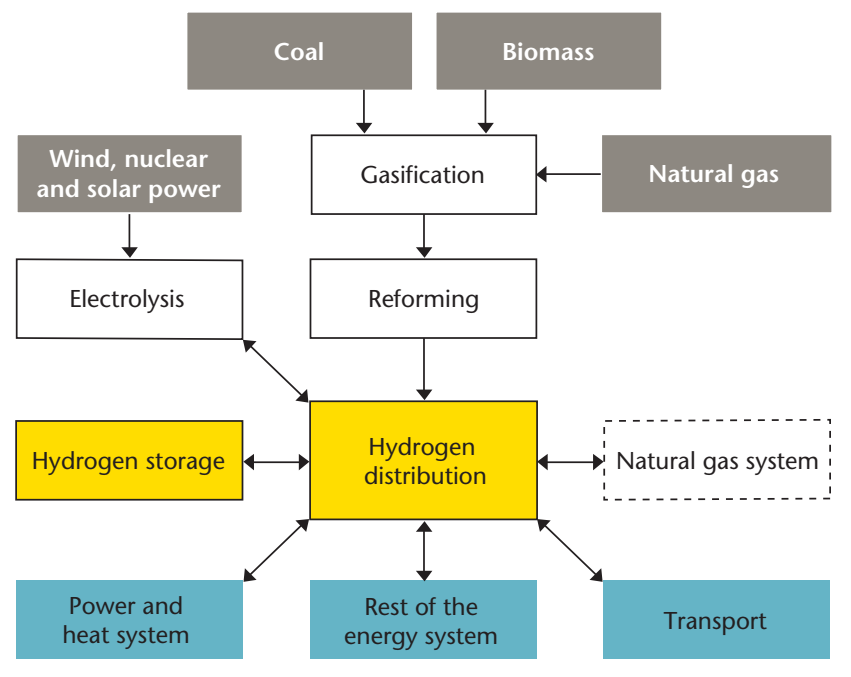

\section{Current driving forces in hydrogen development}

Environmental issues and security of energy supply currently top the list of society's energy-related concerns. In both these areas, the transport sector presents the biggest challenges. With the exception of hydrogen, it is hard to imagine any replacement transport fuel that would be successful. Electric vehicles are one possibility, but to date their technical performance and user-friendliness have not met to expectations.

In terms of the environment and energy security, several factors work in favour of hydrogen. Among the most important are:

- Hydrogen will increase energy efficiency in transport and power generation, which might imply lower primary energy consumption and emissions of greenhouse gases.

- A hydrogen energy system will pave the way for the use of a variety of renewable energy sources in the transport sector. This in turn will increase the diversity of energy sources and reduce overall greenhouse gas emissions.

- Reducing local air pollution is a priority in many cities. The use of hydrogen as a transport fuel would help.

- The introduction of emerging technologies, such as fuel cells with high electrical efficiencies, will be facilitated by a hydrogen infrastructure.

- The robustness and flexibility of the energy system will be increased by introducing hydrogen as a versatile new energy carrier that can interconnect different parts of the energy system.

- Vehicles powered by hydrogen fuel cells are quieter than conventional vehicles, so they would assist governments reach their targets for noise reduction.

Although the transport sector is currently the most important driving force behind the development of hydrogen, the broad scope of interactions between hydrogen and the rest of the energy system makes hydrogen an interesting option for the future. Hydrogen
Figure 1: Hydrogen could provide valuable links between different parts of the complete energy system. could make the existing energy system more robust, and thus improve the security of energy supply and facilitate the introduction of new and environmentally-benign energy sources. The trend towards decentralised energy systems, such as micro-turbines and small-scale local power plants, would also be facilitated by the development of hydrogen systems.

\section{Research and development in hydrogen: selected countries and organisations}

More than 20 countries are engaged in hydrogen R\&D. An increasing number of existing or prospective EU members, including unlikely countries such as Romania, Greece and Finland, are developing hydrogen strategies and policies. Fewer countries are successfully developing hydrogen fuel cells and storage technologies, and at present the field is dominated by the USA, Canada, Germany and Japan. The following sections give more details on hydrogen research in each of these countries [6].

\section{Germany}

Germany is without doubt the European leader in hydrogen and fuel cell R\&D. Intensive research dates back to the mid-1980s, though the level of research has declined in recent years. Much of Germany's interest in hydrogen is rooted in the transport sector, where companies including BMW, DaimlerChrysler, General Motors and Volkswagen are developing fuel cells. The automotive manufacturers have also launched a Transport Energy Strategy, which with government support aims at developing a national policy strategy on alternative transport fuels in the medium term. A number of German companies are working on developing a hydrogen infrastructure.

\section{Current projects include:}

The Clean Energy Partnership (CEP). Based in Berlin, the CEP was established by the German Energy Agency in 2002 with the objective of demonstrating hydrogen as a 
viable fuel for vehicles. The four-year project will use a fleet of cars to test a hydrogen infrastructure, including hydrogen production and storage, filling stations, fuel cells and internal combustion engines running on hydrogen.

Munich Airport hydrogen service station (ARGEMUC H2) is also concerned with the daily use of hydrogen as a transport fuel. The project began in 1999 and is demonstrating hydrogen refuelling facilities for buses, cars and a fork lift truck.

CUTE, a project co-funded by the European Commission but with highly active German partners. The objective is to demonstrate hydrogen production, storage and use in fuel cells. Nine European cities are involved in building test facilities, including production (steam reforming and electrolysis), hydrogen filling stations and buses powered by fuel cells.

\section{Japan}

Japan has for a number of years been one of the most ambitious countries in developing hydrogen energy technologies and strategies. In 2002 the Japanese Ministry of Economy, Trade and Industry (METI) launched a comprehensive programme aiming at full commercialisation of fuel cells and a hydrogen infrastructure by 2020 . The total budget is approximately $\$ 4$ billion, with $\$ 250$ million set aside for the first five years. The programme has three phases. The demonstration phase focuses on developing technology, demonstrating mobile and stationary fuel cells and establishing codes and standards. The introductory phase, which will last from 2002 to 2010, concentrates on research and demonstration. By 2010, 50,000 fuel cell vehicles and 2.1 GW of stationary fuel cells are expected to be in operation. The "diffusion" phase, which will run from 2010 to 2020 , will concentrate on the wide implementation of hydrogen technology. By 2020, Japan expects to have 5,000,000 fuel cell vehicles, 4,000 hydrogen filling stations and $10 \mathrm{GW}$ of stationary fuel cell cogeneration plants.

This ambitious programme is the latest part of an intensive hydrogen R\&D effort that began in the early 1980s. The result is that Japan is a world leader in hydrogen technology, especially in commercialisation as opposed to basic research. The work has largely been co-ordinated by the government - METI and NEDO (New Energy and Industrial Technology Development Organisation) - but has also been driven by car manufacturers and other industries. This public-private partnership makes the Japanese hydrogen programme extremely efficient, because everybody is pulling in the same direction.

Though Japan is developing a broad range of hydrogen technologies, most of the work is on developing, demonstrating and implementing fuel cells. Japanese researchers are working on all four of the main types of fuel cells: phosphoric acid fuel cells (PAFCs), molten carbon fuel cells (MCFCs), solid oxide fuel cells (SOFCs) and proton exchange membrane fuel cells (PEMFCs). This year Japan will become the first country in the world to begin mass-producing fuel cell vehicles, with 50 or more vehicles planned.

Japan's comprehensive commercialisation strategy for hydrogen is made up of a number of individual programmes. Some of the most important of these are ${ }^{4}$ : The New Hydrogen Project. This project is a continuation of WE-NET (International Energy Network Using Hydrogen Conversion), which began in 1992. The main objective of the programme is to develop safety technologies for fuel cell vehicles and hydrogen filling stations, but R\&D on hydrogen production and storage is also carried out.

Japan Hydrogen and Fuel Cell Demonstration Project. This project aims to demonstrate fuel cell vehicles and hydrogen filling stations. Ten hydrogen filling stations using various energy sources (gasoline, naphtha, methanol, kerosene, natural gas, LPG) and technologies (reforming, electrolysis, liquid storage, high-pressure gas storage, recovery of waste hydrogen from industrial processes) will be tested in seven fuel cell vehicles and one fuel cell bus. Both Japanese and foreign car manufacturers are participating.

Development of regulations, codes and standards for hydrogen vehicles and filling stations are in preparation for the use of privately-owned hydrogen vehicles on Japanese roads.

\section{USA}

The USA has recently launched a comprehensive strategy for the development of hydrogen vehicles and hydrogen infrastructure. Over the next five years the Department of Energy (DOE) will spend approximately $\$ 1.5$ billion on hydrogen R\&D. The work will centre on developing fuel cells for automotive and stationary purposes, but will also cover hydrogen production, storage and infrastructure as set out in the recent National Hydrogen Energy Roadmap. Basic research issues important for realization of a hydrogen economy will also be addressed.

The programme will include research into three types of fuel cells: PEMFCs, SOFCs and MCFCs. The production of hydrogen from natural gas, clean coal, nuclear, biomass and other renewables will be investigated, as well as hydrogen storage, delivery technologies, sensors and control technologies. Another important task is to develop codes and standards in readiness for the eventual commercialisation of hydrogen technologies. Specific projects include: ${ }^{5}$

Solid State Energy Conversion Alliance (SECA), a partner-

4. The hydrogen and fuel cell development in Japan is further described in [9].

5. More information on the development of hydrogen in USA can be found in [13], [14] and [15]. 
ship between the DOE, research institutions and industry. The main objectives of SECA are to develop high-temperature SOFCs and MCFCs operating on natural gas and syngas, primarily for stationary purposes. Targets for stationary fuel cell systems are a design life of 40,000 operating hours and electric efficiencies of 60 $70 \%$, the higher figure to be achieved by combining fuel cells with gas turbines.

The FreedomCAR partnership, an alliance between the DOE and car manufacturers including General Motors, Ford and DaimlerChrysler. The aim is to develop the PEMFCs for transport purposes. The programme sets specific cost targets, such as $\$ 45 / \mathrm{kW}$ for the fuel cell system and $\$ 30 / \mathrm{kW}$ for the engine power train.

International Partnership for Hydrogen Energy Economy (IPHE), a group formed in October 2003 under the leadership of the DOE with the aim of harmonising progress towards a global hydrogen infrastructure. The partners are Australia, Brazil, Canada, China, the European Commission, France, Germany, Iceland, India, Italy, Japan, Norway, Russia, South Korea, the UK and the USA.

\section{Canada}

For almost two decades Canada has been highly active in developing hydrogen energy systems. In the mid-1980s the Canadian government set up comprehensive national programmes for fuel cells and hydrogen, and this resulted in the establishment of several private companies, including Ballard Power Systems (fuel cells) and Stuart Energy (electrolysis). Important Canadian projects include:

The National Hydrogen and Fuel Cell Programme covering three areas: R\&D, hydrogen infrastructure (developed through the Canadian Fuel Cell Alliance), and early market introduction of hydrogen and fuel cell technology. The latter is carried out through the Early Adopters Program, which is led by Industry Canada.

The Fuel Cell Commercialisation Road Map, whose objective is to accelerate full-scale commercialisation of fuel cells in Canada. Published in 2003, the Road Map sought opinions from all the relevant stakeholders in Canada. The work was led by industry and supported by the government.

\section{Other countries}

The UK government recently published an Energy White Paper setting out a long-term strategy for sustainable energy. One option is a hydrogen economy, especially the use of hydrogen fuel cells in transport. A recent document entitled A Fuel Cell Vision for UK - The First Steps underlines the need for more long-term investments in fuel cells and hydrogen systems, with the aim of making the UK a world leader in the development and deployment of fuel cells.

Iceland plans to establish a national infrastructure for hydrogen for transport and fishery so as to make the country independent of imported oil. The country's first hydrogen filling station was inaugurated recently.

In Norway, quite an impressive number of research projects are presently being carried out, partly driven by big industrial players within the oil-business such as Norsk Hydro and Statoil, but also research institutions and universities are active within the hydrogen field.

Austria was one of the pioneers of fuel cells in Europe, and is still carrying out important research in fuel cells for both stationary and mobile applications. Although fairly new in the hydrogen field, interest is rapidly growing in countries such as Romania and Greece. In Greece the development of hydrogen systems to make smaller islands independent of the supply of oil has a high priority.

Korea, though still at an early stage in hydrogen development, has started an impressive number of projects, especially in relation to fuel cells.

Australia is still in the process of developing a co-ordinated national policy for hydrogen. Initiatives to date include the preparation of a National Hydrogen Study. China and India are showing increasing interest in hydrogen, and policy initiatives are on the way.

\section{International research programmes}

Although most of the driving force for the development of hydrogen comes from individual countries, organisations including the EU and the IEA are also conducting and co-ordinating hydrogen research.

The development of a hydrogen economy is a longstanding research objective in the EU. The European Commission has supported hydrogen $R \& D$ since the 1970s, mainly within its scheduled research programmes. Under the 5th Framework Programme (FP5, 1999-2002) hydrogen R\&D was part of the programmes on energy and the environment, rather than having its own subject area. Nevertheless, FP5 provided funding of approximately $€ 150$ million for projects on fuel cells and hydrogen production, storage and infrastructure.

The EU's Sixth Framework Programme (FP6) began in 2003. In FP6 research into hydrogen and fuel cells falls under the heading "Sustainable development, global change and ecosystems", which has separate sub-headings for fuel cells and hydrogen as an energy carrier. Around $€ 400$ million is budgeted for R\&D in fuel cells, new technologies for energy carriers (hydrogen and electricity) and new concepts for renewable energy. In 2002 the European Commission also established a High Level Group (HLG) on hydrogen and fuel cells. Its main objective is to provide a strategic-level policy framework to promote hydrogen and fuel cells in FP6 and subsequently.

The HLG recommended starting a European Hydrogen and Fuel Cells Technology Platform (HTP). The HTP brings together EU stakeholders in these areas to co-ordinate work on both R\&D and deployment. Finally, the 
European Commission supports the European Hydrogen Network (HyNet), which was established in 1999 with the main objective of bringing together European hydrogen stakeholders from industry, research institutions and governments. Thus the European Commission is focusing more and more on the likelihood of a future hydrogen economy.

The IEA has also taken an interest in hydrogen and fuel cells, although to a lesser extent than the EU. The IEA has set up Hydrogen Program Implementing Agreements, whose main purpose is to co-ordinate ongoing $R \& D$ between IEA member countries. These are normally set up on a cost-shared basis and are open to any IEA member, both OECD and non-OECD, who wishes to participate. Implementation agreements exist for both hydrogen and fuel cells.

\section{Long-term visions for the hydrogen society}

Long-term challenges, such as climate change, security of energy supply and depletion of oil resources, require long-term solutions. Many politicians and scientists believe that a combination of fuel cells and hydrogen infrastructure will be a practical way to create an efficient, clean and sustainable energy system within the next 20-40 years.

One of the most ambitious recent initiatives is the International Partnership for the Hydrogen Economy (IPHE, above). Its main goal is "to serve as a mechanism to organize and implement effective, efficient and focused international research, development, demonstration and commercial utilization activities related to hydrogen and fuel cell technologies. The IPHE also provides a forum for advancing policies, and common codes and standards that can accelerate the cost-effective transition to a global hydrogen economy to enhance energy security and environmental protection" [8].

The EU High Level Group for Hydrogen and Fuel Cells (HLG) has also looked into the possibilities of creating a hydrogen economy in the long term. One of the HLG's conclusions is [4]:

"...hydrogen and electricity together represent one of the most promising ways to realise sustainable energy, whilst fuel cells provide the most efficient conversion device for converting hydrogen, and possibly other fuels, into electricity. Hydrogen and fuel cells open the way to integrated 'open energy systems' that simultaneously address all of the major energy and environmental challenges, and have the flexibility to adapt to the diverse and intermittent renewable energy sources that will be available in the Europe of 2030".

Some highlights from the HLG report include:

- Hydrogen opens up the possibility of using a broad range of primary energy sources, including fossil fuels, nuclear and renewable energy.

- The combination of the electricity grid and a hydrogen system, including hydrogen storage, provides flexibility in balancing conventional and intermittent renewable energy sources, while hydrogen as an energy carrier makes new energy sources available to the transport sector.

- Hydrogen produced from carbon-free or carbonneutral energy sources can provide significant reductions in carbon dioxide emissions by replacing fossil energy sources. This is especially relevant to the transport sector.

To support the development of a hydrogen economy, the partners of the European Hydrogen Energy Thematic Network (HyNet) have developed a European Hydrogen Energy Roadmap. The main conclusions from this roadmap are [5]:

Hydrogen production: In the short and medium term, technologies that are already commercially available - steam reforming and electrolysis - will be vital for the production of hydrogen, although at a higher cost than conventional fuels. In the longer term, hydrogen could be produced at costs that would make it competitive with diesel and gasoline, based on current predictions for advances in technology and economies of scale in manufacturing.

Hydrogen infrastructure: The costs of transport, storage and refuelling facilities are key obstacles to the hydrogen economy. Investment costs and associated risks are high, so a hydrogen infrastructure will require significant commitment from industry, governments and other stakeholders. Hydrogen storage is an essential technology that has the potential to become a bottleneck. Extensive R\&D is required to develop innovative storage solutions.

Demand for hydrogen: Small portable applications for hydrogen are expected to enter the market within the next 2-3 years, and these will help pave the way for larger hydrogen users. Stationary fuel cells, mostly based on natural gas, are expected to be commercialised before 2010. Transport applications will be the main driver for the development of hydrogen systems, but this market will not take off before 2010-2015.

Legal requirements, regulations and standards need to be in place in order to facilitate hydrogen development.

Socio-economic issues and government policies are important. Governments have to stimulate R\&D and largescale demonstration projects, while long-term policy support is needed if hydrogen is to become commercially successful in a reasonable timescale.

Figure 2 shows a possible timeline for the development of hydrogen production technologies. Short-term hydrogen development will rely mainly on conventional fossil fuels, whilst in the very long term technologies could include photo-biological or photo-electrochemical conversion processes and thermonuclear conversion cycles. It is clear that a number of initiatives are under way to develop hydrogen systems. A good deal of research is going on, and a number of demonstration plants have already been established. Nevertheless, high 
costs prohibit the large-scale use of hydrogen at present. Significant cost reductions must be made in the coming years before hydrogen can even come close to commercialisation.

But what are the perspectives for hydrogen in the long term? Will it eventually develop into a major energy carrier and displace significant amounts of oil? That depends on two further questions:

- Will the necessary technologies become available in the medium to long term, at reasonably competitive prices and with efficiencies that make them suitable substitutes for existing technologies?; and

- Will it be possible to build the necessary hydrogen infrastructure, and to harvest the energy resources needed to fuel a worldwide hydrogen system?

Progress in fuel cells carries high expectations. Fuel cells for portable and stationary applications should become commercially available within 5-10 years. Fuel cells for transport will take longer and are not expected to be commercialised in another 10-15 years from now. However, there are still significant uncertainties in fuel cell development. A more pressing technological issue is the development of ways to store hydrogen. At present there are a number of possible technologies, but no single solution stands out. The lack of a really good storage method is likely to hinder the large-scale take-up of hydrogen.

Finally, some experts are worried that although individual hydrogen technologies may be acceptably efficient, the efficiency of the complete hydrogen chain may turn out to be too low to be useful as the core of a sustainable energy economy [1].

The development of hydrogen systems is in line with the existing trend towards decentralised and distributed energy systems, which are expanding rapidly, especially in the USA. It does not make sense to transport hydrogen over long distances, so hydrogen should be an integral part of a distributed energy system that in the longer term is based mostly on renewable sources. In this way, hydrogen could stimulate the expansion of renewable energy, especially in transport, and create a faster transition to renewables than is currently anticipated without the benefit of hydrogen.

The infrastructure needed for a hydrogen economy is expected to be technically feasible, though it will require tremendous investment and research effort. The transition towards a comprehensive hydrogen-based energy system, however, will be highly risky for the pioneers. Strong policy initiatives are required from the EU and its Member States if the change to hydrogen is to take place at a cost that is acceptable to the societies concerned.

Looking ahead to 2050, it is possible to imagine three scenarios for producing hydrogen $[10,11,12]$ : clean fossil fuels, safe nuclear power and renewable energy. In each case the efficiency of energy conversion would have to be well above today's standards, to meet future global increases in energy consumption.

In the clean fossil fuels scenario, hydrogen would be generated from coal or oil. The resulting carbon dioxide would be removed from the flue gas and disposed in aquifers or at the bottom of the ocean. The environ-

Figure 2: Timeline for hydrogen production technologies [5].

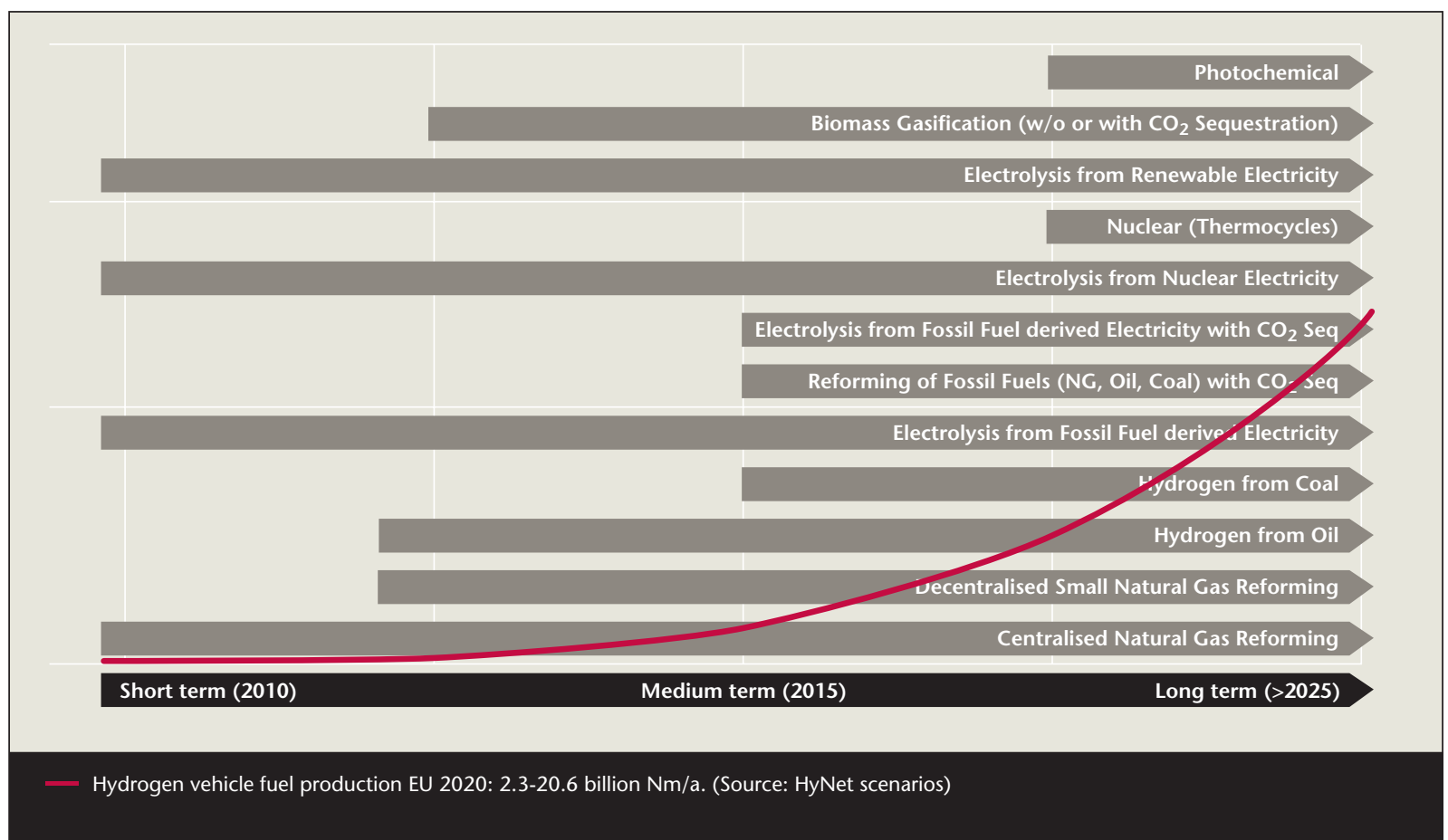


mental consequences of sequestering carbon dioxide in this way are uncertain, and a cause for some concern. The "safe nuclear" scenario requires the development of nuclear power plants that do not rely on control systems to remain stable in the event of a malfunction. Engineers call this "inherent safety". It is not certain that it is possible to develop practical inherently-safe nuclear plants. In the renewable energy scenario, hydrogen storage would be used to compensate for variability in the supply of energy from renewable sources, especially solar, wind and wave power. ${ }^{6}$

Subject to the provisos mentioned above, all three scenarios are considered to be technically feasible. The general conclusion is that enough hydrogen is available in the very long term for hydrogen to become a significant part of the world's energy system.

The decision on whether to place hydrogen alongside electricity in the backbone of our energy supply needs to be taken within the next ten years. At present it is difficult to see any practical alternatives. Hydrogen presents big challenges to both technology and policy, but it also offers huge opportunities for the European and global energy economies.

6. There are actually four scenarios, since the renewable scenario exists in two versions, centralised and decentralised, which are rather different, especially as regards hydrogen production and infrastructure. 


\section{Hydrogen in the Danish energy system}

BIRTE HOLST JøRGENSEN, RISØ NATIONAL LABORATORY; IB CHORKENDORFF, TECHNICAL UNIVERSITY OF DENMARK

\section{Introduction}

Hydrogen used as an energy carrier may not solve all our energy problems related to security of supply, climate change and environmental degradation, but hydrogen energy in combination with fuel cells may fit well into a future energy system based on renewables. If Denmark with a small open economy wants to compete and become a key knowledge contributor to this technological field, there is high demand for correlation of knowledge creation and diffusion between knowledge producers and users. Thus the efforts must include basic research, access to highly qualified human resources, knowledge and technology transfer to the market, alignment of the relations between universities and users of knowledge and technology in the society at large, and better focus and prioritisation of research, technology and innovation $[8,10,11]$.

This chapter focuses on Danish R\&D in hydrogen and fuel cells, in the context of European and global R\&D. The first section is an introduction to the Danish energy research funding system and Denmark's involvement in international energy research. This is followed by an account of Denmark's national and international R\&D in the period 1998-2003, including EU-funded projects. Finally, an assessment is given of the competitiveness of Danish fuel cell and hydrogen research, and prospects for a national research strategy for hydrogen and fuel cells, including the major challenges facing Danish universities and industry are discussed.

We conclude that "strategic intelligence" - knowledge creation and diffusion along the whole value chain - in Danish hydrogen R\&D is closely related to the involve- ment of stakeholders from government, the energy sector, research and industry. A dialogue is needed to set goals and decide on actions, so that once a national R\&D and demonstration programme is launched, all the key stakeholders are fully committed.

\section{Danish R\&D in hydrogen and fuel cell technologies}

Danish researchers have over the years developed outstanding competences in hydrogen R\&D at national, Nordic and European levels. Their scope of work covers the entire value chain of the hydrogen economy, including the production, storage, distribution, conversion and end-use of hydrogen in both transport and stationary applications.

In the last five years, Danish energy research on hydrogen and fuel cells has been supported by the National Energy Research Programme (EFP), the Public Service Obligation Funds for R\&D relating to environment and electricity (PSO), the Research Councils and the short-lived Hydrogen Programme (1999-2001). A strict division between hydrogen and fuel cell R\&D is difficult to make. The National Energy Research Programme has historically supported R\&D projects on SOFCs, but the Hydrogen Programme has supported both hydrogen and fuel cell R\&D.

A total of 34 projects with a total budget of $€ 22.1$ million were approved in the period 1998-2002. Some of these are now complete, while others are still running.

The Hydrogen Programme was launched in 1999 with total government funding of around $€ 10$ million over four years, but with the new government in office in

Table 1: Overview of Danish hydrogen and fuel cell R\&D projects, 1998-2002. Including the Centre of Excellence "Towards a Hydrogen Based Society" covering catalysis, storage, conversion and demonstrations.

\begin{tabular}{|c|c|c|c|c|c|c|}
\hline & \multicolumn{2}{|c|}{ Hydrogen Programme } & \multicolumn{2}{|c|}{ EFP; PSO; Research Councils } & \multicolumn{2}{|l|}{ Total } \\
\hline & No. of projects & Million $€$ & No. of projects & Million $€$ & No. of projects & Million $€$ \\
\hline Production & & & 1 & 0.15 & 1 & 0.15 \\
\hline Catalysis \& Storage & 2 & 0.6 & 31 & 5.62 & 5 & 6.22 \\
\hline Distribution & 1 & 0.27 & & & 1 & 0.27 \\
\hline Conversion: combustion & 1 & 0.23 & 1 & 0.24 & 2 & 0.47 \\
\hline Conversion: fuel cells (SOFCs) & & & 12 & 10.95 & 12 & 10.95 \\
\hline Conversion: fuel cells (PEMFCs) & 7 & 3.1 & & & 7 & 3.1 \\
\hline Other & 3 & 0.6 & 3 & 0.42 & 6 & 1.02 \\
\hline Total & 14 & 4.8 & 20 & 17.33 & 34 & 22.13 \\
\hline
\end{tabular}


2001 the programme was cancelled. Its goal was to study the use of hydrogen in a future Danish sustainable energy system. Priority was given to pre-competitive research and demonstration projects in hydrogen technologies, and the development and application of PEM fuel cells for stationary and mobile applications. The programme supported 14 projects with a total budget of $€ 4.8$ million. The abrupt cancellation of the project caused temporary set back in R\&D activities among applicants, especially small and medium sized technology providers.

Over the years the National Energy Research Programme has given priority to R\&D in SOFCs. In the period 19982002 it supported 12 projects with a total budget of $€ 10.95$ million, which is more than half the total spent on Danish R\&D in hydrogen and fuel cells. Other projects on hydrogen storage and networks have also been supported through the National Energy Research Programme and the Public Service Obligation funds.

In 2002 the Research Councils launched an initiative to support centres of excellence, with the aim of promoting research across institutional and disciplinary boundaries. A centre of excellence entitled "Towards a Hydrogen Based Society" was among the first of these institutions to be founded, with a budget of $€ 3$ million. Towards a Hydrogen Based Society deals with R\&D in catalysis and hydrogen storage, plus small demonstration projects. It has a strong focus on fundamental research, and represents an important opportunity to boost basic research in Denmark. At the same time it is promoting collaboration between basic and applied science groups, including Danish industry.

Danish involvement in international research

Danish researchers are well represented in European fuel cell R\&D. In the period 1999-2002, Danish partners were represented in 9 out of 43 fuel cell projects supported by the European Commission's Fifth Framework Programme (FP5) on Energy, Environment and Sustainable Development (EESP), and in many other EU projects (Table 2).

In the Sixth Framework Programme (FP6), Danish partners are represented in four out of ten projects on hydrogen and six on fuel cells, including the projects HySafe, Real-SOFC, Naturalhy and FURIM.

\section{Competitiveness of Danish research}

The competitiveness of Danish research in hydrogen and fuel cells can be measured in different ways. We can look at both the "internal" quality of research (measured through the so-called Merton values, which relate to scientific excellence, public good, universality etc.), and the "external" quality (relevance to society and wealth creation) [6]. No single approach to measuring research quality is the correct one; instead we need to take account of as many factors as possible, and try to understand the links between science and economic activities [1].

Citations are often used as an indicator of scientific quality [5]. Although this approach has many pitfalls, citation studies at national level give good insights into the relative positions of nations in specific technology areas.

The success of emerging hydrogen energy technologies depends strongly on the scientific quality of the research, but also on the availability of development know-how and the investment needed to bring new ideas on the market. One way to measure the practical application of R\&D is to study patent applications.

An application for a patent indicates the existence of

Table 2: Overview of EU FP5 and other projects with Danish partners.

Fifth Framework Programme (EESP) projects

Scale-up of the IP-SOFC to multi-tens of kW Level (MF-SOFC) (Risø)

Component reliability in SOFC Systems for Commercial Operation (CORE-SOFC) (Risø, Haldor Topsøe A/S)

Pressurized IP-SOFC (PIP-SOFC) (Risø)

Integrated Researches on Materials, Technologies and Processes to Enhance MCFC (Rich Müller)

50 kW PEM fuel cell generator for CHP and UPS applications (50PEM-HEAP) (IRD Fuel Cells A/S)

High-temperature PEMFC Stack with Methanol Reforming (AMFC) (Technical University of Denmark)

Development of Low-cost, High-efficient PEMFC (APOLLON) (Technical University of Denmark)

A 1 kW DMFC Portable Power Generator (PORTAPOWER) (IRD Fuel Cells A/S)

Thematic network on SOFC Technology (SOFCnet) (Risø)
Other EU projects

Advanced solid polymer fuel cells for operation at temperatures up to $200^{\circ} \mathrm{C}$ (Technical University of Denmark)

Ammonia Cracking (Risø)

Synthesis, fabrication and characterisation of alternative anodes for direct methane oxidation in SOFC (Risø)

Advanced prediction, monitoring and controlling of anaerobic digestion processes behaviour towards biogas usage in fuel cells (Gascon) 


\begin{tabular}{|c|c|c|c|c|}
\hline Rank & Country & Total citations & Total papers & Average citations per paper \\
\hline 1 & USA & 4420 & 713 & 6.2 \\
\hline 2 & Japan & 1816 & 434 & 4.2 \\
\hline 3 & Germany & 1420 & 258 & 5.5 \\
\hline 4 & England & 1133 & 192 & 5.9 \\
\hline 5 & Canada & 879 & 146 & 6.0 \\
\hline 6 & Italy & 571 & 119 & 4.8 \\
\hline 7 & Denmark & 393 & 45 & 8.7 \\
\hline 8 & Switzerland & 362 & 44 & 8.2 \\
\hline 9 & South Korea & 314 & 126 & 2.5 \\
\hline 10 & Sweden & 299 & 76 & 3.9 \\
\hline
\end{tabular}

Table 3. Scientific papers and citations relating to fuel cell R\&D, 1993-2003.Source: www.esi-topics.com/fuelcells/index.html.

new knowledge that may have an economic return. The granting of a patent gives legal recognition to the inventor, who in return must publish the nature of the invention. The inventor's knowledge, and ultimately market share, is protected for a limited period of time normally 20 years [9]. The requirement to publish the invention can be a commercial drawback, so that companies may prefer to rely on secrecy [2]. And patents are often used in a negative way, to exclude competitors from large areas of research. However, patent analysis on a sufficiently large scale is a good way to learn about trends in R\&D.

\section{Competitiveness in fuel cell technology}

In fuel cell technology Denmark scores relatively high on internal and external research quality measured through citations (scientific excellence) and patents (business development).

Denmark was among the top ten nations in fuel cell research during the period 1993-2003, with 393 citations to 45 scientific papers. As Table 3 shows, Denmark's average of 8.7 citations per paper is above the figure of 6.2 for the USA, which tops the list for the total number of citations. Note that these averages may conceal rather large variations between individual papers, especially since the number of Danish papers is relatively low.

Risø National Laboratory scored even better than the Danish average, with 270 citations from 24 papers, giving an average of 11.3 citations per paper. This impressive result is down to the priority given to SOFC research over many years of Danish national R\&D funding, as well as Risø's long-term collaboration with outstanding partners abroad.

The fuel cell industry being young, patents are important in establishing market positions. The global picture of fuel cell patents in the periods 1991-2000 and 2001-2003 shows an exponential growth in the number of patents filed.

The top patenting nations are Japan, the USA and
Germany, but Denmark also appears on the world list. A detailed study of Danish patents on fuel cells reveals that Danish assignees filed 28 patents in the period 19912003. Table 4 compares the Danish patents with those from France and the UK. It is interesting to note that the Danish assignees include universities and research and technology institutes as well as companies large (Haldor Topsøe, Danfoss, Vaillant), medium (Oticon) and small (IRD Fuel Cells, Danacell, Danish Power System).

Although Danish research institutes and companies are well positioned at global level in selected technology areas, and even better when normalised to a per capita basis, it is also obvious that the numbers of Danish citations and patents are small when viewed in a global context. This leaves the Danish R\&D community with a challenge: to acquire the critical mass needed to take advantage of the skill and talent that undoubtedly exists in Denmark.

Danish fuel cell researchers have for many years been involved in larger research communities, especially in Europe and often in the context of the EU's Framework Programmes for research. In industry too, both large and small companies have strategic alliances in fuel cell R\&D. Haldor Topsøe A/S, for instance, has recently begun a collaboration with the Finnish company Wärtsilä on fuel cells with power outputs of around $200 \mathrm{~kW}$ for distributed power generation and marine applications. In 2002 another Danish company, IRD Fuel Cell A/S, signed a co-operation agreement to develop and manufacture fuel cells and components for the "home energy centre", a domestic-scale CHP system being developed by European Fuel Cell GmbH in Germany (source: www.fuelcelltoday.com).

\section{Towards a national research strategy for hydrogen technologies}

Danish energy research is an example of how the interplay between research communities, industry and society at large can reach a consensus on research strate- 


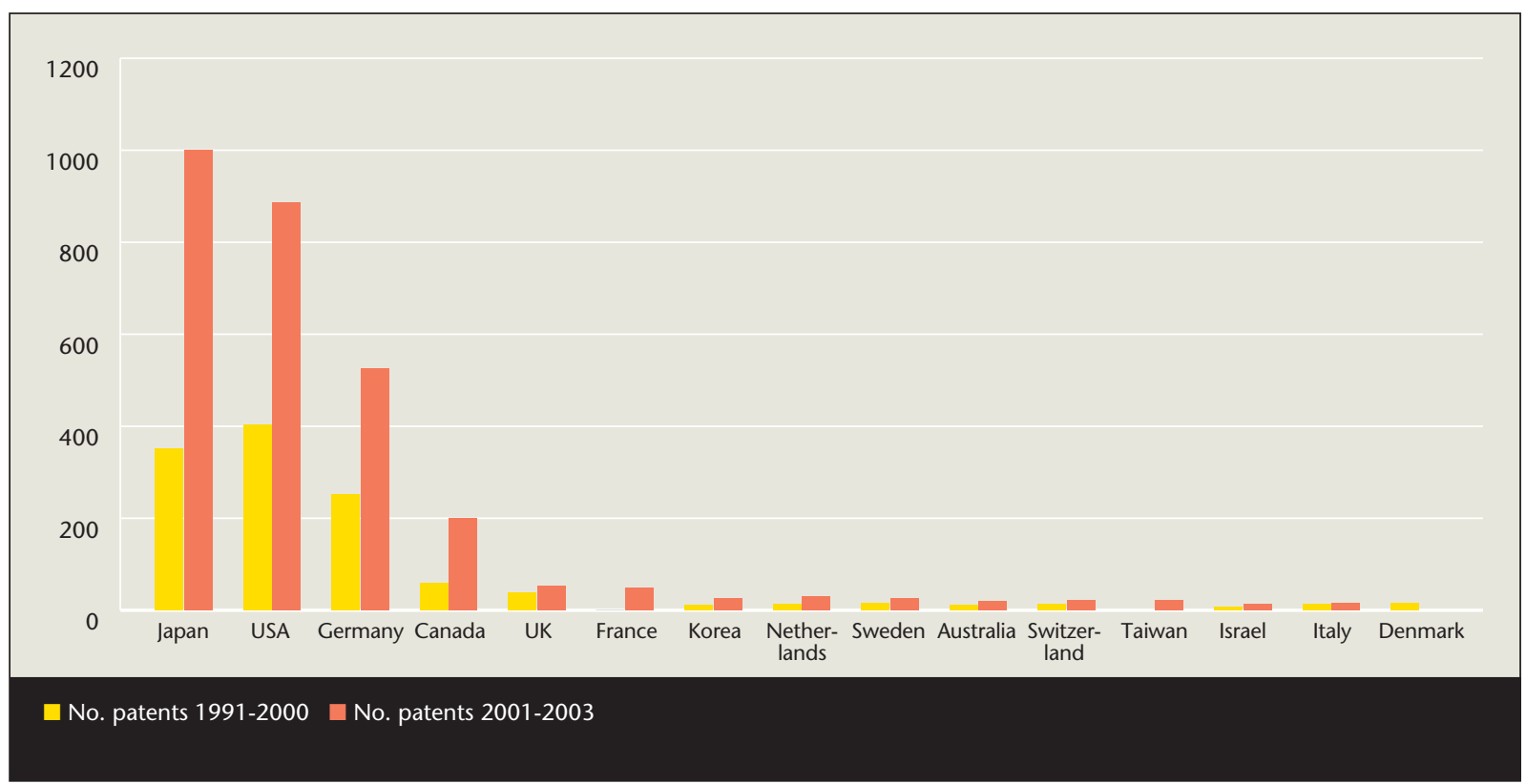

Figure 3: Overview of fuel cell patents, 1991-2003. Source: Fuelcelltoday.com.

gies and the standards by which research proposals are assessed, especially in applied research and pre-commercial activities [3].

The Advisory Council for Energy Research (REFU) plays a central role in developing research strategies and setting priorities. As a result of the budget cuts in 2001, the REFU decided to concentrate on four areas: biomass, photovoltaics, wind energy and fuel cells. The first round of energy research strategies covering these four areas was formulated in consultation with key stakeholders in science and industry (see also www.energiforskning.dk). In 2004 it was decided to draw up a national research strategy for hydrogen energy technologies, covering research, development and demonstration projects. Unlike its predecessors, the new strategy covers the full spectrum of knowledge creation and diffusion in fuel cell and hydrogen technologies, from basic research to precommercial activities. The plan is to get input to the strategy from all the key stakeholders: research communities, industry, energy companies and government.

Many serious obstacles need to be overcome before a hydrogen-based society can become a reality. In principle, all the pieces of the hydrogen jigsaw are available today, but most studies agree that key hydrogen technologies are still too inefficient or too expensive to match the performance of the current energy network. A recent white paper on Danish hydrogen-related research, covering all the significant hydrogen and fuel cell research in Denmark, confirms that Denmark is well placed in terms of $\mathrm{R} \& \mathrm{D}$ in the most interesting and

Table 4. Fuel cell patents, 1991-2003. Source for French and UK patents: fuelcelltoday.com.

\begin{tabular}{|lll|}
\hline UK (139 patents) & France (110 patents) & Denmark (28 patents) \\
\hline Johnson Matthey & Commissariat à L'Energie Atomique & Haldor Topsøe A/S \\
British Nuclear Fuels Ltd. & Renault & Risø National Laboratory \\
Victrex & Sorapec & Niels Bjerrum, DTU \\
Morgan Crucible & Alcatel & Danacell Aps. \\
Regenesys & L'Air Liquide & Danfoss A/S \\
Rolls Royce & Centre National de la Recherche Scientifique (CNRS) & Danish Power System Aps. \\
ICl / Ineos Chlor & Institut Français du Pétrole (IFP) & Danish Technological Institute \\
BG Technology /British Gas & Peugeot Citroën & IRD Fuel Cells A/S \\
Qinetiq & Valeo Thermique Moteur & Jens Nørskov, DTU \\
BP & Compagnie Générale des Matières Nucleaires & Oticon A/S \\
Ceres Power Ltd. & Snecma Moteurs & Vaillant A/S \\
Intelligent Energy Ltd. & &
\end{tabular}


important hydrogen technologies [7]. Danish R\&D in hydrogen production, for instance, ranges all the way from processes based on fossil fuels, through biomass, to basic research on hydrogen-producing enzymes, biomimetics and photo-catalysis.

Of course, these different R\&D areas are at very different stages of development. Hydrogen production from fossi fuels is well established, and hydrogen from biomass is close to commercial use. More direct methods, such as hydrogen from enzymes or photo-catalysis, still requires substantial fundamental research. Both the Technical University of Denmark (DTU) and the Southern University of Denmark (SDU) have strong backgrounds in these new methods of producing hydrogen.

Fuel cells probably take up even more of Denmark's R\&D resources than do hydrogen production technologies. Danish researchers have a good basic background in fuel cells, especially in the development of electrodes (both anodes and cathodes). Both PEMFCs and SOFCs face similar issues when it comes to basic research on electrodes, and this work also applies to fuel cells run in reverse to produce hydrogen by electrolysis. Danish researchers are also working hard to develop better electrolytes.

Fuel cell technology has already entered the demonstration phase, but new materials are needed before the technology can become viable for mass production. For example, platinum and related metals have been used as catalysts in demonstration PEMFCs, but the total world production of platinum could only equip fuel cells for a maximum of 10-20 million cars a year. Platinum must therefore be replaced by materials that are available in greater quantities.

Risø National Laboratory, DTU and the University of Aarhus are particularly strong in developing new electrode materials. The same three institutions, plus the Aalborg University and SDU, are active in optimising the design and manufacture of fuel cells and developing new membranes.

Danish researchers are also working on hydrogen storage. Their emphasis is mainly on metal hydrides and hydrogen-carrying compounds, but they are also looking at the problem of hydrogen embrittlement of materials. Hydrogen storage in metal hydrides is being studied in closely related projects at the University of Aarhus, Ris $\varnothing$ National Laboratory and DTU, and DTU is also investigating alternative hydrogen carriers such as ammonia. Carbon-based hydrogen carriers such as methane and methanol are well known, but practical alternatives will require a good deal more research. We are not aware of any Danish research in the important area of the environmental impact of hydrogen.

The R\&D barriers to affordable and efficient hydrogen use are too large to be overcome by incremental improvements of existing technology. Instead, real breakthroughs are needed - and these will require large investments. Danish companies such as Haldor Topsøe, IRD Fuel Cells and Danfoss are certainly capable of picking up on any such breakthroughs.

We should probably not expect hydrogen technology to be implemented through standard market mechanisms. Fossil fuels are still too cheap for this to happen at present. We must hope that they remain cheap for a considerable time to come, given the current lack of technically and economically competitive hydrogen and fuel cell technologies.

Instead, the driving forces for a hydrogen-based society should be found in the ability to reduce environmental impact and provide a safe and sustainable energy supply, on both short and long perspectives [4]. Focused technology push, regulation and market incentives are needed to bring these new technologies to market before our energy demands start to exceed our resources.

There is, however, a growing niche market for hydrogen and fuel cells in applications such as portable power supplies and backup systems, where cost and efficiency are less important than weight and reliability. Such applications could help drive the technology forward to the point where it is cheap enough for large-scale use and penetration into the energy sector.

Another area that may be worth exploring is the production and consumption of hydrogen by fuel cells connected directly to wind turbines, since Denmark already has a unique market position in wind energy.

\section{Conclusion}

As this chapter has shown, Denmark has a strong R\&D community in hydrogen and fuel cells, whose work is of high scientific quality and market relevance. The competitiveness of Danish R\&D is due to a continued effort by both research institutions and industry, supported by public funds. The emphasis is on SOFCs, but good work is also being done on basic research in catalysis, hydrogen storage, and demonstration of small energy conversion units. A less concerted effort has been made in demonstration technology for stationary and transport applications, mainly financed through the short-lived Hydrogen Research Programme.

Over the years, Danish researchers have worked on a number of European R\&D projects, especially in fuel cells. Recently Danish partners have also been involved in projects dealing with safety (HySafe) and distribution (Naturalhy).

A big challenge is how to get the best results from $R \& D$ investment in new energy technologies. Experience shows that close collaboration across disciplinary and institutional boundaries is essential to progress in developing new energy systems and to the competitiveness of Danish industry. To work effectively with research teams abroad and to be an attractive partner in large international projects, Denmark needs a research community on a national level. It is therefore important to have R\&D 
strategies that are comprehensive and consistent across different programmes and institutions, backed up by funding that is both adequate and continuous.

A reasonable balance between fundamental research, applied research and demonstration projects is needed. Demonstration projects are important in proving that technology is viable, and in providing valuable operating experience, but they are expensive. Although most demonstrations include some research, they are not designed to make technological breakthroughs. Demonstrations should therefore be limited to projects where there really is something new to demonstrate. They should be based on Danish research and industrial competences, and should be closely aligned with major ongoing and future EU demonstrations, thereby ensuring that new knowledge is created.
Breakthroughs created through continuous R\&D effort are essential if Danish research institutions and industry are to compete in the global market for hydrogen and fuel cell technologies. This will require large resources, and in the long term it will be necessary to attract more investments, both public and private. Funding should be targeted at areas in which Danish institutions and firms are already strong, and at new areas from which Denmark could gain particular benefits.

The challenge is to get critical mass and strategic intelligence into R\&D and demonstration projects, and thus strengthen the overall competitiveness of Danish research and industry. This is the task for stakeholders as they draw up a national research, development and demonstration strategy for hydrogen energy. 


\section{Hydrogen system energy technologies in global, European and Danish perspective}

HANS LARSEN, ROBERT FEIDENHANS'L, LEIF SøNDERBERG PETERSEN, RISØ NATIONAL LABORATORY

The following chapter presents the status of R\&D in progress for essential elements in the hydrogen economy. Selection is based on evaluation of technologies and systems needed to phase in the hydrogen economy, and characterized by requiring large research efforts in a longer time scale. The presented technologies and systems are assessed with respect to status, trends and perspectives for the technology together with international R\&D plans. 


\subsection{Technologies for producing hydrogen}

MOGENS MOGENSEN AND ERIK STEEN JENSEN, RISø NATIONAL LABORATORY; JENS SEHESTED AND KIM AASBERG-PETERSEN, HALDOR TOPSøE A/S

\section{Introduction}

Hydrogen is not an energy source but an energy carrier, and as such it requires an energy source for its manufacture. Hydrogen is already produced in very large quantities - several tens of millions of tonnes a year worldwide - for use in the process industries.

Hydrogen may be produced in many different ways. Table 5 lists the main hydrogen production methods, but there are many others.

Table 5: The main methods of producing hydrogen.

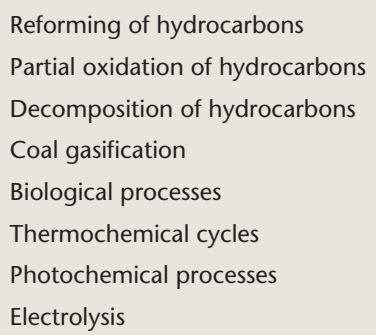

The main uses of hydrogen are for ammonia synthesis and in the refining of crude oil. The primary means of production is catalytic reforming of hydrocarbons, especially of natural gas. The next section discusses this in more detail.

Hydrogen can also be produced through the gasification of coal using steam. The first step in this process creates a mixture of hydrogen and carbon monoxide (the old "town gas"), which is further processed using the shift reaction (see below) to yield a mixture of hydrogen $\left(\mathrm{H}_{2}\right)$ and carbon dioxide $\left(\mathrm{CO}_{2}\right)$ from which the hydrogen is extracted. Hydrogen from coal gasification is not competitive with reforming of natural gas at present. $\mathrm{CO}_{2}$-free production of hydrogen and carbon black from natural gas or heavy fuel oil and electricity is possible using the so-called Kvaerner process [1]. Since the beginning of the 1980s the Norwegian firm Kvaerner Engineering has been developing a plasma-arc process that separates hydrocarbons into pure carbon and hydrogen at a temperature of $1600^{\circ} \mathrm{C}$. The process itself produces no significant emissions, though it requires cooling water and electricity as well as natural gas or oil as the primary energy source. A pilot plant was able to produce about $500 \mathrm{~kg} / \mathrm{h}$ of pure carbon (carbon black) and 2,000 $\mathrm{Nm}^{3} / \mathrm{h}$ of hydrogen from $1,000 \mathrm{Nm}^{3} / \mathrm{h}$ of natural gas and 2.1 MW of electricity. Another by-product is 1,000 $\mathrm{kW}$ of heat in the form of high-temperature steam. Taking into account all usable products, the plant works with almost $100 \%$ mass efficiency: the product split is $48 \%$ hydrogen, $10 \%$ steam and $40 \%$ carbon black.

Biological methods, of which there are several (see below) seem to have great potential for hydrogen production, even though at the moment it is too expensive compared to hydrogen from fossil fuels.

Hydrogen can also be produced by splitting water (methods 6, 7 and 8 in Table 5). At around $2000^{\circ} \mathrm{C}$ water can be decomposed directly into hydrogen and oxygen (thermochemical cycles), but it is difficult to find materials that can tolerate such high temperatures. Photochemical methods are still at the early R\&D stage, so it is difficult to assess their potential. Electrolysis, the third water-splitting method, is a 200 -year-old process that is still believed to have significant potential (see below). None of the water-splitting methods are interesting unless energy from fossil fuels is significantly more expensive than renewable (such as wind, solar or hydro) or nuclear energy, or unless fossil fuel consumption is restricted by political means.

Instead of molecular hydrogen $\left(\mathrm{H}_{2}\right)$, substances known as hydrogen carriers might be more effective as energy vectors. Potential carriers are hydrocarbons, ammonia $\left(\mathrm{NH}_{3}\right)$ and methanol $\left(\mathrm{CH}_{3} \mathrm{OH}\right)$. All these substances are already produced and handled in large quantities, so they have the considerable advantage that a suitable infrastructure is already in place. Hydrocarbons are the most effective hydrogen carriers known, and they can be produced in a $\mathrm{CO}_{2}$-neutral manner using water, $\mathrm{CO}_{2}$ and energy as the raw materials (see below).

\section{Hydrogen from fossil fuels}

Hydrogen is produced from fossil fuels on both small and large scale using industrial processes based on feedstocks including natural gas, LPG, liquid hydrocarbons and coal. The choice of technology depends on the feedstock and the scale of operation. The following sections describe the main technologies currently used to make hydrogen from hydrocarbons, and briefly discusses prospects for the future. Table 6 lists the key reactions involved in making hydrogen from hydrocarbons.

Steam reforming of hydrocarbons is the dominant process for hydrogen production today [2]. Most of the hydrogen produced is used in refineries. Natural gas is the typical feedstock, but liquid hydrocarbon streams including naphtha/gasoline are also used. Figure 4 is a block flowsheet of a steam reforming plant. The first step is purification of the hydrocarbon feed. Natural gas and naphtha contain traces of sulphur, which will rapidly poison the reforming catalyst if allowed into the 


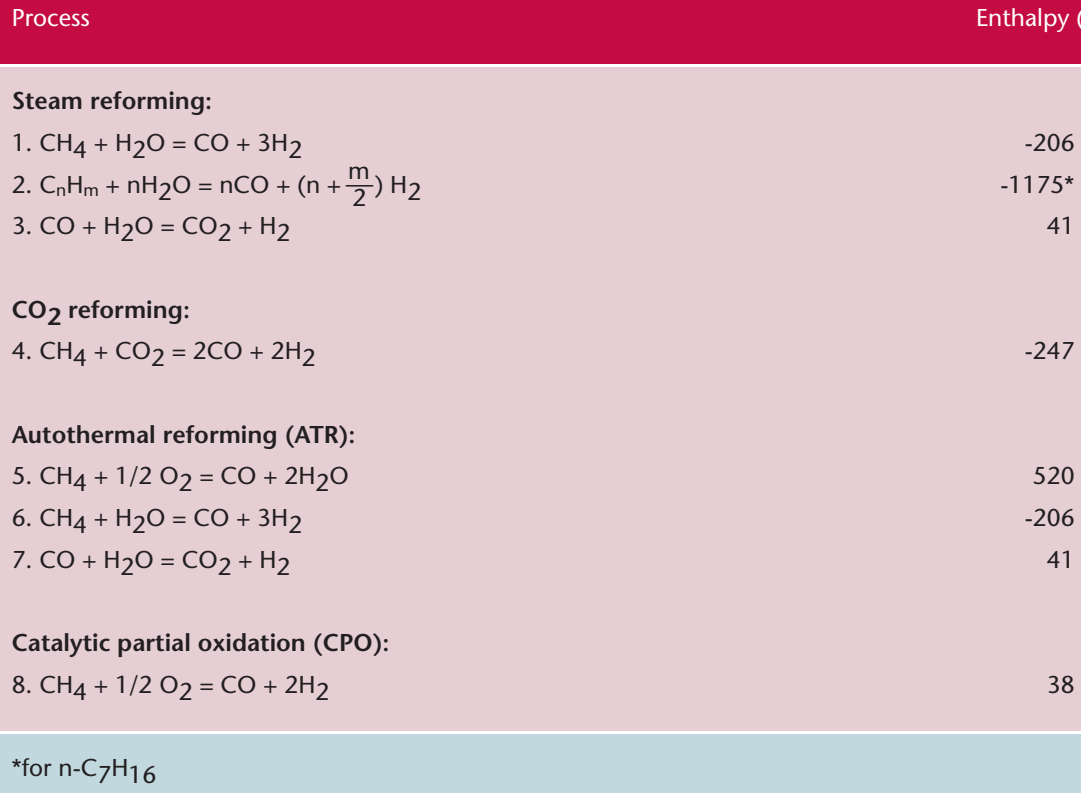

Table 6: Reactions for making hydrogen from fossil fuels.

reforming unit. Purification of the feed is normally done using a hydrogen desulphurization (HDS) catalyst, which converts all sulphur-containing compounds to hydrogen sulphide $\left(\mathrm{H}_{2} \mathrm{~S}\right)$. The $\mathrm{H}_{2} \mathrm{~S}$ is then absorbed in a zinc oxide $(\mathrm{ZnO})$ bed, with zinc sulphide $(\mathrm{ZnS})$ as the product. A copper-based purification catalyst may be installed after the $\mathrm{ZnO}$ reactor for final purification.

After purification, steam is added to the feed and the gas is converted to synthesis gas (a mixture of hydrogen and carbon monoxide) by steam reforming. The steam reforming reactions are strongly endothermic and cause the gas stream to expand. Pressures of 20-40 bar are typically used in industrial reformers. The operating pressure is a compromise: raising the pressure allows the plant's throughput to increase, but also reduces the fraction of the feed that is converted to hydrogen and increases equipment costs.

Modern steam-reforming units consist of a primary reformer with an upstream pre-reformer (Figure 5). The adiabatic pre-reformer converts the higher hydrocarbons into a mixture of carbon oxides, methane, steam and hydrogen according to reactions 1 to 3 in Table 6 . The primary reformer contains a large number of high-alloy steel tubes filled with catalyst and placed in a furnace.
The tubes are typically $100-150 \mathrm{~mm}$ in diameter and 10$13 \mathrm{~m}$ long. The inlet temperature is in the range 450$650^{\circ} \mathrm{C}$ and the outlet temperature is $800-950^{\circ} \mathrm{C}$. A nickel catalyst supported on a ceramic carrier is preferred industrially. Precious metals are more active and resist carbon formation better, but are too expensive for industrial hydrogen plants.

The product from the reformer contains $\mathrm{CO}, \mathrm{CO}_{2}$ and a small amount of unreacted methane, and these have to be removed to obtain pure hydrogen. The water gas shift reaction (reaction 3 in Table 6 ) is used to remove $\mathrm{CO}$ and create extra $\mathrm{H}_{2}$. This is carried out in one or two adiabatic reactors using a copper-based catalyst. After the shift section, the remaining $\mathrm{CO}$, methane and $\mathrm{CO}_{2}$ are generally removed by pressure swing adsorption (PSA) or chemical scrubbing. Removal of CO is done by methanation (the reverse of reaction 1 in Table 6). Oxidation with molecular oxygen is also being tested as a way to produce CO-free hydrogen as a feedstock for PEM fuel cells.

Partial oxidation (Table 6) is an alternative to steam reforming. It can be carried out in three ways. Noncatalytic partial oxidation (POX) requires high temperatures to ensure complete conversion of methane and to

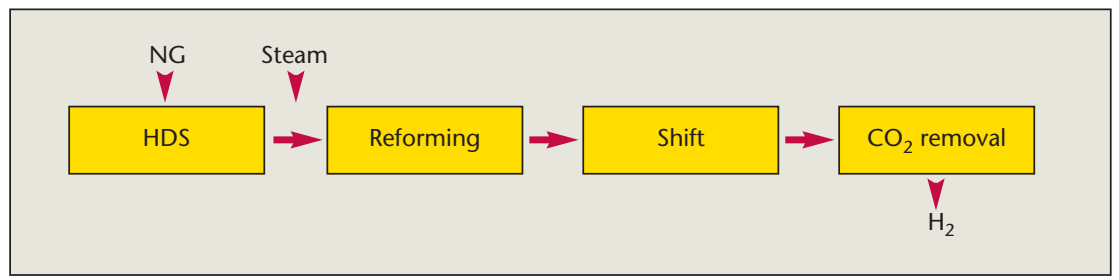

Figure 4: Block flowsheet of a typical hydrogen plant based on steam reforming. Natural gas (NG) and steam are the feeds, and hydrogen is the final product. 


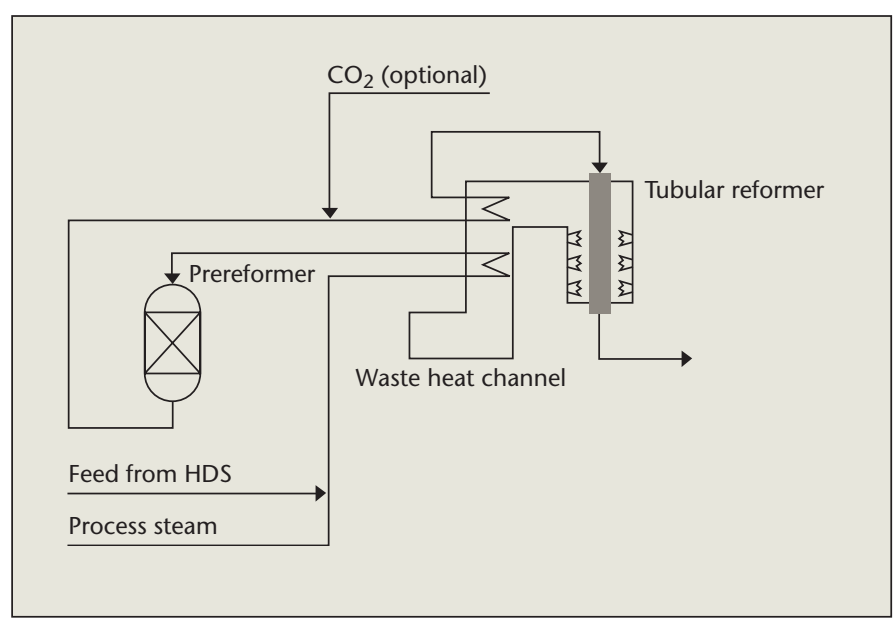

Figure 5: Flowsheet of a typical reforming unit.

reduce soot formation. This method is mostly used for heavy feeds. Some soot is formed and is removed in a separate scrubber system downstream of the partial oxidation reactor [3]. As with other thermal methods, this process typically produces a gas containing hydrogen and CO in the ratio 1.7-1.8:1. Downstream CO removal is therefore needed to produce pure hydrogen. The auto-thermal reforming (ATR) process [4] is a hybrid of partial oxidation and steam reforming, using a burner and a fixed catalyst bed to allow the gas to reach equilibrium. ATR is the preferred technology for the large-scale production of synthesis gas for methanol or synthetic diesel plants based on Fisher-Tropsch synthesis. For hydrogen plants, ATR using oxygen is only economic at very large scales because of the capital cost of the oxygen plant.

In catalytic partial oxidation $(\mathrm{CPO})$ the reactants are premixed, and all the chemical conversions take place in a catalytic reactor without a burner $[5,6]$. The direct CPO reaction (Table 6) yields a hydrogen/CO molar ratio of 2 and has a low heat of reaction $(38 \mathrm{~kJ} / \mathrm{mol})$. In practice, the reaction is accompanied by the reforming and water gas shift reactions, and at high conversions the product gas will be close to thermodynamic equilibrium [2]. CO removal is necessary to produce pure hydrogen.

Table 7: Comparison of CPO and steam reforming for producing hydrogen to supply low-temperature fuel cells [10].

\begin{tabular}{|ll|}
\hline CPO & Steam reforming \\
\hline $\begin{array}{l}\text { Compact } \\
\text { Higher combined } \\
\text { (heat + power) efficiency } \\
\text { No steam added } \\
\text { Short start-up time }\end{array}$ & $\begin{array}{l}\text { Higher cell voltage } \\
\text { Higher hydrogen yield at }\end{array}$ \\
$\begin{array}{l}\text { Fewer heat exchangers } \\
\text { Autothermal }\end{array}$ & $\begin{array}{l}\text { Noformer outlet } \\
\end{array}$ \\
\hline
\end{tabular}

For automotive applications $[7,8]$, the choice of hydrogen generation technology for small fuel cells $(5-50 \mathrm{~kW})$ is dictated by criteria such as simplicity of design and rapid response to transients (Table 7). Steam reforming is likely to be the most energy-efficient process for these applications, but catalytic partial oxidation or autothermal reforming with air may be preferred because the equipment is more compact [9].

\section{Hydrogen from biomass and micro- organisms \\ General aspects}

Biomass and biomass-derived fuels are renewable energy sources that can be used to produce hydrogen sustainably. Using biomass instead of fossil fuels to produce hydrogen reduces the net amount of carbon dioxide released to the atmosphere, since the carbon dioxide released when the biomass is gasified was previously absorbed from the atmosphere and fixed by photosynthesis in the growing plants.

Most regions of the world have enough suitable biomass - agricultural crops, crop residues, wood, agro-industrial waste, household waste, animal manure, sewage sludge and so on - to provide significant economic and environmental benefits. The eventual aim should be to coproduce hydrogen alongside other value-added by-products.

A wide range of technologies exists for transforming biomass into hydrogen (Figure 6). The conversion may take place either directly or via storable intermediates. Processes can be grouped into thermochemical and biological (fermentation) routes, both of which are relevant in the near- and mid-term. In the long term it may also be possible to produce hydrogen using photobiological processes, such as photosynthesis in cyanobacteria and algae.

Hydrogen or hydrogen-rich gas derived from biomass can readily be used in most hydrogen energy conversion devices and fuel cells. However, no technology for producing hydrogen from biomass or microbes is yet 


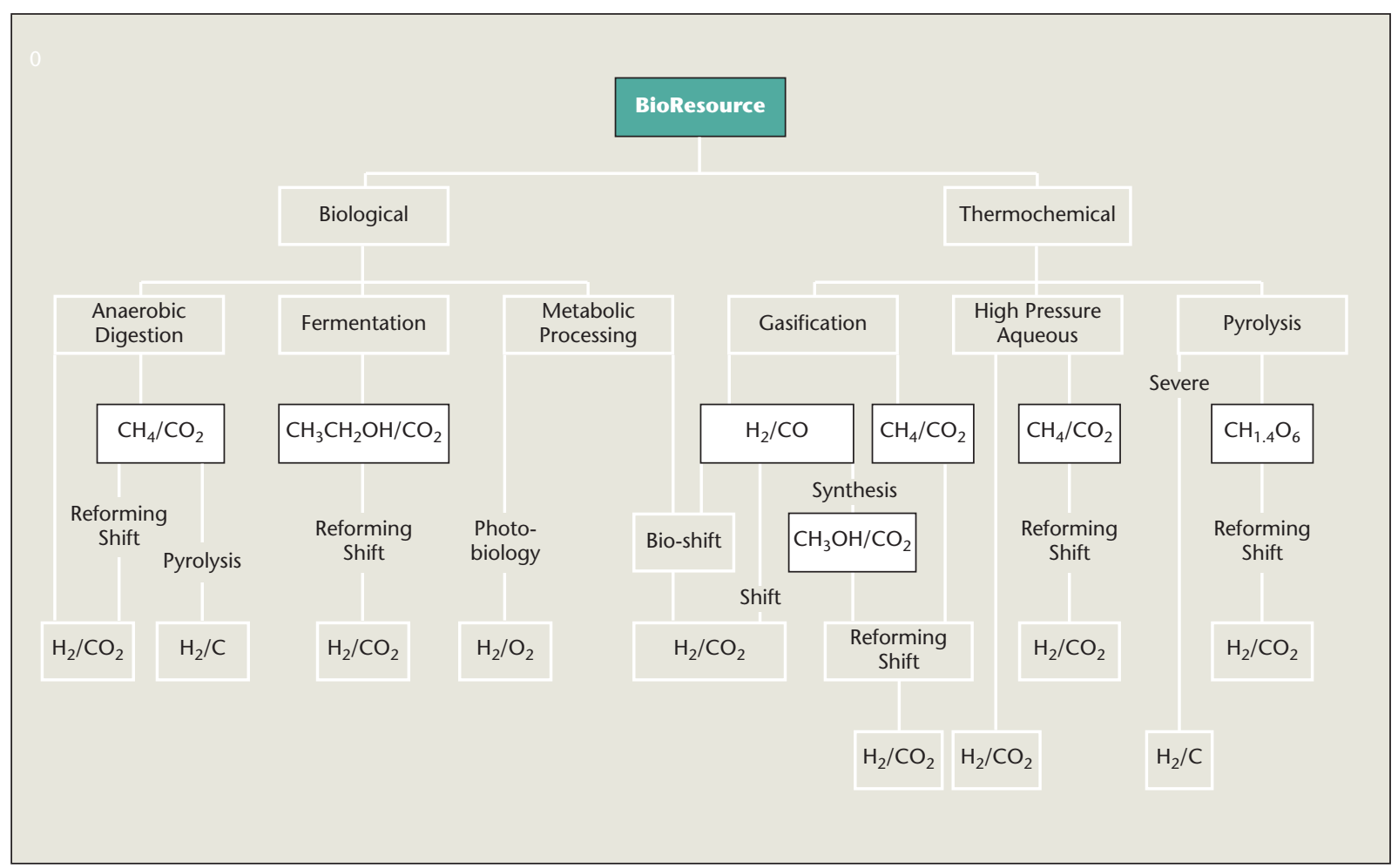

Figure 6: Pathways from biomass to hydrogen. Storable intermediates are shown in boxes. [11].

economically competitive or commercially available. In particular, biomass cannot currently compete with steam reforming of natural gas as a source of hydrogen.

\section{Biological production}

Hydrogen can be produced via purely biological routes through the fermentation of biomass using micro-organisms, or directly from cyanobacteria and micro-algae. Algae, and some microbial fermentations, use photosynthesis to produce hydrogen. Other fermentation processes, and direct production of hydrogen from cyanobacteria, can take place in the absence of light.

All biological hydrogen production processes depend on the presence of a hydrogen-producing enzyme. Nitrogenase, Fe-hydrogenase and NiFe hydrogenase are three such enzymes currently known to exist in micro-organisms.

Research on fermentation of biomass for hydrogen is increasing rapidly, especially on thermophilic bacteria and hydrogenases. Photobiological processes appear promising, but are not likely to become commercially available for some years [12].

Photobiological hydrogen production is based on photosynthesis in bacteria and green algae. The organism's photosynthetic apparatus captures light, and the resulting energy is used to couple water splitting to the generation of a reducing agent which is used to reduce a hydrogenase enzyme within the organism. Thus photosynthesis uses solar energy to convert water to oxygen and hydrogen.
Hydrogen production in photobiological systems is presently limited by low energy conversion efficiencies. Solar conversion efficiencies are normally less than $1 \%$ in cultures of micro-algae, and a tenfold increase is required before hydrogen production from micro-algae can become practical.

Another difficulty is the fact that hydrogenase enzymes are inhibited by oxygen at concentrations above $0.1 \%$. This has been a key problem during 30 years of research on hydrogen-producing micro-organisms [13], but strains of algae that can overcome oxygen intolerance are now being developed [12].

Another serious barrier is the "light saturation effect", in which cells near the outside of the culture medium absorb all the available sunlight. In the laboratory this is not a problem, but in large-scale plants it seriously reduces the yield of hydrogen. Photosynthetic bacteria also tend to absorb much more light than they can effectively convert into hydrogen, resulting in wasted energy. Research in these areas is aimed at distributing the available light more evenly - by stirring the culture medium or by using reflecting devices to transfer light into the depths of the culture - and developing algal strains that capture light less efficiently [13].

In photofermentation, photosynthetic bacteria produce hydrogen from organic acids, food processing and agricultural wastes, or high-starch biomass produced in turn by micro-algae grown in open ponds or photobioreactors. There are some reports of high hydrogen yields, but these systems have several drawbacks: the nitrogenase 


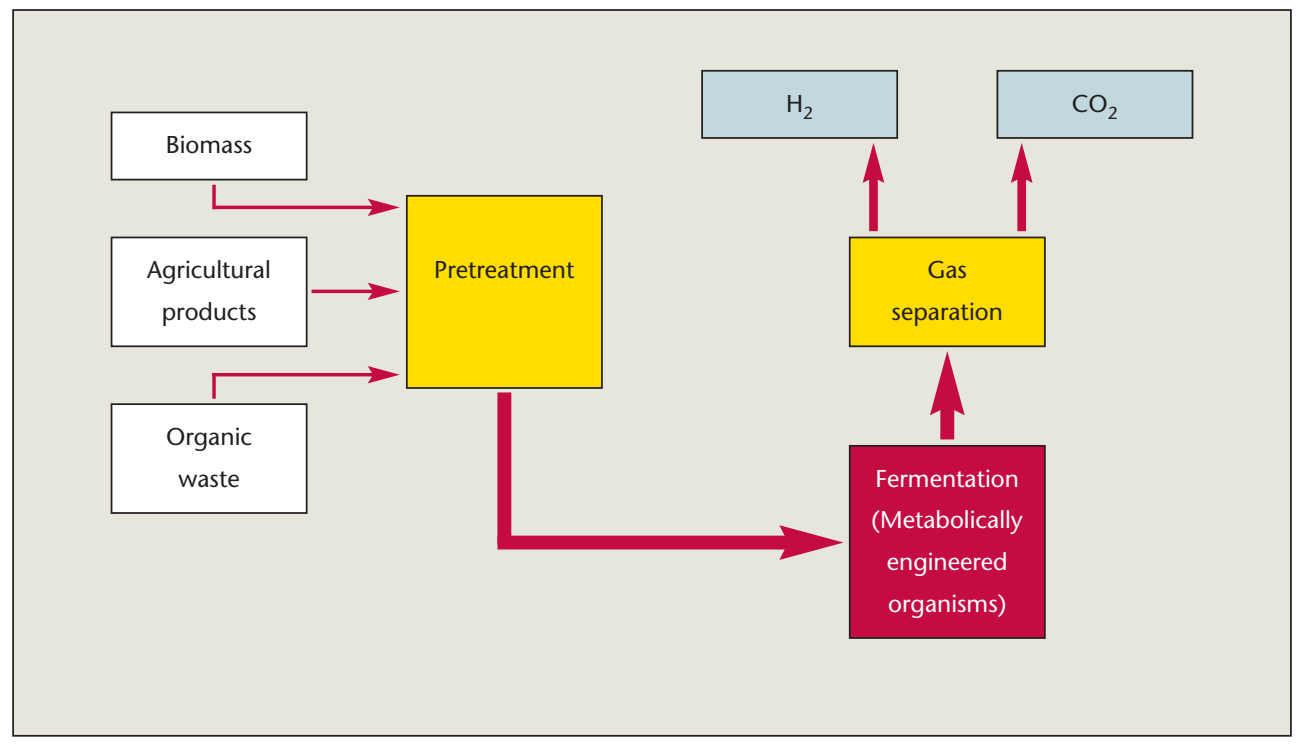

Figure 7: Hydrogen production based on fermentation [13].

enzymes used have high energy demands, solar energy conversion efficiencies are low, and huge areas of photobioreactors are needed [13].

It is often argued that it is simpler and more efficient to extract the hydrogen from organic substrates using a dark fermentation process.

Dark fermentation under aerobic conditions uses biomass such as plant materials and organic waste streams (Figure 7). Most of the hydrogen is actually produced during anaerobic metabolism of pyruvate formed during the catabolism of carbohydrates and other substrates. There is scope for metabolic engineering of the micro-organisms to redirect electrons so as to increase the hydrogen yields [13].

\section{Thermochemical conversion}

Biomass consists of carbon, hydrogen, oxygen, and nutrients such as nitrogen and sulphur. Figure 8 compares the composition of wood with that of hydrocarbon fuels. Wood consists mainly of cellulose, which contains $6.2 \%$ hydrogen. As a result, the total hydrogen content of wood is close to $6 \%$ and biomass is a reasonable feed for hydrogen production.

A large number of thermochemical processes to produce hydrogen from biomass are under development ([11,14]; see also other references to reviews of processes and experimental technologies).

In thermal gasification, solid biomass is first converted thermochemically into a gas. In the case of steam gasification and other indirectly-heated gasification processes, the result is a synthesis gas which can then be converted to hydrogen.

The first step in gasification is pyrolysis, in which the dissociated and volatile components of the biomass (70$85 \%$ of the dry weight) are vaporised at temperatures of typically around $600^{\circ} \mathrm{C}$. The resulting gas, which contains $\mathrm{H}_{2}, \mathrm{CO}, \mathrm{CO}_{2}$, tar and water vapour, is first cleaned to remove impurities and then optionally upgraded using the water gas shift reaction to yield $\mathrm{CO}_{2}$ and hydrogen. The final step is to purify the hydrogen. The residue from pyrolysis is a mixture of char (fixed carbon) and ash. The char is subsequently gasified by reacting it with oxygen, steam and/or hydrogen, and this provides the heat needed to run the gasifier.

Many gasification systems have been developed [11]. Among the more unusual of these are the use of solar energy to provide the heat for gasification [15] and the aqueous conversion of biomass to hydrogen under supercritical conditions $\left(374^{\circ} \mathrm{C}\right.$ and $\left.22 \mathrm{MPa}\right)$ [16].

Fast pyrolysis processes can convert biomass into two oxygenated oils. These can be stored as intermediates, and later steam reformed to yield hydrogen and CO. Biomass-derived methanol and ethanol may also be steam reformed in the presence of a catalyst to produce hydrogen. Methane derived from anaerobic digestion can yield hydrogen through pyrolysis as well as reforming [11].

\section{Research needs}

Technologies must be developed and sized according to the availability and quality of locally-available biomass. Biomass is assessed in terms of price (including transport costs), distribution, mass, and physical and chemical properties. Future research should also assess whether thermochemical and biological processes could be combined. Biological processes are in general less energyintensive and more environment-friendly than thermochemical processes.

\section{Biological routes}

- Development of crops with compositions optimised for biological hydrogen production. 


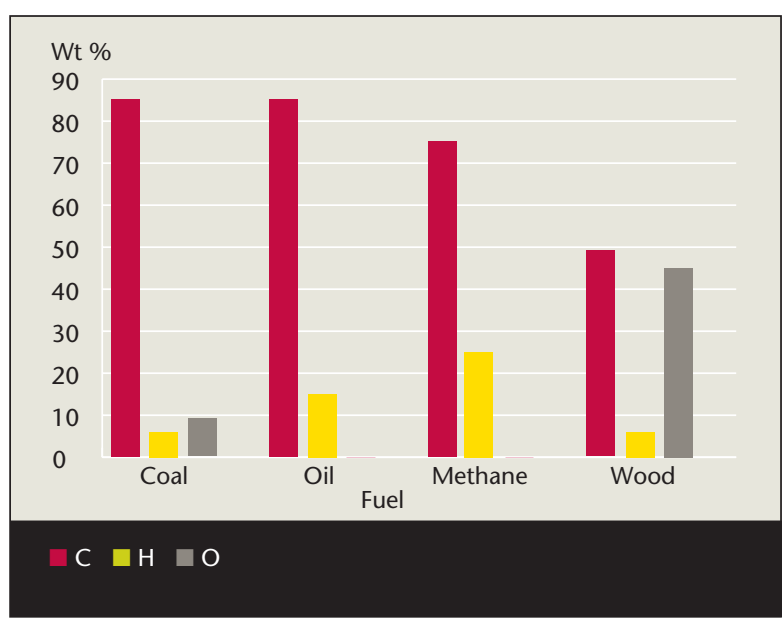

- Pretreatment of feedstock to increase accessibility.

- Systems for fermentable biomass, including light-dark fermentation systems for hydrogen.

- New thermophilic micro-organisms for hydrogen production.

- Effects of culture conditions on hydrogen production.

- Co-production: for instance, the effluent from a fermentation process for hydrogen can be used to generate methane.

\section{Thermochemical routes}

- Biomass feedstock typically has a low bulk density and is fibrous in nature. These properties create challenges in developing feed transport and preparation systems, such as pelletising, that are suitable for reactors operating at high temperatures and pressures.

- Research to improve product selectivity so that only hydrogen, carbon dioxide and water are produced.

- New technologies for gas separation, cleaning and processing so that hydrogen from biomass gasification can be used, for example, in fuel cells.

- Discover new opportunities for technology development by understanding and optimising feedstock conversion technology and market opportunities.

- Develop high-pressure aqueous processing technology to produce hydrogen from biomass.

- Technology for $\mathrm{CO}_{2}$ capture (hydrogen production/ decarbonisation accompanied by the capture and sequestration of carbon).

- Biomass and micro-organisms have the potential to accelerate the development of hydrogen into a major fuel of the future. This will require significant $R \& D$, however, since hydrogen made from biomass, even with reasonably efficient technologies, cannot yet compete with hydrogen from natural gas.

\section{Hydrogen from electrolysis}

Though it has been known for 200 years, electrolysis is still the only practical way to make hydrogen from water - and this situation is not likely to change in the fore-
Figure 8: Composition of common fuels.

seeable future. The largest source of electrolytic hydrogen is in fact the chlor-alkali industry, which has been operating for around 100 years. In chlor-alkali manufacture the main products are chlorine and sodium (or potassium) hydroxide, and hydrogen is regarded as a by-product.

Only a vanishingly small proportion (of the order of $0.1 \%$ ) of the world's hydrogen is produced directly by water electrolysis. Even this small quantity has declined in recent years as energy prices have fallen to the point where hydrogen produced electrolytically for fertiliser manufacture can no longer compete with hydrogen from natural gas. Because electrolytic hydrogen is created indirectly, using electricity as an energy carrier, it is only economic if electricity is extremely cheap. This may be the case in countries that have large hydroelectric systems, such as Egypt, Brazil, Iceland, Canada, Norway and Zaire, or a large nuclear component in the generating mix, such as France, Belgium and Switzerland [17].

\section{Principle}

The decomposition of water by electrolysis involves two partial reactions that take place at the two electrodes. The electron-conducting electrodes are separated by an electrolyte that conduct ions but not electrons. Hydrogen is produced at the negative electrode (cathode) and oxygen at the positive electrode (anode). Energy to split the water molecules is supplied as electricity to the two electrodes, and the necessary exchange of charge occurs as ions flow through the electrolyte.

The following sections describe electrolysis processes as optimised for hydrogen production: the well-tested lowpressure electrolysis method, and two processes - highpressure and high-temperature electrolysis - that are still under development. Chlor-alkali electrolysis is not discussed further here. 


\section{Conventional water electrolysis}

Conventional water electrolysis uses an alkaline aqueous electrolyte. The cathode and anode areas are separated by a microporous diaphragm to prevent mixing of the product gases. At output pressures of 2-5 bar the process can reach efficiencies of around $65 \%$. Instead of the alkaline electrolyte with an inert diaphragm, a solid acid proton conductor of the Nafion type (as used in PEMFCs) can also be used as a combined electrolyte and diaphragm [18].

Electrolysers are commercially available in capacities of 1 $\mathrm{kW}_{\mathrm{e}}-125$ MWe. The Electrolyser Corporation Ltd (Canada), Norsk Hydro Electrolysers AS (Norway) and DeNora (Italy) are well-established manufacturers of electrolysers for hydrogen, though much of their business is in the chlor-alkali market. Electrolyser manufacturers with a more specialized background in hydrogen include Ammonia Casale and Stuart Energy.

\section{High-pressure electrolysis}

As the volumetric energy density of gaseous hydrogen is rather low, it is an advantage to produce pressurised hydrogen directly. High-pressure water electrolysers now being developed can generate hydrogen at pressures up to 120 bar from an alkaline electrolyte. A $5 \mathrm{~kW}_{\mathrm{e}}$ prototype was tested at Forschungszentrum Jülich in Germany [19]. Another advantage of the high-pressure electrolyser is that its internal electrical resistance is lower, so the overall energy efficiency increases.

\section{High-temperature electrolysis}

High-temperature electrolysers started as an interesting alternative during the 1980s. If part of the energy required to split the water molecules is supplied in the form of high-temperature heat, less electricity is needed. High temperatures also speed up the reaction kinetics, decreasing the internal resistance of the cell and increasing the energy efficiency.

High-temperature solid oxide electrolyser cells (SOECs) have the advantage that they can also split $\mathrm{CO}_{2}$ into $\mathrm{CO}$ and $\mathrm{O}_{2}$. A mixture of steam and $\mathrm{CO}_{2}$ can be electrolysed to give a mixture of $\mathrm{H}_{2}$ and $\mathrm{CO}$ - synthesis gas - from which hydrogen carriers such as methane $\left(\mathrm{CH}_{4}\right)$ and methanol $\left(\mathrm{CH}_{3} \mathrm{OH}\right)$ may be easily produced. Note that such artificial $\mathrm{CH}_{4}$ will be a $\mathrm{CO}_{2}$ neutral hydrogen carrier $[20,21]$

The original idea was to use heat from solar concentrators or waste heat from power stations for high-temperature electrolysis [22]. Low energy prices halted this work around 1990, but the current emphasis on hydrogen has brought renewed interest. If fossil fuels become scarce, high-temperature electrolysis may have a future as a way to use heat from renewable or nuclear energy sources. Several R\&D projects on SOECs are in progress in Europe and the USA.

\section{Research needs}

A massive R\&D effort is necessary in order to obtain inexpensive electrolysers with high durability and efficiency. Mainly the following research areas are important in this context: 1) Materials research in order to identify improved materials and fabricate effective structures, 2) Surface science in order to understand the nature of the interfaces between the electrodes and electrolyte, and 3) Solid state electrochemistry in order to understand the processes and the losses involved. It is of major importance that these areas are researched in a close interplay.

\section{Conclusions and recommendations}

At present hydrogen from fossil fuels are by far cheaper than hydrogen from other sources. A massive research effort in the technologies of harvesting the renewable energy as well as in the conversion technologies is necessary in order to decrease the cost of "renewable" hydrogen. Synthetic $\mathrm{CO}_{2}$ neutral hydrocarbons have the potential of being competitors to "renewable" hydrogen, and therefore this option should also be carefully considered through serious research programmes. 


\section{Hydrogen storage}

LOUIS SCHLAPBACH, EMPA MATERIALS SCIENCE AND TECHNOLOGY INSTITUTION OF THE ETH DOMAIN AND UNIVERSITY OF FRIBOURG; ANDREAS ZÜTTEL, UNIVERSITY OF FRIBOURG; ALLAN SCHRØDER PEDERSEN, RISø NATIONAL LABORATORY

Hydrogen is a gas at ambient temperatures and pressures, but it can be stored as a gas, a liquid or a solid. In the case of solid storage, the hydrogen exists as a chemical compound, and not as a pure substance.

None of the existing methods for storing hydrogen are efficient in terms of energy density, neither on a volume nor a mass basis, and release rate at the same time. Compared to fossil fuels such as gasoline, hydrogen has a very obvious shortfall in the amount of energy it can store in a given volume or a given weight. The US Department of Energy has set up a target of $6.5 \%$ hydrogen by weight or $62 \mathrm{~kg} \mathrm{H} / \mathrm{H}^{3}$ and several storage techniques are able to meet these requirements (magnesium being an example, se later). These techniques do not, however, show other needed features like release or filling rate at proper temperature or even reversibility.

This is a critical barrier to the wider use of hydrogen in the transport sector (Figure 9). In stationary applications the problem is less severe.

\section{Storing hydrogen as a gas}

Hydrogen is the smallest and lightest molecule known. As a result, hydrogen in the gaseous state has an extremely high ability to diffuse through solid materials and to escape from even the smallest openings in joints and seals.

Storage of hydrogen as a gas dates back more than a century. Today the most widely used technology for commercial distribution of hydrogen is steel or aluminium cylinders pressurised to 200-250 bar. Such cylinders are heavy and the energy density is relatively low (Table 8). High-pressure cylinders are available in volumes up to about 50 litres; larger volumes are stored at much lower pressures, and the largest compressed

\begin{tabular}{|lrrrr|}
\hline & w-\%h & g H/l & $\mathrm{kJ} / \mathrm{ml}$ & $\mathrm{Kj} / \mathrm{g}$ \\
\hline Hydrogen at 200 bar & 100.0 & 17 & 2.4 & 141.0 \\
Magnesium Hydride & 7.6 & 101 & 14.4 & 10.9 \\
Hydride of Fe-Ti & 1.8 & 96 & 13.7 & 2.7 \\
Hydrie of La-Ni & 1.4 & 89 & 12.7 & 1.9 \\
Liquid Hydrogen & 100.0 & 70 & 10.0 & 141.0 \\
Methanol & 12.5 & 99 & 19.0 & 22.7 \\
Gasoline & & & 33.4 & 47.6 \\
Lead/Acid Battery & & & & 0.2 \\
Advanced battery & & & & 0.5 \\
Liquid Methane & 25.0 & 106 & 25.0 & 55.7 \\
Liquid Ammonia & 17.6 & 120 & 17.9 & 25.2 \\
Fly Wheel & & & & 0.5 \\
\hline
\end{tabular}

Table 8. Physical and chemical properties of hydrogen, methane and gasoline

hydrogen tanks in the world (about $15,000 \mathrm{~m}^{3}$ ) use pressures of only 12-16 bar [1]. Pressurised gas is still the preferred technology for storing and distributing hydrogen because it is well established and has an extensive infrastructure.

If gaseous hydrogen is to replace stores of liquid fossil fuels, the technology needs to be improved significantly. Intensive development taking place at present includes efforts to create lighter storage cylinders made from fibre-reinforced composites. The Canadian company Dynetek Industries Ltd., for example, claims weight savings of $20-50 \%$ for its composite cylinders operating at 200-350 bar. Dynetek has also developed hydrogen cylinders that can operate at 825 bar for stationary use and 700 bar in transport applications [2].

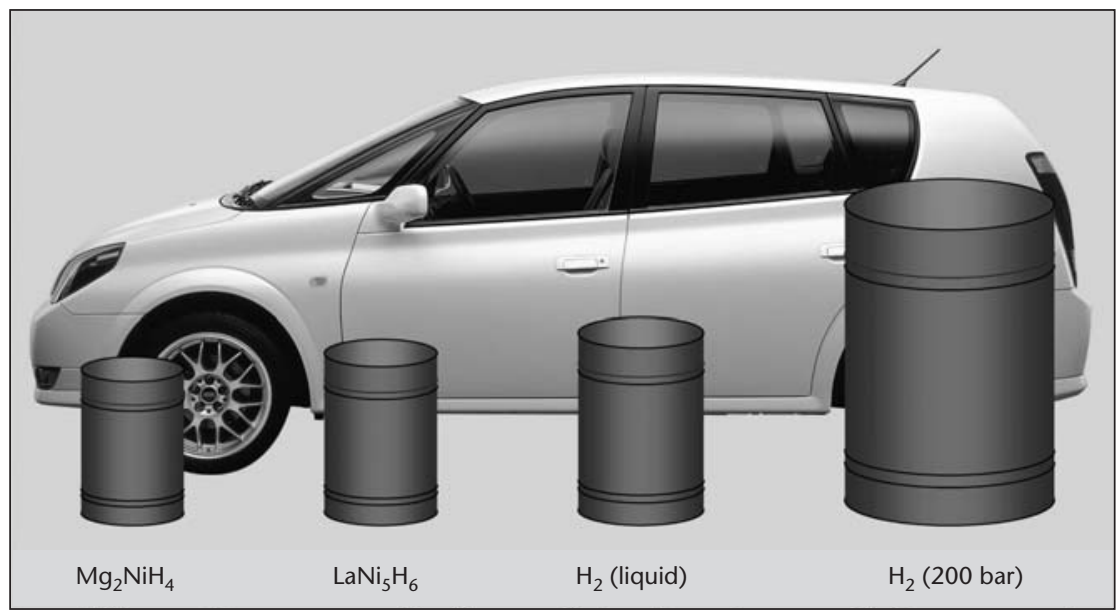


In contrast to liquefaction (see below), compressing hydrogen requires relatively small amounts of energy. Compressing hydrogen from atmospheric pressure to 450 bar requires $25 \mathrm{~kJ} / \mathrm{mol}$, for instance, which is $9 \%$ of the higher heating value of hydrogen $(285 \mathrm{~kJ} / \mathrm{mol})$.

\section{Underground storage of gaseous hydrogen}

A special case of gaseous hydrogen storage is the use of large underground cavities similar to those now used to store natural gas. In both cases the quantities of energy involved have the potential to meet the needs of large communities for extended periods, such as might be needed to ensure security of supply or to meet seasonal variations in energy production. This gives underground storage a special importance.

Two methods of underground storage that are suitable for both hydrogen and natural gas are the use of cavities left after the mining of salt, and in empty aquifers. In the Tees Valley, UK, a salt dome beneath an urban area is used to store 1,000 tonnes of hydrogen for industrial use. Associated with the storage cavity is $30 \mathrm{~km}$ of hydrogen distribution pipeline [3].

\section{Liquid hydrogen}

Liquid hydrogen can exist only at temperatures below $33 \mathrm{~K}\left(-240^{\circ} \mathrm{C}\right)$ - the "critical temperature" of hydrogen [4]. In practice, liquid hydrogen is usually stored at the lower temperature of $20 \mathrm{~K}\left(-253^{\circ} \mathrm{C}\right)$ because at $20 \mathrm{~K}$ it can be stored at atmospheric pressure, whereas liquid hydrogen at $33 \mathrm{~K}$ requires pressurised storage at $13 \mathrm{bar}$. Hydrogen molecules exist in two different forms, distinguished by the alignment of the nuclear spins in each of their two atoms. In ortho hydrogen the nuclear spins are in the same direction, whereas in para hydrogen the spins are in opposite directions. Note that this has nothing to do with isotopes; ortho and para hydrogen have exactly the same molecular weight.

At ambient temperatures hydrogen contains $25 \%$ of the para form and $75 \%$ ortho. At low temperatures para hydrogen is by far the more stable form, and at $20 \mathrm{~K}$ almost all the ortho molecules eventually transform into the para form. The conversion is accompanied by the release of around $1 \mathrm{~kJ} / \mathrm{mol}$ of heat, which is larger than the heat of vaporization of hydrogen (approximately 0.9 $\mathrm{kJ} / \mathrm{mol})$.

This means that until the transformation to the para form is complete, liquid hydrogen has a built-in source

Figure 10: The amount of hydrogen, on a mass and volume basis, stored by metal hydrides, carbon nanotubes, gasoline and other hydrocarbons.

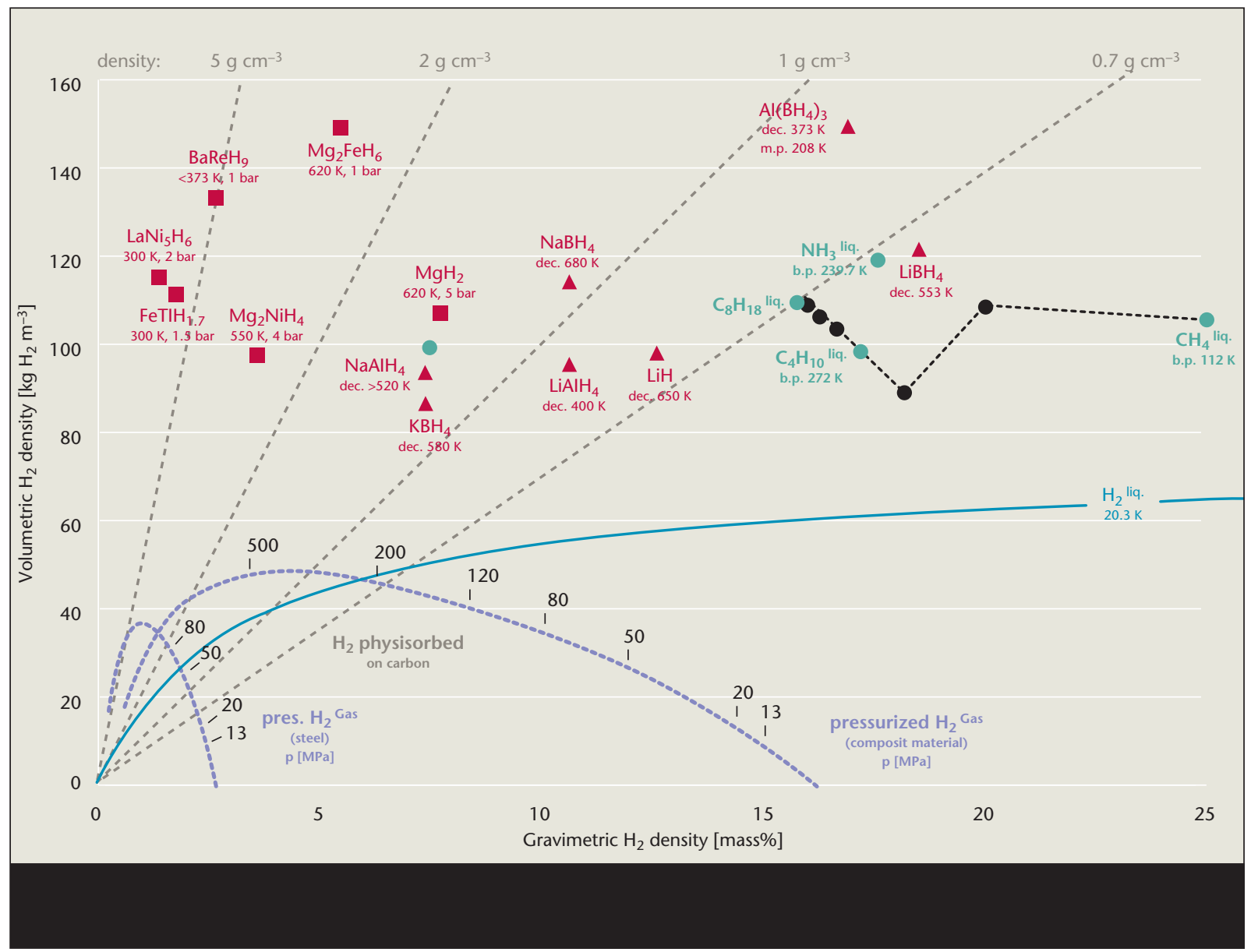




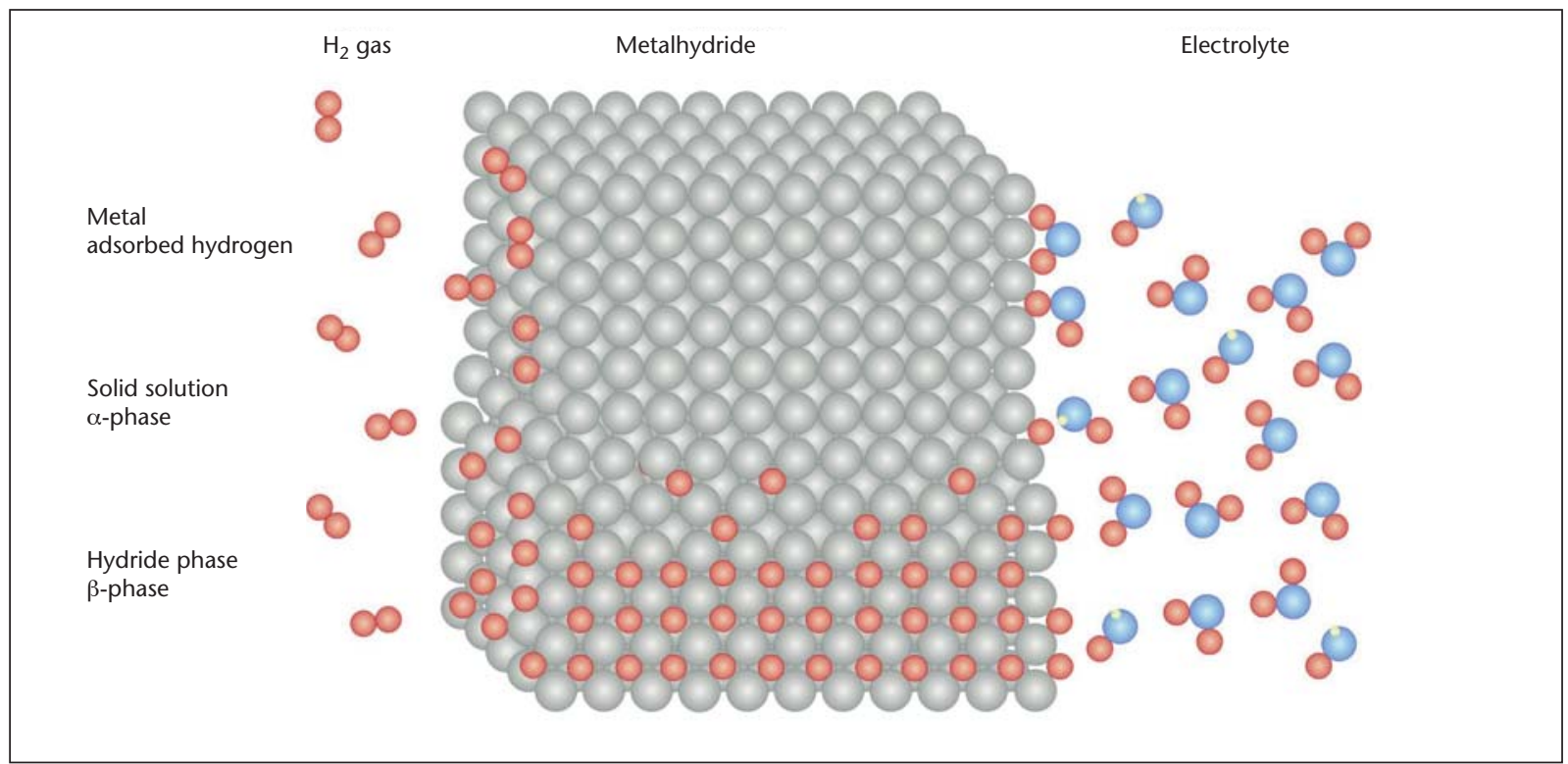

Figure 11: A metal lattice with hydrogen atoms in the interstitial spaces and hydrogen molecules at the surface. The hydrogen atoms come from physisorbed hydrogen molecules (left) and dissociation of water molecules (right).

of heat that is always present, regardless of the amount of insulation, and is sufficient to boil the liquid. It is therefore important to make sure that as much conversion as possible takes place during the liquefaction process, when heat removal is easier [5]. Suppliers of liquid hydrogen are typically able to guarantee that up to $98 \%$ exists in the para form.

The density of liquid hydrogen is $70 \mathrm{~kg} / \mathrm{m}^{3}$. Though this is remarkably low for a liquid, it is still higher than the density of gaseous hydrogen at 200 bar (Figure 10). Liquid hydrogen's greater density and the fact that it can be handled at atmospheric pressure means that the liquid hydrogen is preferred in many large industrial distribution networks.

On the other hand, liquefaction is energy-intensive [6]; the process consumes $30-40 \%$ of the total energy content of the hydrogen. Though the heat of vaporization is only around $1 \mathrm{~kJ} / \mathrm{mol}$, as we saw above, operating the liquefaction plant at temperatures down to $20 \mathrm{~K}$ requires around $90 \mathrm{~kJ} / \mathrm{mol}$.

A typical modern liquid hydrogen storage tank was developed by industrial gas supplier Linde in Germany for a hydrogen-powered bus. The cylindrical tank has an outside diameter of $500 \mathrm{~mm}$ and an overall length of 5.5 $\mathrm{m}$. Its capacity is $540 \mathrm{l}$ of liquid hydrogen, based on an ullage of $10 \%$. It is designed to work at pressures from full vacuum up to $8 \mathrm{bar}$, and at temperatures in the range 20353K [7].

\section{Solid-state storage}

This section is based on reference [8].

Hydrogen adsorption on solids with large surface areas Solid surfaces adsorb hydrogen to an extent that depends on the pressure, temperature and the nature of the surface. The mechanisms include both Van der Waalstype weak physisorption of molecular hydrogen, and chemisorption of atomic hydrogen following dissociation.

Adsorption as a way to store hydrogen has been studied mainly on surfaces based on carbon. A monolayer of hydrogen on a surface contains about $1.3 \times 10^{-5} \mathrm{~mol} / \mathrm{m}^{2}$. A graphene sheet with a specific surface area of 1,315 $\mathrm{m}^{2} / \mathrm{g}$ has been shown to adsorb a maximum of 0.4 hydrogen atoms for each carbon atom on the surface, giving a total of 3.3\% hydrogen by weight for adsorption on one side of the sheet only.

On activated carbon with the same specific surface area, at a temperature of $77 \mathrm{~K}$, hydrogen is reversibly sorbed to a maximum of $2 \%$ by weight. Nanostructured graphite, produced by ball milling for 80 hours in an atmosphere of hydrogen at 10 bar, adsorbs up to 0.95 hydrogen atoms per carbon atom, or $7.4 \mathrm{wt} \%$. $80 \%$ of this hydrogen could be desorbed again by heating to $600 \mathrm{~K}$ [9]. Carbon nanotubes may be a promising material for hydrogen storage, but experimental results to date have been controversial $[10,11]$ - probably because the carbon compounds actually used were of different kinds and not well characterised. One group of researchers [12] concluded that at both $77 \mathrm{~K}$ and ambient temperature, physisorption is the mechanism for hydrogen storage on carbon nanotubes. The maximum amount of hydrogen adsorbed depends on the specific surface area, and is around $1.5 \mathrm{wt} \%$ for a specific surface area of $1,000 \mathrm{~m}^{2} / \mathrm{g}$.

\section{Hydrogen storage in metal hydrides}

Many metals and alloys can reversibly absorb large amounts of hydrogen. The hydrogen can be introduced 


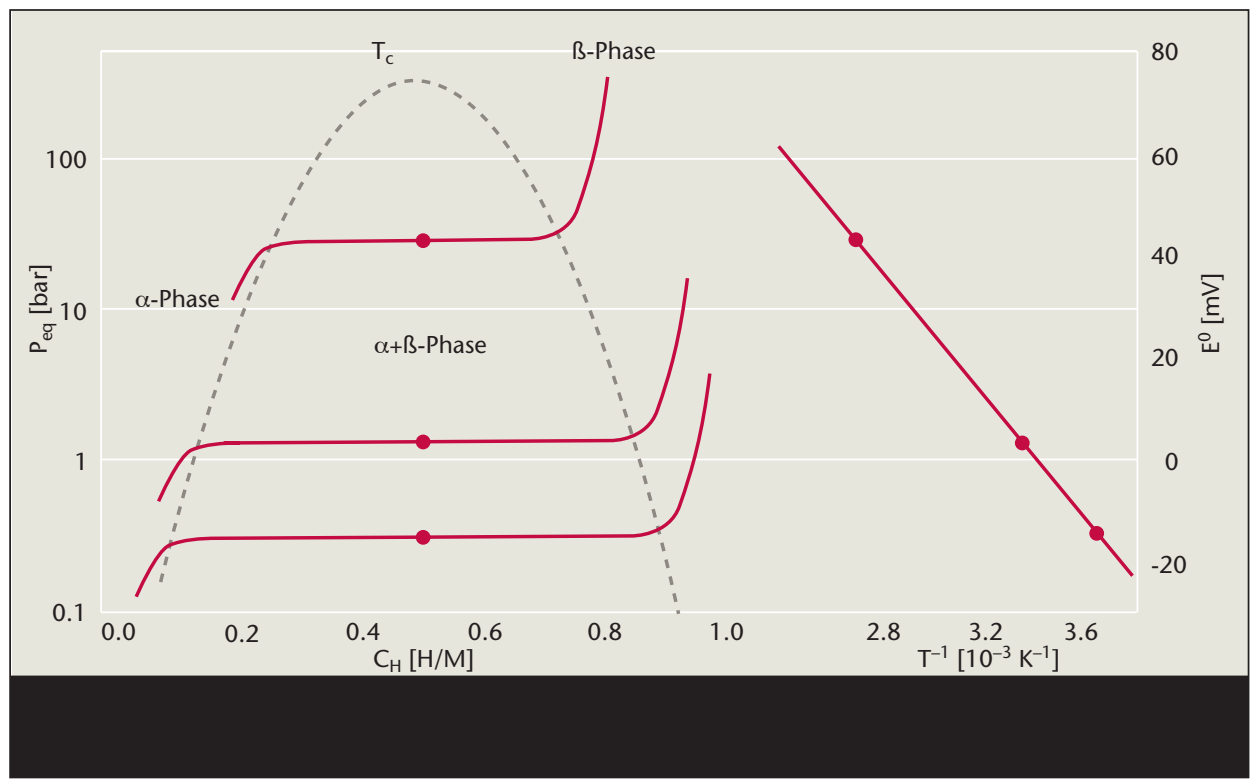

Figure 12: Pressure-concentration-temperature (pcT) plot and Van't Hoff curve (logarithm of the equilibrium pressure vs. the reciprocal temperature) for $\mathrm{LaNi}_{5}$. The vertical axis indicates the corresponding hydrogen pressure or the equivalent electrochemical potential.

to the metal either as molecules, in the gas phase, or as atoms from an electrolyte (Figure 11). In the former case, hydrogen molecules dissociate at the surface before absorption; desorption releases hydrogen atoms, which recombine to form $\mathrm{H}_{2}$.

The thermodynamics of hydride formation from gaseous hydrogen are described by pressure-composition isotherms or pcT curves (Figure 12). The host metal dissolves some hydrogen as a Sieverts-type solid solution phase. As the hydrogen pressure increases, so does the concentration of hydrogen atoms in the metal $\left(\mathrm{c}_{\mathrm{H}}\right)$. At some point, $\mathrm{H}-\mathrm{H}$ interactions become locally important and a hydride phase starts to nucleate and grow.

While the solid solution and the hydride coexist, the isotherms show a plateau whose length determines how much hydrogen can be stored and recovered by means of small pressure changes. In the pure hydride phase, the hydrogen pressure rises steeply with concentration.

The plateau or equilibrium pressure $\mathrm{p}_{\mathrm{eq}}(\mathrm{T})$ depends strongly on temperature. The enthalpy of hydride formation $(\Delta \mathrm{H})$ can be found from the slope of a Van't Hoff plot of the logarithm of the plateau pressure against $1 / \mathrm{T}$. For an equilibrium pressure of 1 bar at $300 \mathrm{~K}, \Delta \mathrm{H}$ should be $19.6 \mathrm{~kJ} / \mathrm{mol}$ hydrogen. The operating temperature of a metal hydride system is fixed by the plateau pressure in thermodynamic equilibrium and by the overall reaction kinetics $[13,14]$.

Hydrogen is stored in the interstices of the host metal lattice as atoms, never as molecules. As hydrogen is absorbed, the lattice expands and often loses some of its symmetry. The co-existence of the non-expanded solid solution phase and the anisotropically expanded hydride phase gives rise to lattice defects and internal strain fields, ultimately causing the decrepitation of brittle host metals such as intermetallics. The hydrogen atoms vibrate about their equilibrium position, move locally and also undergo long-range diffusion.

In terms of electronic structure, the hydrogen atom's nuclear proton attracts the electrons of the host metal. As a result, the metal's electron bands are lowered in energy and hybridise with the hydrogen band to form low-lying bands 6-8 eV below the Fermi level. The Fermi level itself is shifted, and various phase transitions (metal-semiconductor, magnetic-nonmagnetic, reflecting-transparent, order-disorder) may occur.

The metal-hydrogen bond has the advantages of providing very high hydrogen storage density at moderate pressure, and desorption of all the stored hydrogen at the same pressure.

Which metallic systems are appropriate for hydrogen storage? Hydrides can be formed from many metals, including palladium $\left(\mathrm{PdH}_{0.6}\right)$, the rare earth metals $\left(\mathrm{REH}_{2}\right.$ and $\left.\mathrm{REH}_{3}\right)$ and magnesium $\left(\mathrm{MgH}_{2}\right)$. However, none of these are in the pressure-temperature range attractive for mobile storage: $1-10$ bar and $0-100^{\circ} \mathrm{C}$, corresponding to $\Delta \mathrm{H}$ in the range $15-24 \mathrm{~kJ} / \mathrm{mol}$ hydrogen.

The discovery of hydrogen sorption by intermetallic compounds created a flurry of R\&D effort worldwide, in the hope that some of these compounds would be suitable for practical hydrogen storage systems (Table 9).

Alloys based on $\mathrm{LaNi}_{5}$ have some very promising properties, including fast and reversible sorption with little hysteresis, a plateau pressure of just a few bars at room temperature, and good cycling life. The volumetric (crystallographic) density of hydrogen in $\mathrm{LaNi}_{5} \mathrm{H}_{6.5}$ at 2 bar is equal to that of gaseous molecular hydrogen at 1,800 bar, and all this hydrogen is desorbed at only 2 bar. In prac- 


\begin{tabular}{|llllll|}
\hline Type & metal & hydride & Struc. & $m \%$ & Peq, $\mathrm{T}$ \\
\hline $\mathrm{A}$ & $\mathrm{Pd}$ & $\mathrm{PdH}_{0.6}$ & $\mathrm{Fm} 3 \mathrm{~m}$ & 0.56 & $0.02 \mathrm{bar}, 298 \mathrm{~K}$ \\
$\mathrm{AB}_{5}$ & $\mathrm{LaNi}_{5}$ & $\mathrm{LaNi}_{5} \mathrm{H}_{6}$ & $\mathrm{P} 6 / \mathrm{mmm}$ & 1.37 & 2 bar, $298 \mathrm{~K}$ \\
$\mathrm{AB}_{2}$ & $\mathrm{ZrV}_{2}$ & $\mathrm{ZrV}_{2} \mathrm{H}_{5.5}$ & $\mathrm{Fd} 3 \mathrm{~m}$ & 3.01 & $10^{-8} \mathrm{bar}, 323 \mathrm{~K}$ \\
$\mathrm{AB}$ & $\mathrm{FeTi}$ & $\mathrm{FeTiH}_{2}$ & $\mathrm{Pm} 3 \mathrm{~m}$ & 1.89 & 5 bar, 303 K \\
$\mathrm{A}_{2} \mathrm{~B}$ & $\mathrm{Mg}_{2} \mathrm{Ni}$ & $\mathrm{Mg}_{2} \mathrm{NiH}_{4}$ & $\mathrm{P} 6222$ & 3.59 & 1 bar, $555 \mathrm{~K}$ \\
$\mathrm{bcc}$ & $\mathrm{TiV}_{2}$ & $\mathrm{TiV}_{2} \mathrm{H}_{4}$ & bcc & 2.6 & 10 bar, 313 K \\
\hline
\end{tabular}

tice, the packing fraction of $\mathrm{LaNi}_{5}$ powder reduces the amount of hydrogen that can be stored, but the hydrogen density is still above that of liquid hydrogen (Figure 10). Intermetallic compounds such as $\mathrm{LaNi}_{5}$ are also a very safe way to store hydrogen.

As La and Ni have high molecular weights, the amount of hydrogen in $\mathrm{LaNi}_{5} \mathrm{H}_{6.5}$ is less than $2 \mathrm{wt} \%$. This is an attractive material for electrochemical hydrogen storage in rechargeable metal hydride electrodes, such as electrodes for commercially-available $\mathrm{AB}_{5}$ type metal hydride batteries that have capacities of up to 330 $\mathrm{mAh} / \mathrm{g}$.

For mobile hydrogen storage applications, however, low mass density is a general weakness of all known metal hydrides working around room temperature. Practical applications require hydrogen storage densities of 4-5 $\mathrm{wt} \%$, short term US DOE target is even higher, at $6.5 \%$ hydrogen by weight or $62 \mathrm{~kg} \mathrm{H} / \mathrm{m}^{3}$. Many intermetallic compounds and alloys form hydrides with up to $9 \%$ hydrogen by weight $\left(\mathrm{Li}_{3} \mathrm{Be}_{2} \mathrm{H}_{7}\right.$ [15]) and 4.5 hydrogen atoms per metal atom $\left(\mathrm{BaReH}_{9}[16]\right)$, but they are not reversible within the required range of temperature and pressure.

When hydride formation and decomposition are limited by reaction kinetics instead of thermodynamic equilibrium, various physical and chemical pre-treatments can be used to improve performance. Ball milling, for instance, has beneficial effects on the grain size and defect concentration, and shortens the diffusion path. Fluorination has been shown to render surfaces active [17], apparently to a greater extent than the use of surface nickel precipitates, whose role in the hydrogen dissociation process is well known.

New families of Laves-phase-related BCC solid solution alloys are being studied in several Japanese laboratories [18]. These are based on vanadium, zirconium and titanium as the more electropositive components, combined with $3 \mathrm{~d}$ and $4 \mathrm{~d}$ transition metals. Reversible hydrogen storage capacities approaching $3 \mathrm{wt} \%$ around room temperature have been reported.

Higher mass density can only be reached using light elements such as calcium and magnesium. In fact, magnesium forms an ionic, transparent hydride $\left(\mathrm{MgH}_{2}\right)$ containing $7.6 \mathrm{wt} \%$ hydrogen, but its formation from bulk magnesium and gaseous hydrogen is extremely
Table 9: $A B_{5}, A B_{2}, A B, A_{2} B$ and bbc intermetallics and their hydrogen storage properties [14]

slow. Once the hydride does reach equilibrium, a plateau pressure of 1 bar requires a temperature of $300^{\circ} \mathrm{C}$.

Various micro- and nano-structuring processes have been used to treat magnesium with the aim of improving the kinetics of $\mathrm{MgH}_{2}$ formation. Precipitation from metal-organic solutions or high-energy ball milling yielded good storage and discharge kinetics, even at $150^{\circ} \mathrm{C}$, and the equilibrium was evidently not affected $[14,19]$. Alloying is another approach: $\mathrm{Mg}_{2} \mathrm{Ni}$, for instance, forms a ternary complex hydride $\mathrm{Mg}_{2} \mathrm{NiH}_{4}$ that can hold $3.6 \mathrm{wt} \%$ of hydrogen. The hydride forms quite rapidly, probably due to the action of nickel as a catalyst for the dissociation of molecular hydrogen, but the thermodynamics still dictate a temperature of $280^{\circ} \mathrm{C}$ to operate at 1 bar. Magnesium does not form a binary intermetallic compound with iron, but the presence of hydrogen allows the formation of the rather stable ternary hydride $\mathrm{Mg}_{2} \mathrm{FeH}_{6}$, which contains $5.5 \mathrm{wt} \%$ hydrogen [15].

Another approach is to make composite materials containing two or more distinct components, in an effort to compensate for the weaknesses of each. Magnesium, for instance, can be ball-milled with graphitic carbon or mixed with hydrides such as $\mathrm{LaNi}_{5}$ or $\mathrm{Mg}_{2} \mathrm{Ni}$, which have fast kinetics. Not surprisingly, the hydrogen capacities of these materials fall between those of their individual constituents.

\section{Alanates and other light hydrides}

Some of the lightest elements in the periodic table including lithium, boron, sodium, aluminium and their compounds - form stable ionic hydrides. One of these, $\mathrm{LiBH}_{4}$, has the highest hydrogen density known: $18 \mathrm{wt} \%$ hydrogen at room temperature [20]. However, the light hydrides desorb their hydrogen only at temperatures in the range $80-600^{\circ} \mathrm{C}$, and it is not yet known to what extent all of them are reversible.

One group showed in 1996 that the decomposition temperature of $\mathrm{NaAlH}_{4}$ can be lowered by doping with $\mathrm{TiO}_{2}$ [21]. Recently, the same group showed that hydride formation was reversible for several cycles of absorption and desorption. This highlights the potential of such hydrides, which were discovered more than 50 years ago, but several points need to be clarified. First, is the high desorption temperature reported earlier due to poor 
kinetics or the thermodynamic stability of the hydride? If the process is rate-limited, the kinetics can be improved by incorporating a catalyst [22], or by ball milling and the introduction of defects.

Second, what are the conditions for a reversible reaction? The reversible formation of $\mathrm{LiBH}_{4}$ and most of the other hydrides in this potentially very attractive group is a challenge. Desorption of hydrogen requires the formation and stabilisation of clusters of an intermetallic compound containing the remaining metals. $\mathrm{SiO}_{2}$ is known to play a catalytic role, but these light-metal hydrides need much more research.

\section{Heat Management in Hydride Operation}

As discussed above, a considerable absorption or release of heat is involved in metal hydriding/hydriding process. In several cases the reaction heat amounts to about $25 \%$ of the combustion energy of the stored hydrogen and this fact calls for clever, dedicated solutions for exchanging heat with the hydride material. One example of such heat management could be a hydride store, which should feed a fuel cell with hydrogen. In this case the heat produced by the fuel cell may be used to dissociate the metal hydride and the systems may be tailored for an optimal thermal match. Large Danish companies have long experience in handling and exchanging heat, and for such companies the topic of thermal management of hydride stores could be of commercial interest.

\section{Other hydrogen-rich compounds}

Similarly to storing hydrogen in metal hydrides also the formation of other types of hydrogen-rich compounds could be attractive for hydrogen storage. For instance it is possible to form methane by direct electrolysis of water in the presence of carbon dioxide and indeed it is possible to form liquid compounds like methanol by properly reacting hydrogen and carbon dioxide. Both reactions may be done in an environmentally friendly way by taking the carbon dioxide from the atmosphere. The attractive features of such carbon based compounds is that we have a long handling experience and that an infrastructure is existing or at least well-known.

\section{Visions for the future}

It is reasonable to hope that improvements in the performance of hydrogen storage materials will one day match those of high-temperature superconductors and permanent magnets. In developing sustainable energy policies, however, we must look at society, economics and the way we think about energy, as well as the scientific and technical challenges.

As mobility continues to increase, we must decide whether prestige, size and power should remain important in vehicle design. And do vehicles really need strong, heavy structures to protect their occupants, or are electronic control and collision-avoidance systems a better approach? They could certainly make it possible for much lighter and more energy-efficient vehicles to be built in those countries that do not consider energy availability to be unlimited. Europe and Japan already have small, light cars whose engines consume as little as 31 of gasoline per $100 \mathrm{~km}$. A single kilogramme of hydrogen can fuel an engine-driven car for $100 \mathrm{~km}$; with a hydrogen fuel cell the range is $200 \mathrm{~km}$. 


\subsection{Hydrogen conversion technologies}

SØREN LINDEROTH, RISØ NATIONAL LABORATORY; JOHN BØGILD HANSEN, HALDOR TOPSøE A/S; DR. MOHSEN ASSADI AND PROFESSOR BENGT JOHANSSON, LUND INSTITUTE OF TECHNOLOGY.

\section{Introduction}

Hydrogen needs to be converted into power and heat with high efficiency and little or no pollution from NOx, particles and noise. Emerging technologies can make this possible. Most of these technologies can also convert hydrogen-rich fuels with high efficiency and little pollution. For fuels such as natural gas, methanol, bioethanol and biogas, technologies that are either already existing or will be available in the near future provide clean and efficient conversion to power and heat, thus paving the way for a hydrogen society based on hydrogen-rich fuels. These technologies can also be combined in hybrid cycles to reach electrical efficiencies of up to around $70 \%$. This chapter outlines the technologies, their status, advantages and areas for improvement, and shows how they can be combined.

\section{Fuel cells}

Fuel cells are likely to play an important role in future energy supply as sources of both power and heat. Fuel cells of the future will be highly efficient, clean, quiet, scalable, reliable and potentially cheap.

Various kinds of fuel cells are being developed worldwide for commercial use in portable, transport and stationary applications (Table 10).

Low-temperature fuel cells, notably PEMFCs, are most useful for converting high-purity hydrogen into electricity and heat. Electrical efficiencies reach nearly 50\% using hydrogen.

With other fuels the electrical efficiency decreases, so that the efficiency for natural gas is expected to be around $35 \%$. This is because the feedstock must first be "reformed" into a mixture of hydrogen, carbon

Table 10: Types of fuel cells and their properties. Fuel cells fall into two types: low-temperature, which operate at temperatures below $450^{\circ} \mathrm{C}$, and high-temperature. This chapter deals mainly with PEMFCs and PAFCs $\left(50-200^{\circ} \mathrm{C}\right)$ and SOFCs $\left(550-1,000^{\circ} \mathrm{C}\right)$.

\begin{tabular}{|c|c|c|c|c|}
\hline Fuel cell type & $\begin{array}{l}\text { Solid polymer or } \\
\text { Proton exchange } \\
\text { membrane }\end{array}$ & Phosphoric acid & Molten carbonate & Solid oxide \\
\hline & PEMFC & PAFC & MCFC & SOFC \\
\hline Electrolyte & Proton-conducting polymer & $\mathrm{H}_{3} \mathrm{PO}_{4}$ & $\mathrm{~K}-\mathrm{Li}-\mathrm{CO}_{3}$ & $\mathrm{Y}-\mathrm{Zr}_{2} \mathrm{O}_{3}$ \\
\hline Operating temperature & $\sim 80^{\circ} \mathrm{C}$ & $\sim 200^{\circ} \mathrm{C}$ & $\sim 650^{\circ} \mathrm{C}$ & $\sim 600-1000^{\circ} \mathrm{C}$ \\
\hline Advantages & $\begin{array}{l}\text { Works at ambient } \\
\text { temperature } \\
\text { High power density } \\
\text { Quick to start up } \\
\text { Solid electrolyte }\end{array}$ & $\begin{array}{l}\text { Reliability } \\
\text { Tolerates above } \\
\sim 1 \% \text { of CO }\end{array}$ & $\begin{array}{l}\text { Internal reforming } \\
\text { Fuel flexibility } \\
\text { High-temperature } \\
\text { waste heat } \\
\text { No noble metals }\end{array}$ & $\begin{array}{l}\text { Internal reforming } \\
\text { Fuel flexibility } \\
\text { High-temperature } \\
\text { waste heat } \\
\text { Solid electrolyte } \\
\text { Very durable } \\
\text { No noble metals }\end{array}$ \\
\hline Disadvantages & $\begin{array}{l}\text { Very sensitive to CO } \\
\text { Water management } \\
\text { Limited durability } \\
\text { Low-temperature waste } \\
\text { heat }\end{array}$ & $\begin{array}{l}\text { Relatively low efficiency } \\
\text { Limited durability } \\
\text { Loss of phosphoric } \\
\text { acid electrolyte }\end{array}$ & $\begin{array}{l}\text { Requires expensive } \\
\text { alloys } \\
\text { Corrosive liquid } \\
\text { electrolyte } \\
\mathrm{CO}_{2} \text { needed in the air } \\
\text { to the cathode } \\
\text { Low power density }\end{array}$ & $\begin{array}{l}\text { Sealing problems } \\
\text { Thermal cycling } \\
\text { Slow to start up }\end{array}$ \\
\hline
\end{tabular}




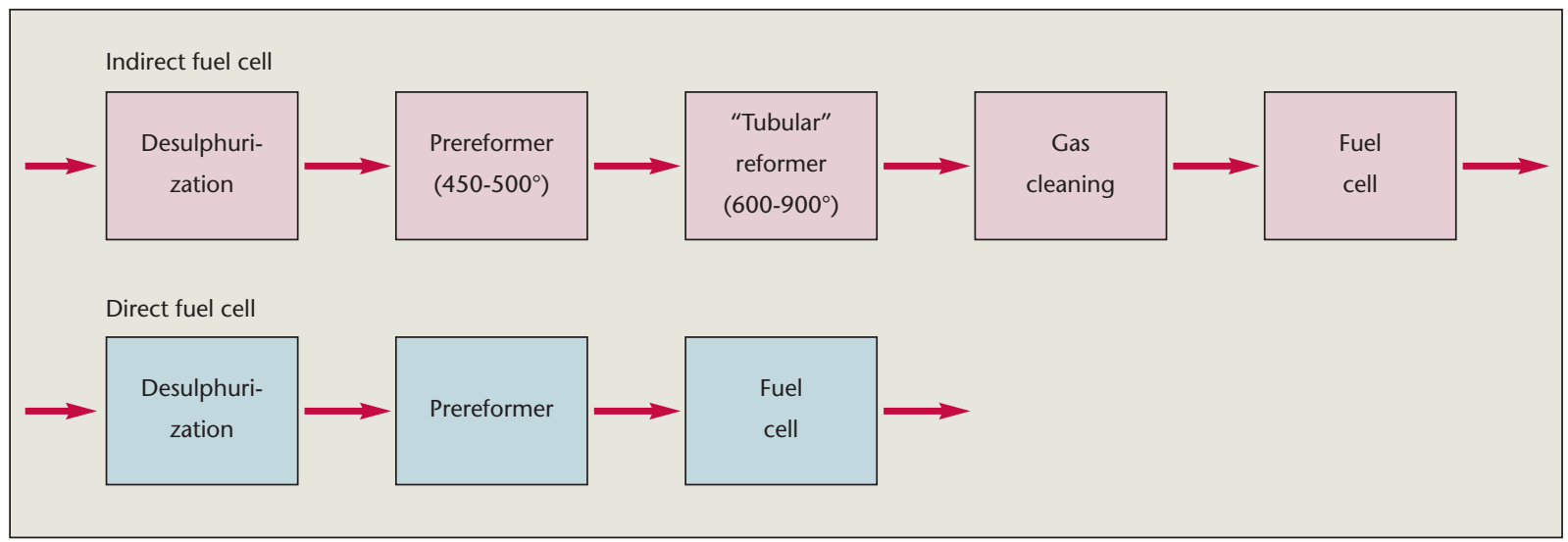

Figure 13: SOFC system design. Fuel Processing Schemes

monoxide and carbon dioxide, which is then treated to remove carbon monoxide (CO). Allowable $\mathrm{CO}$ contents are around $10 \mathrm{ppm}$ for PEMFCs operating at $80^{\circ} \mathrm{C}$ and around $1 \%$ for PAFCs operating at $150-200^{\circ} \mathrm{C}$.

Methanol may also be used directly as a fuel, in which case PEMFCs are sometimes referred to as DMFCs (direct methanol fuel cells). NEC and Toshiba expect to commercialise DMFCs in 2005, primarily for portable applications such as laptop computers and personal digital assistants (PDAs). Although their efficiency is rather low, at around 30\%, DMFCs are ideal replacements for batteries in portable equipment. Their energy density is 4-5 times that of batteries, and they can be refuelled easily.

High-temperature fuel cells (SOFCs) can run on fuels such as natural gas, biogas and methanol, thanks to their ability to reform hydrocarbons within the cell itself.

Reforming is an endothermic process, meaning that it absorbs heat, and thus it can use waste heat created during the electricity generation process. Direct fuelling with methane or methanol therefore increases both the electrical efficiency and the total efficiency of the fuel cell compared to using hydrogen as the fuel.

High-temperature fuel cells typically operate at about $1,000^{\circ} \mathrm{C}$, and the materials needed to withstand such high temperatures make these fuel cells rather expensive. More recently, intermediate-temperature fuel cells operating below $750^{\circ} \mathrm{C}$ promise to be more competitive because they are more durable as well as cheaper to build. Current R\&D aims at developing SOFCs that can operate at $550-600^{\circ} \mathrm{C}$.

Direct SOFCs have the advantage that it is easy to remove carbon dioxide from the exhaust, because the gas streams leaving the anode and cathode remain separate. The anode gas contains water, carbon dioxide and unburned hydrogen. One approach to exhaust cleanup uses a membrane to remove the hydrogen, which is then recycled to the inlet of the fuel cell. An alternative is to oxidise the hydrogen, using oxygen extracted from atmospheric air by another type of membrane. In each case the result is a gas stream containing only water and carbon dioxide. The carbon dioxide can then be separated by cooling to condense out the water.

\section{SOFC systems}

In a complete SOFC system (Figure 14), natural gas is first pre-heated and desulphurised. It is then mixed with recycled anode off-gases, which provide steam and heat, before passing through an adiabatic pre-reformer. The pre-reformer yields a mixture of methane, hydrogen, carbon monoxide and carbon dioxide. After passing through a final heat exchanger which increases its temperature to around $650^{\circ} \mathrm{C}$, the fuel gas enters the anode compartment of the SOFC.

Off-gas from the anode first heats the incoming fuel gas. Part of the off-gas stream is then mixed with the fuel entering the pre-reformer, while the rest goes to a catalytic incinerator. Heat from the incinerator exhaust is recovered in a further series of heat exchangers.

On the cathode side, air is compressed in a blower and pre-heated in a heat exchanger, also to around $650^{\circ} \mathrm{C}$. Off-gas from the cathode, consisting of depleted air, is first cooled against the incoming cathode air. Some of the off-gas then goes directly to heat recovery, while the rest passes through the incinerator.

Such a system has an electrical efficiency of nearly $56 \%$ and a total efficiency of $88 \%$.

\section{PEMFC and PAFC systems}

PEMFCs and PAFCs have attracted a lot of research effort in the last decade, especially for mobile applications, where they have the advantages of operating at temperatures close to ambient and fast start-up. PEMFCs will be the preferred choice for devices such as uninterruptible power supplies (UPSs). The main disadvantage of PEMFCs is their need for very pure hydrogen: state-ofthe-art PEMFCs cannot tolerate much more than $50 \mathrm{ppm}$ of carbon monoxide in the anode feed without serious deterioration in performance. Water management around PEMFCs is complicated, and waste heat is only available at moderate temperatures. 


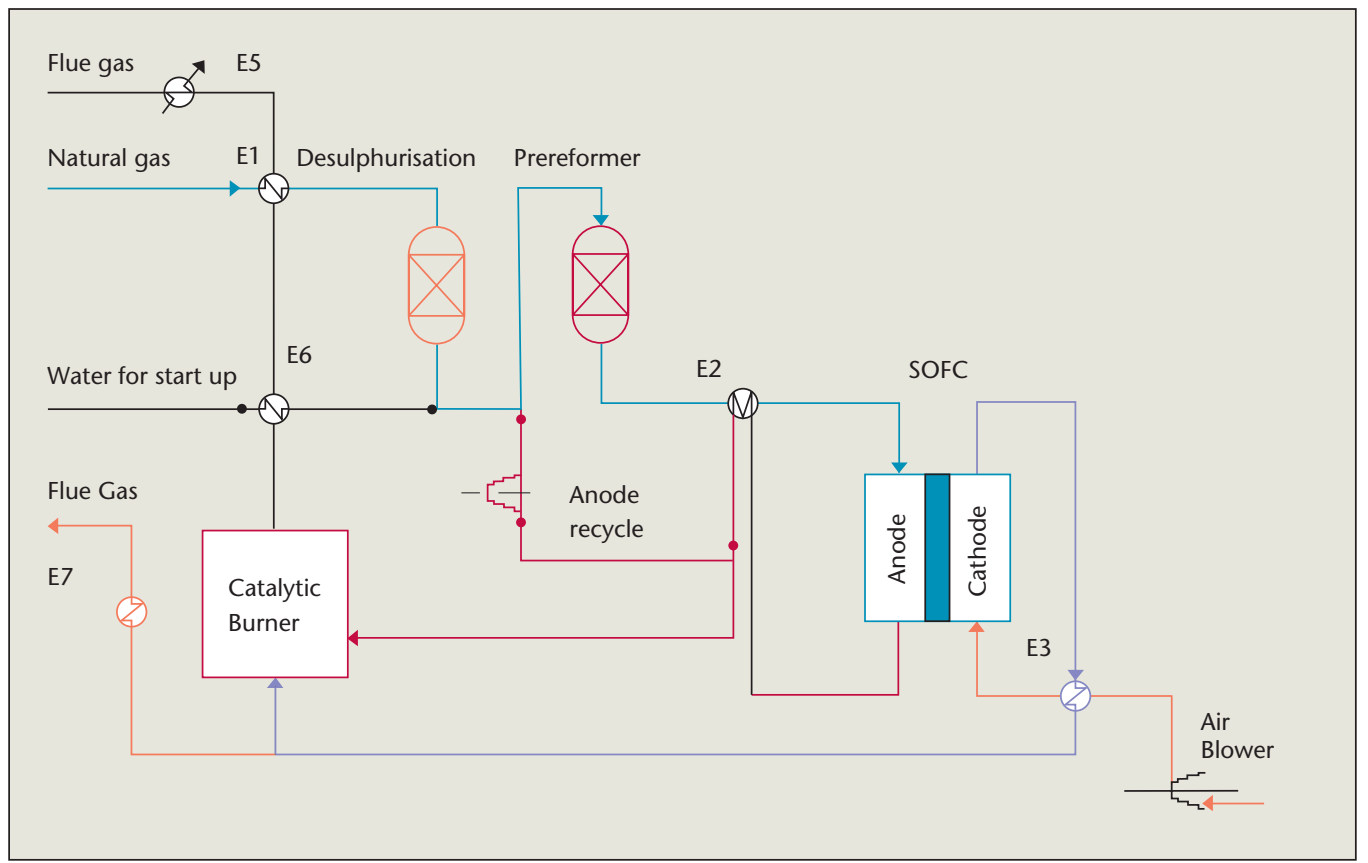

Figure 14: Basic layout of an SOFC-based CHP system.

In a complete PEMFC system (Figure 15) the feed is preheated and desulphurised before steam is added. Steam reforming is carried out in a heat exchange reformer, using heat supplied by a gas-fired heater and also recovered from the reformer exhaust stream.
The carbon monoxide content in the reformed gas is first lowered to a few thousand ppm in a shift reactor, and then reduced to below $50 \mathrm{ppm}$ in a preferential oxidation (PROX) reactor, which uses air to selectively oxidise carbon monoxide to carbon dioxide. The exit gas from the PROX unit is cooled to $80^{\circ} \mathrm{C}$ before entering the

Figure 15: Basic layout of a PEMFC-based CHP system.

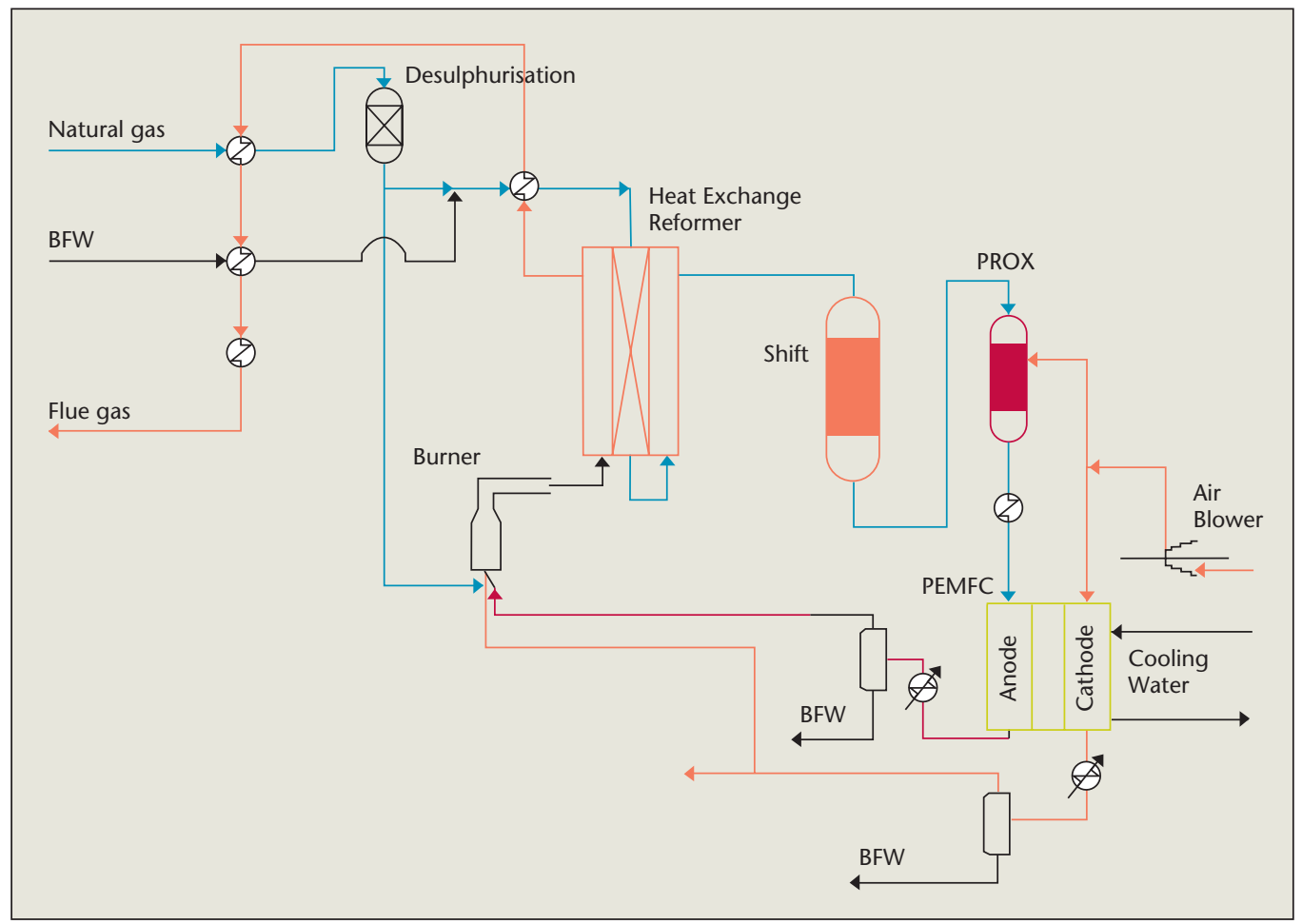


anode compartment of the PEMFC. The PEMFC itself is cooled by water, from which heat is recovered.

Off-gas from both the anode and the cathode is first cooled to condense out pure water (boiler feed water, BFW) for re-use. The offgas, which contains unburned hydrogen, is then burned in the reformer heater.

Such a system has an electrical efficiency of $37 \%$ and a total efficiency of $82 \%$.

\section{Homogeneous charge compression ignition}

Homogeneous charge compression ignition (HCCI) is an emerging technology for internal combustion engines that can provide high efficiency (up to 43\%) using various fuels, including hydrogen. HCCI creates very little pollution, with almost no $\mathrm{NO}_{\mathrm{x}}$ or particulates. The technology is of interest for both transport and electricity generation, and is being followed closely by automotive manufacturers. The basic advantage of HCCI is to combine the very low emissions of an SI engine using a three-way catalyst and the very high efficiency of a diesel (CI) engine.

HCCI combines the characteristics of spark-ignition (SI, or Otto) engines, such as standard gasoline engines, and compression-ignition (CI or diesel) engines. Fuel and air are mixed before combustion, as in a conventional SI engine. As in a diesel engine, however, there is no spark plug, and combustion is started by autoignition instead. To ensure that the autoignition temperature is reached just as the piston reaches top dead centre, HCCI engines control the inlet temperature, the compression ratio, or both.

Because the fuel/air mixture is close to homogeneous when the charge is ignited, there is no differences between local and global combustion rates, in contrast to the situation in a SI or CI engine. This means that to prevent excessive combustion rates, the mixture must be very lean. A too rich mixture will burn the entire charge in a small fraction of the power stroke, producing very high combustion pressures, high stresses and high noise levels. A too lean mixture produces slow and incomplete combustion.

Lean burning means that the HCCI engine cannot create particulates, and the low combustion temperature limits thermal $\mathrm{NO}_{\mathrm{X}}$ to 0.1-2 ppm. On the other hand, a problem with current HCCI engines running on hydrocarbon fuels is higher levels of unburned hydrocarbons and carbon monoxide in the exhaust.

An HCCI engine running on hydrogen, however, cannot form carbon monoxide or emit unburned hydrocarbons - in fact its only exhaust product is steam. Researchers at Lund Institute of Technology in Sweden are developing hydrogen-fuelled HCCI engines.

The main problem with HCCI is to control the combustion process, balancing the inlet conditions to get combustion at the correct point in the cycle. Changing the inlet temperature by just a few degrees, for instance, can be enough to stop the engine. This degree of control cannot be achieved with a direct link between the accelerator pedal and the throttle. Modern electronic engine management systems, however, are capable of the closed-loop control that HCCI requires.

\section{Gas turbines}

Hydrogen as a fuel for gas turbines (GTs) has been investigated for several decades. Producing exhaust gases containing only water vapour, oxygen, nitrogen and some unburned hydrogen, gas turbines running on hydrogen offer the prospect of environment-friendly and $\mathrm{CO}_{2}$-free electricity generation.

Burning hydrogen in gas turbines raises issues including: - high flame speed can cause the flame to move upstream and stabilise on the fuel injector, resulting in damage to the burner;

- increased risk of flashback in premix mode;

- high flame temperatures increase $\mathrm{NO}_{\mathrm{X}}$ emissions; and

- hydrogen can cause embrittlement of metal components in the fuel system.

\section{Hybrid cycles with fuel cells and $\mathrm{HCCl} / \mathrm{GT}$}

Because of their high electrical conversion efficiencies, SOFCs will probably form the basis of the best future CHP plants. Adding a heat engine such as a HCCI or a gas turbine can improve the operation of a SOFC plant even further.

A stand-alone atmospheric-pressure SOFC plant uses a catalytic incinerator with waste heat recovery to destroy unburned fuel in the anode exhaust gas. Replacing the incinerator with an HCCI engine improves overall efficiency, increases the proportion of shaft power available from the plant, reduces exhaust gas volumes and provides greater flexibility during load following, startup and shutdown.

Running the SOFC under pressure reduces the volume of the fuel cell stack and improves performance by allowing the electrochemical reactions to operate more effectively. If we use a gas turbine instead of an HCCI engine to replace the incinerator, there is the further advantage that compressed air from the gas turbine's compressor can be used to supply the SOFC.

Calculations show that small hybrid SOFC/GT plants of around $350 \mathrm{~kW}_{\mathrm{e}}$ could achieve electrical efficiencies of $60-70 \%$, which is considerably better than competing technologies of this size. Burning hydrogen instead of natural gas would further increase the efficiency by a few percentage points.

Disadvantages of hybrid systems include:

- the need to develop new gas turbines specifically for SOFC/GT hybrid systems. Off-the-shelf GTs would not be suitable;

- lack of operating flexibility, especially at part load, because of the strong interdependency between the SOFC and the GT; and

- complications during start-up, shutdown and load change, because of the risk of compressor surge. 


\section{3}

in the commercialization and use of fuel cell systems and hence an important entry in the hydrogen economy. Risø together with industrial partners in Denmark and Nordic countries (especially Sweden) could form the basis in a lighthouse project for the demonstration of fuel cell systems for different use, e.g. an Örestad Ligthhouse project, much in line with projects proposed by the European Hydrogen and Fuel Cell Technology Platform.

Table 11: Emerging SOFC hydrogen technologies and their time to market.

\section{Conclusions and recommendations}

SOFC systems is the most interesting and prospective systems for the Danish and Global energy systems. This stems from the high electrical efficiency of such systems, the high quality steam produced, the possibility to separate the $\mathrm{CO}_{2}$ exhaust gas (in case of C-containing fuels) for possible sequestration and the high degree of fuel flexibility. Fuels, such as natural gas, will be most important in Denmark due to the natural gas grid already available in Denmark, but also biogas, biodiesel, methanol, ethanol, gasified coal gas, as well as hydrogen (pure or less pure) can be utilised directly or after pre-reforming. The possibility for module building of systems and the integration with other systems like gas turbines enhances the benefit of SOFCs.

Both SOFC and PEMFC fuel cells can be used in very many applications (portable, APUs, transport, single houses, UPS, medium size CHPs and large power stations) and can be integrated with the electricity and gas grids and wind power-and-electrolysis systems thus providing the most flexible and efficient overall system. The strength and competences already existing in Denmark both at research institutions and in industry provide a strong basis for Denmark to play a major role

Table 11 compares expected efficiencies and commercial availability market for the various stand-alone and hybrid SOFC technologies.

Figure 16 shows the range of plant size and electrical efficiency expected for a range of energy conversion technologies. It is clear that, from today's perspective at least, the eventual winners will be SOFCs as either stand-alone units or in combination with gas turbines.

Figure 16: Expected plant size and electrical efficiency for a range of energy conversion technologies.

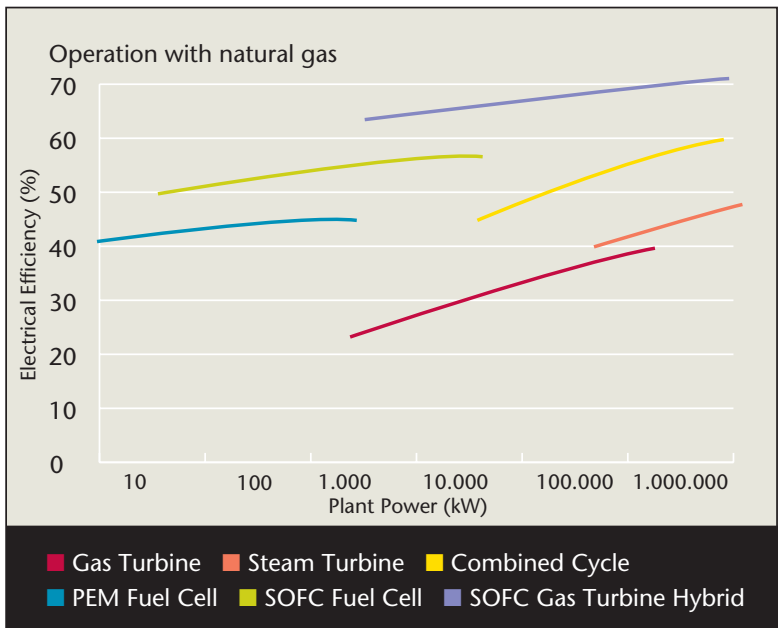




\subsection{Hydrogen for transport}

ANTONIO FUGANTI AND EMANUELE BELLERATE, CENTRO RICERCHE FIAT; ALLAN SCHRØDER PEDERSEN, RISø NATIONAL LABORATORY

\section{Introduction}

One reason to look seriously at hydrogen as an energy carrier is that it can readily be used to power road vehicles, locomotives, ships and aircrafts. The most advanced use of hydrogen in the transport sector is for motor vehicles, especially cars. This is why automotive manufacturers all over the world are putting a lot of money into hydrogen R\&D.

Hydrogen can be used to power vehicles by means of internal combustion engines (ICEs), fuel cells or gas turbines. Since fuel cells have higher useful energy conversion efficiencies than simple ICEs, they are very attractive in automotive applications (see below and also Chapter 5.3).

ICEs, however, are a well-established technology that is fairly easy to convert from conventional liquid fuels to hydrogen. For these reasons, some car manufacturers are also working on ICEs specifically for hydrogen.

Most gas turbines today are much too large to be used in road vehicles. However, $R \& D$ in countries including Germany and the USA aims to develop small hydrogenfuelled gas turbines suitable for road vehicles. When used with other energy conversion technologies in hybrid cycles, gas turbines should be able to match the efficiency of fuel cells. For this reason, some people believe that gas turbines may be the winning technology in hydrogen for transport applications.

Hydrogen has been applied for transport purposes in aviation (Russian and American aeroplanes) as well as in several areas of surface transport (buses, cars and trucks). As mentioned, however, the most intense and advanced developments have been done in the automobile sector and therefore a detailed description hereof is given in the following section.

\section{Hydrogen from the car manufacturers' point of view \\ Drivers and technology}

Energy consumption associated with transport is expected to grow around 2\% per year in Europe over the next few years, and much faster in developing countries such as China and India. Oil is the source of $96 \%$ of the energy currently used in transport.

Within this context, automakers face increasingly tight legal restrictions on polluting emissions. There is also growing public pressure to decrease emissions of carbon dioxide and other greenhouse gases (GHGs), which are particularly associated with transport. In Europe, a voluntary agreement by all the car manufacturers has set carbon dioxide emissions targets of $140 \mathrm{~g} \mathrm{CO}_{2} / \mathrm{km}$ for 2008 and $120 \mathrm{~g} \mathrm{CO}_{2} / \mathrm{km}$ for 2012.

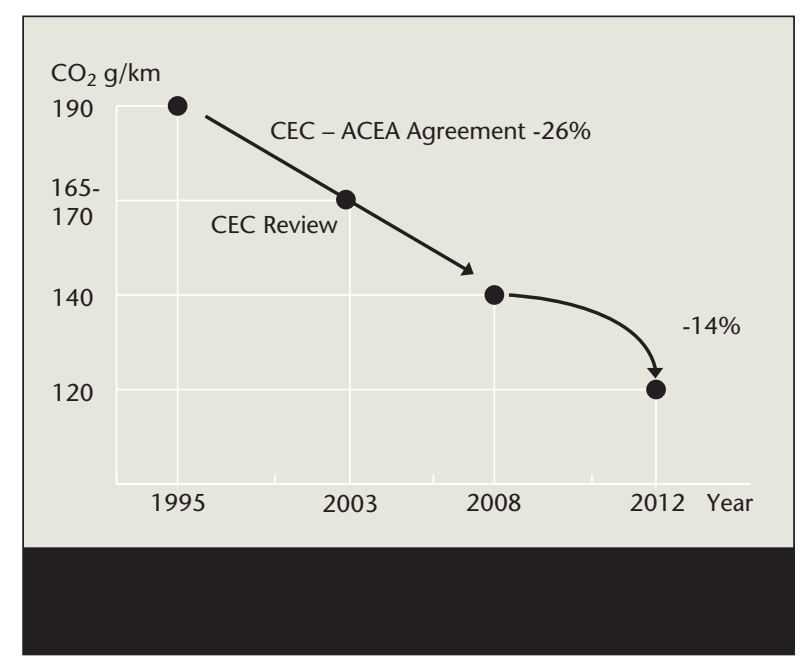

Figure 17: Targets for $\mathrm{CO}_{2}$ emissions.

Refinements in conventional engine technology will probably be able to keep pace with legislative requirements for pollutants such as $\mathrm{NO}_{\mathrm{X}}$ and hydrocarbons. The targets for $\mathrm{CO}_{2}$, however, require improvements in fuel economy that conventional engines will probably not be able to meet (because with conventional fuels, a given amount of energy is always associated with a fixed quantity of $\mathrm{CO}_{2}$ ).

The answer may be to use hydrogen-fuelled internal combustion engines (ICEs) or fuel cells. ICEs running on hydrogen emit $\mathrm{NO}_{\mathrm{X}}$, but since their fuel contains no carbon, their exhaust contains no $\mathrm{CO}_{2}$ or hydrocarbons. Fuel cells are more efficient than ICEs, and have no moving parts. When fuelled by hydrogen, they produce only water. For these reasons, most of the hydrogen R\&D carried out by automotive manufacturers in recent years has focused on fuel cells, particularly proton exchange membrane fuel cells (PEMFCs). Among the favourable characteristics of PEMFCs for transport applications are low operating temperatures and short start-up times.

Figure 18 shows the power train of a simple fuel cell vehicle. The fuel cell generates electricity, which drives an electric motor. Although the fuel cell vehicle has two separate energy conversion steps, compared to one in a conventional ICE vehicle, its overall efficiency can be higher because the fuel cell and especially the electric motor have very high individual conversion efficiencies. Fuel cells can overcome the problems of range, performance and refuelling time associated with traditional electric vehicles, which use accumulators to store electricity. Because chemical energy storage media such as hydrogen have a higher energy density than accumulators, fuel cell vehicles have better range and performance than tradi- 


\section{4}

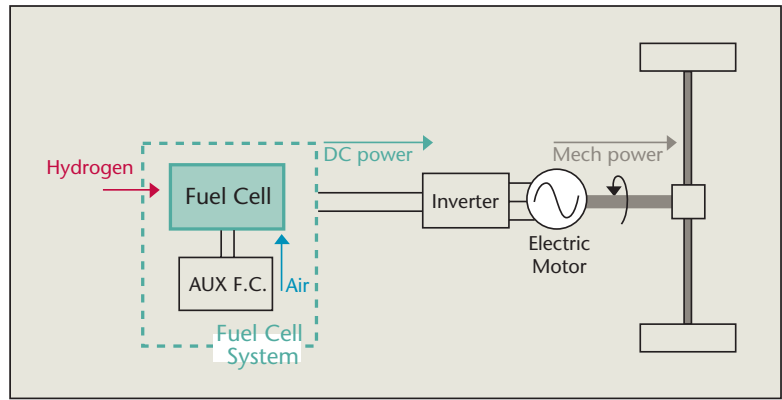

Figure 18: The power train of a simple fuel cell vehicle.

Figure 20: Figures for prototype fuel cell vehicles show that although methanol was a popular choice some years ago, the consensus is now to use pure hydrogen.

tional electric vehicles. They can also be "recharged" in a few minutes, compared to the hours needed to charge a battery-powered vehicle.

\section{Fuels for fuel cell vehicles}

The range of a fuel cell vehicle depends on the amount of hydrogen it can carry. Weight for weight, hydrogen contains more energy than any other chemical energy storage medium, but its low density is a problem in both the liquid and gas phases. Gasoline, for example, has a volumetric energy content of around $32 \mathrm{MJ} / \mathrm{l}$, but liquid hydrogen is only around $8.4 \mathrm{MJ} / 1$.

The low volumetric energy content of hydrogen, and the lack of infrastructure for hydrogen refuelling, has encouraged car manufacturers to study the use of more conventional liquid fuels that can be converted to hydrogen-rich gas mixtures by a "fuel processor" in the

Figure 19: Car manufacturers have in the past had differing ideas about the use of liquid hydrogen and alternative liquid fuels that can be converted to hydrogen on board the vehicle.

\begin{tabular}{|c|c|c|c|c|}
\hline & $\begin{array}{l}\text { Compressed } \\
\text { hydrogen }\end{array}$ & $\begin{array}{l}\text { Liquid } \\
\text { hydrogen }\end{array}$ & $\begin{array}{l}\text { Gasoline } \\
\text { reformer }\end{array}$ & $\begin{array}{l}\text { Methanol } \\
\text { reformer }\end{array}$ \\
\hline BMW & & $\square$ & & \\
\hline $\mathrm{DC}$ & $\square$ & $\square$ & & $\square$ \\
\hline Ford & $\square$ & & & \\
\hline GM & 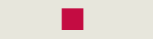 & $\square$ & $\square$ & \\
\hline Hyundai & & & & \\
\hline Honda & $\square$ & & & $\square$ \\
\hline Nissan & 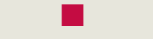 & & & \\
\hline Opel & - & & & \\
\hline Renault & L & & $\square$ & \\
\hline Toyota & & & & $\square$ \\
\hline VW & & $\square$ & & \\
\hline Fiat & & & & \\
\hline
\end{tabular}

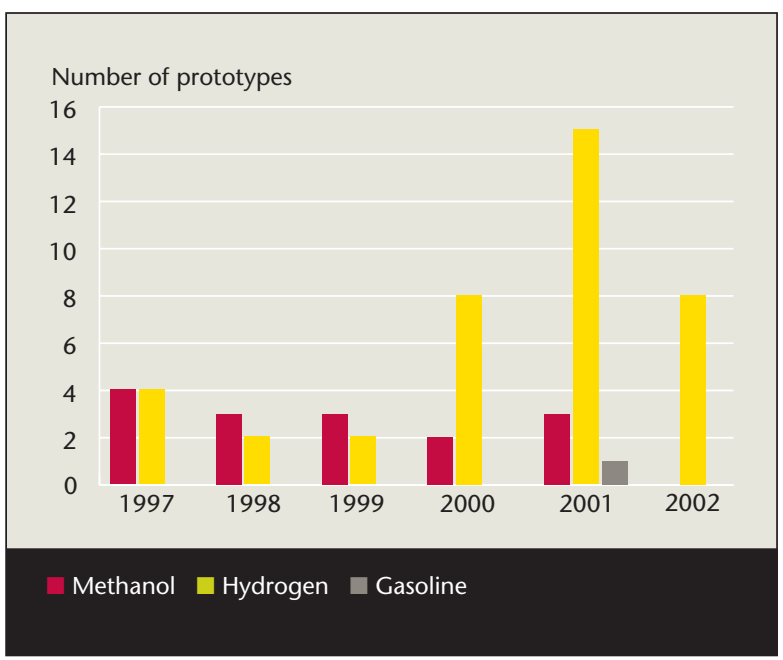

vehicle. Gasoline and methanol are two obvious choices (Figure 19).

An example of parallel development in different fuel technologies is that of DaimlerChrysler. Different prototypes of NECAR (a prototype fuel cell vehicle based on a Mercedes-Benz A-Class) used both methanol reforming (NECAR III and V) and pure hydrogen (NECAR II and IV). Today, however, there is a clear consensus among the car manufacturers on the use of direct hydrogen fuel cells (Figure 20). In most cases, high-pressure gaseous hydrogen is preferred over liquid hydrogen.

The reason is that on-board reforming has not lived up to its original promise. It implies additional complexity and cost, and has seriously hindered vehicle performances because of time lags in the reformer. It reduces overall efficiency and eliminates the "zero emission" benefit of fuel cell vehicles, to the extent that a fuel cell vehicle with an onboard fuel processor has no environmental advantages over ICE vehicles. Figure 21 shows, for example, that overall ("well to wheel") $\mathrm{CO}_{2}$ emissions for a fuel cell vehicle with a gasoline fuel processor are the same as those for an ordinary diesel vehicle.

\section{Technology barriers to the development of fuel cells in transport}

PEMFCs and related components have shown stunning progress in the last decade, notably in power density and specific power (Figure 22).

Nevertheless, serious technology barriers remain at the component level. Laboratory tests cannot prove that PEMFCs will be commercially viable in mass-produced vehicles. The main challenges now are to:

- reduce the cost of the fuel cell stack itself;

- reduce cost of other devices required by the fuel cell system;

- improve performance at temperatures below freezing;

- increase tolerance to carbon monoxide and other contaminants in the hydrogen; 


\section{4}

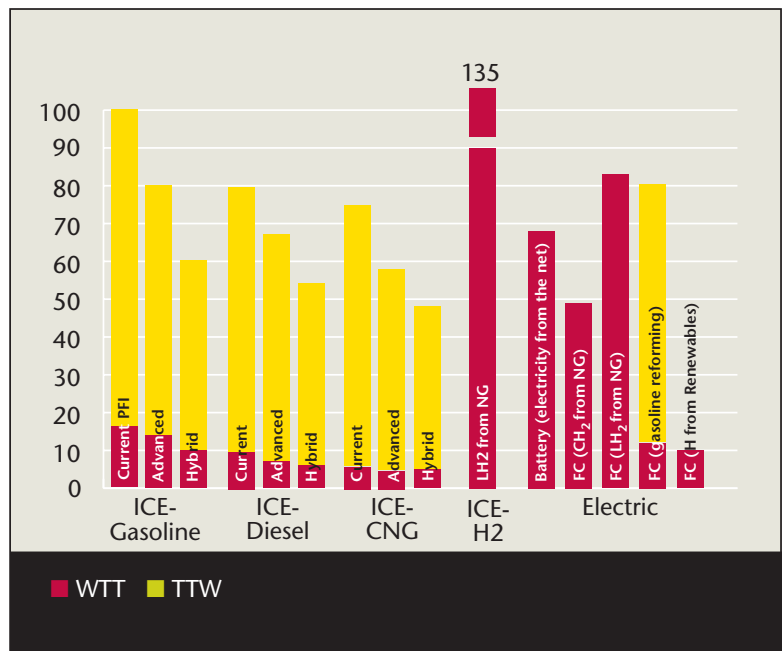

Figure 21: Overall $\mathrm{CO}_{2}$ emissions from different fuels and engine types. WTT=well to tank, i.e. emissions incurred in extracting, refining and distributing the fuel. TTW=tank to wheel, i.e. emissions created by the vehicle itself. $\mathrm{CNG}=$ compressed natural gas.

- demonstrate the durability of individual components and the complete system;

- develop high-efficiency thermal, water, and air management subsystems;

- develop and put in place a suitable fuel infrastructure; and

- solve the problem of hydrogen storage.

The last point, storage, is the biggest research problem remaining in the development of hydrogen-powered vehicles. Hydrogen's low density makes it difficult to store sufficient amounts on board a vehicle to achieve a useful range without the container being too large or too heavy.

Currently, hydrogen must be either pressurised to several hundred atmospheres or stored as a liquid at cryogenic temperatures. Neither of these options are appropriate for normal road vehicles. There has therefore been much research into new storage technologies such as carbon nanotubes and metal hydrides, both of which can theoretically hold large amounts of hydrogen safely in a relatively small space (see also Chapter 5.2). The difficulty of this research, however, is shown by the extremely low level of patenting in this area.

\section{Market projections and cost targets}

It is difficult to predict the market share of fuel cells in future transport applications, since a significant market for fuel cell vehicles cannot emerge until the current technical and infrastructure challenges have been solved. Fuel cells also have to compete with gasoline and diesel ICE technologies, which also are improved continuously.

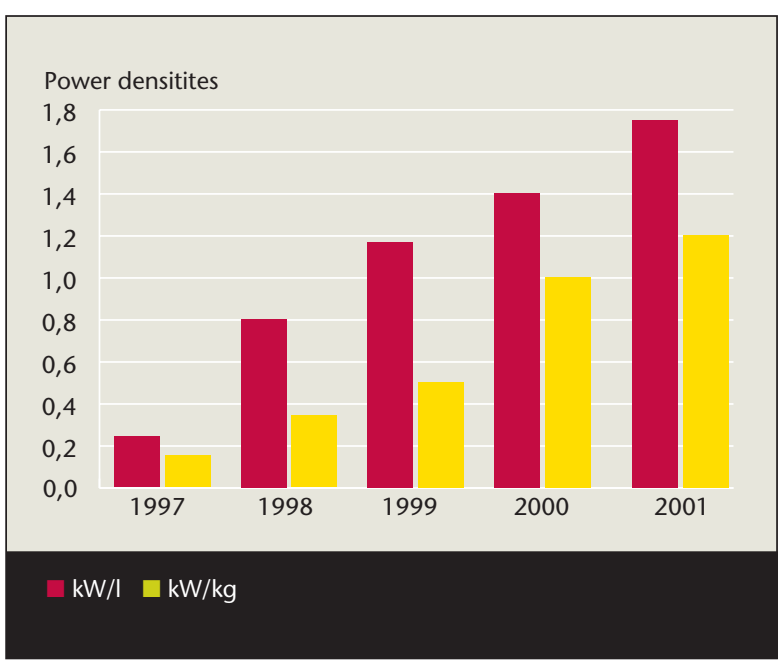

Figure 22: Technical progress in power density and specific power for PEMFCs over the last decade.

Figure 23 combines the results of several studies to give a qualitative view of how fuel cell vehicle sales may grow. It is important to remember that estimates of the potential market for fuel cells in the transport sector vary enormously in terms of both value and number. Uncertainties associated with fuel cell technology are probably responsible for the fact that no such market studies have been published since 2002 .

A study by Allied Business Intelligence (ABI), not shown in Figure 23, predicts a market in the range $\$ 608,000$ $\$ 1.2$ million for fuel cell vehicles in the USA by 2010 , and a global market of $\$ 1.5$ million by 2011, accounting for $2.7 \%$ of all new road vehicles. New regulatory incentives or unexpected technical progress could increase the global market to $\$ 2.4$ million, or $4.3 \%$ of all vehicles, according to ABI. The study suggests that the number of vehicles produced could reach 800,000 by 2012 .

It is highly significant that METI, the Japanese Ministry of Economy, Trade and Industry, at the end of 2003 announced that it forecasts an eventual total of 50,000 fuel cell vehicles on Japanese roads. Also important is the fact that electric vehicles are already available for leasing from car manufacturers including Toyota, Honda, Nissan, DaimlerChrysler and Opel.

Notwithstanding the different forecasts for growth rate and eventual market size, most experts believe that fuel cells will not enter the vehicle market in commercial numbers until after 2015. The reason is because of the time needed for testing, first in niche areas and then in small fleets.

Fuel cell vehicles also need to be supported by a distribution infrastructure for hydrogen. At the start, with very few hydrogen vehicles on the market, refuelling stations 


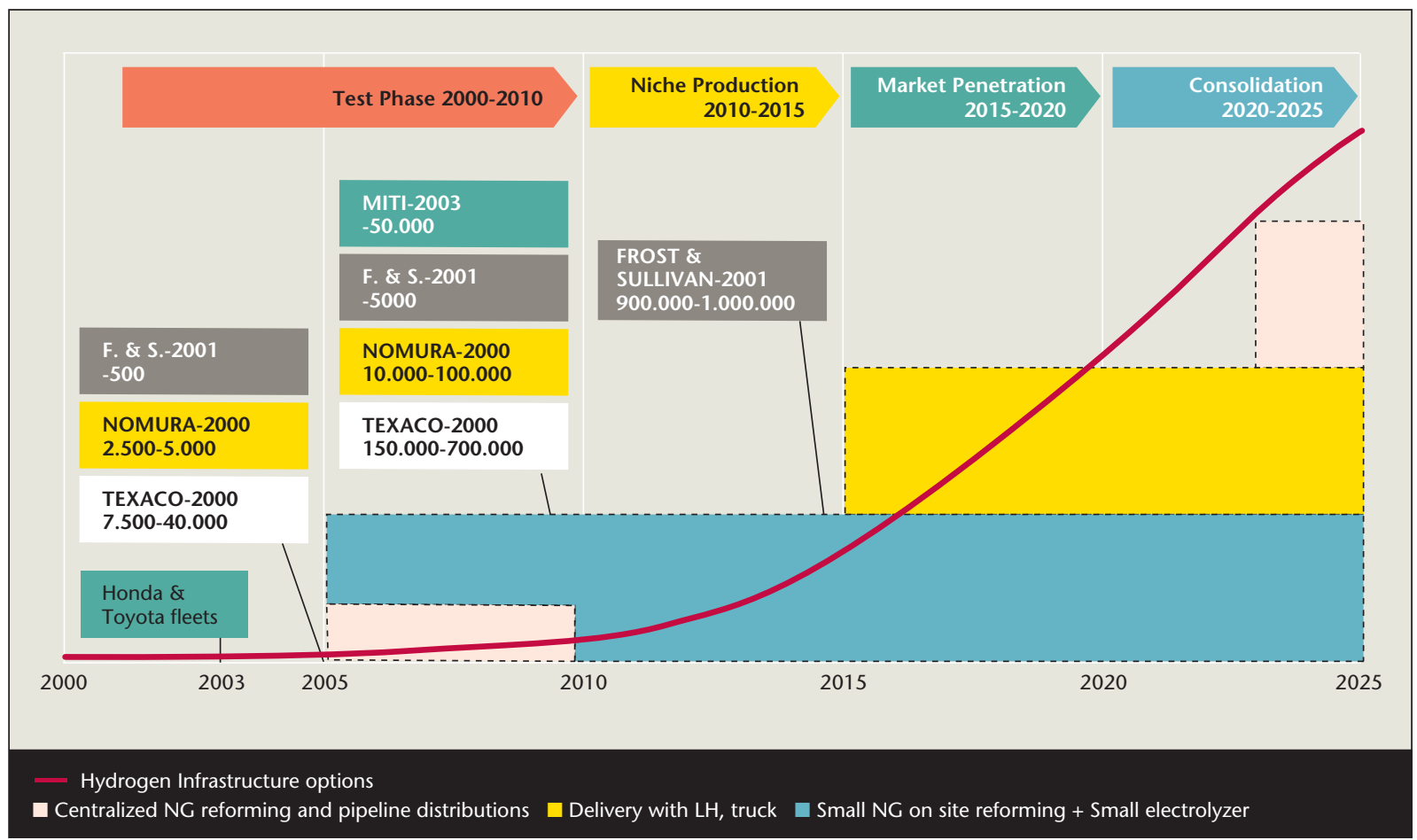

Figure 23: Many studies have tried to predict the growth of fuel cell vehicles, but uncertainty surrounding the technological problems still to be solved has yielded a wide range of answers - and no new market studies since 2002.

generating their own hydrogen from natural gas reforming or electrolysis would be the best option. As the number of hydrogen vehicles increases, liquid hydrogen may be distributed to filling stations by road tanker. Eventually, when the market matures some time after 2020 , centralised steam reforming of natural gas and distribution by pipeline may become economic.
Turning to costs, the US Department of Energy has estimated that light-duty fuel cell vehicles will be commercially viable by $2015-2020$ provided that:

- advances in technology allow hydrogen vehicles to be manufactured in volumes of over 500,000 units a year;

- fuel cell costs fall to $\$ 45 / \mathrm{kW}$ for a $50-\mathrm{kW}$ unit (i.e. a unit cost of $\$ 2,250)$;

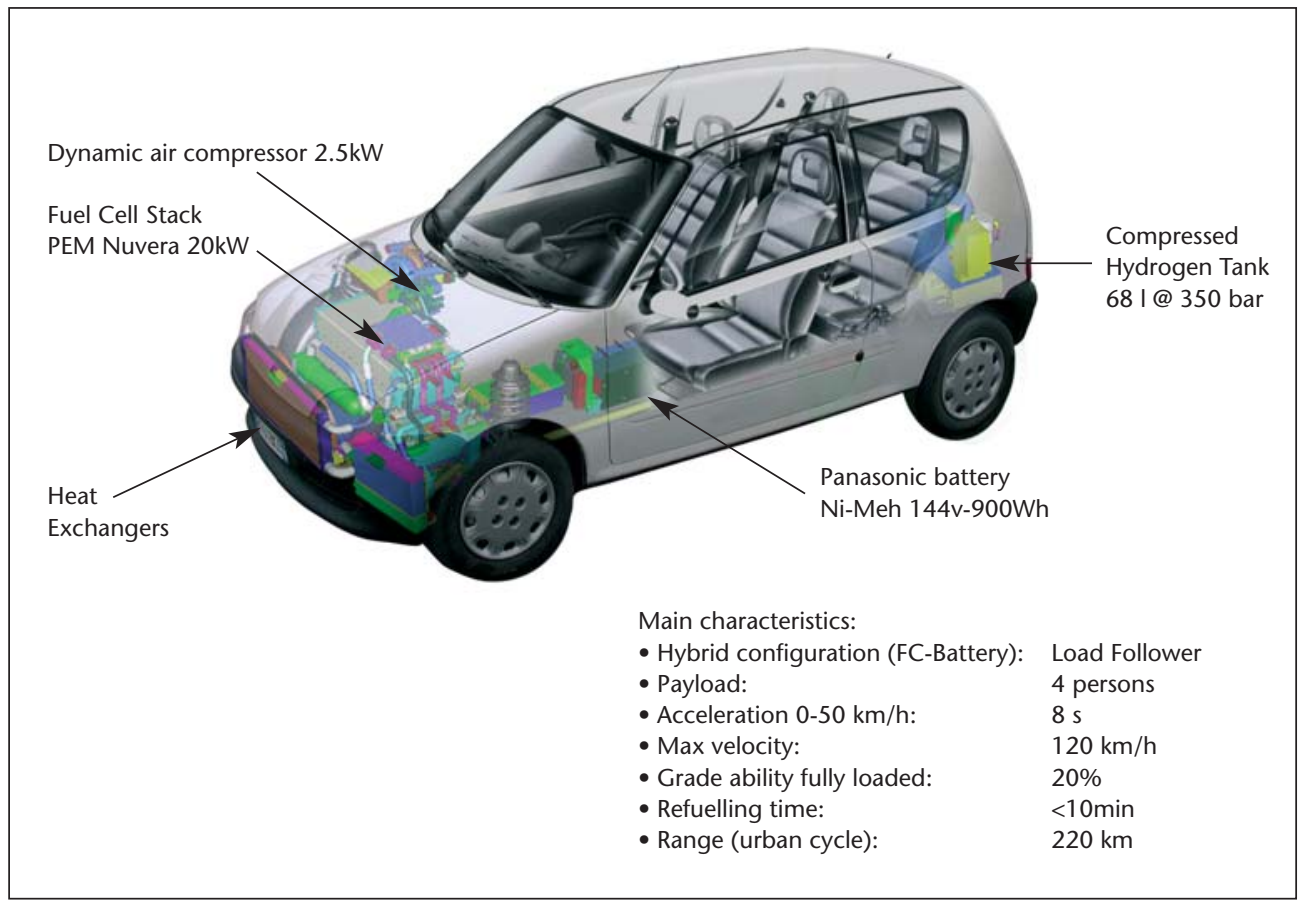


- vehicles can maintain full performance over 5,000 operating hours; and

- hydrogen costs fall to $\$ 1.50-\$ 2.10$ per gallon gasoline equivalent.

The Fuel Cell Commercialization Conference of Japan (FCCJ) arrived at a similar estimate for the threshold cost of fuel cells: $¥ 5,000$ ( $\$ 42) / \mathrm{kW}$, including auxiliary equipment.

\section{CRF prototypes}

In projects funded by the Italian Ministry of the Environment, Fiat's CRF research centre developed two concepts for PEMFC city cars (Figure 24).

\section{Conclusions and recommendations}

Estimations of the size of a future market for hydrogenpropelled cars have shown dramatic divergences and there is still no consensus concerning the near future. Although direct hydrogen fuel cells and pressurised onboard hydrogen storage currently seem to have a leading position in the competition between hydrogen technologies for transport purposes, it is still uncertain what the winning technology will be.

The problem of cost effective and energy effective hydrogen storage onboard vehicles is persistent and needs considerable scientific and technical attention if we want hydrogen vehicles to be comparable to conventional vehicles concerning operation range. 


\subsection{Hydrogen in portable devices}

JUERGEN GARCHE, ZSW - ELECTROCHEMICAL ENERGY STORAGE AND ENERGY CONVERSION DIVISION; ULRICH STIMMING, TECHNISCHE UNIVERSITÄT MÜNCHEN; ANDREAS KASPER FRIEDRICH, ZAE BAYERN; ROBERT FEIDENHANS'L, RIS $\varnothing$ NATIONAL LABORATORY

\section{Introduction}

Fuel cells were originally intended for use in power plants and vehicles. More recently, developers realised that it is possible to build much smaller units and for lower prices per kilowatt than their larger relatives. This has led to strong interest in developing small fuel cells. Small fuel cells could replace batteries in portable electronic equipment (up to $100 \mathrm{~W}$ ) and internal combustion engines in portable generators. The upper limit for portable generators is about $5 \mathrm{~kW}$, mainly because of the weight of the fuel cell.

The International Electrotechnical Commission IEC says of fuel cells for hand-held or portable devices: "The fuel cell power unit may be intended for mounting in a dedicated cavity in the device for easy removal, or maybe a stand-alone electrical power source system intended for connecting to one or more devices with a wiring and connector means" [1].

The main applications for low-power fuel cells are mobile phones, personal digital assistants (PDAs), laptop and notebook computers, cameras, medical equipment, military applications and other portable electronic devices. In comparison to batteries, fuel cells can supply much more power per unit volume or weight, though they have lower output voltages and are slower to respond to transients.

Applications for fuel cells up to $5 \mathrm{~kW}$ include portable generators, uninterruptible power supplies (UPSs), auxiliary power units, power tools, light vehicles such as electric trolleys, lawn mowers and roadside equipment.

Fuel cell types that are suitable for portable applications include:

- proton exchange membrane fuel cells (PEMFCs) using pure hydrogen ( $\mathrm{H}_{2}$-PEMFCs);

- PEMFCs using hydrogen-rich gases from hydrocarbon or alcohol reforming (Ref-PEMFCs);

- direct methanol fuel cells (DMFCs); and

- high-temperature fuel cells such as solid oxide fuel cells (SOFCs) and molten carbonate fuel cells (MCFCs) using hydrocarbons directly.

DMFCs are mostly used for small units and devices in integrated systems because they use a liquid fuel with a high energy density that is easy to distribute. PEMFCs are better for high-power systems because of their higher power density. Applications of small high-temperature fuel cells are limited to auxiliary power units that are in frequent use, and therefore they will not be dealt with further in this chapter.

PEMFCs for portable generators do not differ much from the large PEMFCs used in stationary and transport appli- cations. However, PEMFCs that are to be integrated into small electronic devices, need to be specially designed for miniaturisation.

Fuel cells for portable applications have the advantage that the cost per $\mathrm{kW}$ is much less important than for stationary and transport applications. They are usually only required to have relatively short lifetimes, typically of the order 2,000 hours. This makes them suitable for rapid market introduction.

Fuel cells do not create new applications for portable equipment, but they can improve the practical value of existing devices. As battery replacements, for instance, fuel cells can increase the operating time of electronic and electrical equipment. In portable generators they eliminate the noise and emission characteristics of internal combustion engines.

These advantages will only be taken up if the costs of fuel cells are comparable with those of the technologies they replace. As shown in Figure 25 this is already close to be the case for portable equipment. In this marked sector it is therefore only necessary to solve the remaining problems associated with reliability, lifetime, volume and weight.

\section{Applications \\ Low-power applications in electronic devices} (up to $20 \mathrm{~W}$ )

Fuel cells for small electronic devices such as mobile and cordless phones, pagers, radios, portable CD players, tape recorders and battery chargers are known as "device-integrated" because the requirements set limits on the fuel

Figure 25: Costs at which fuel cells will become competitive in different applications (" $4 \mathrm{C}$ " = camcorders, cellular phones, computers, cordless tools).

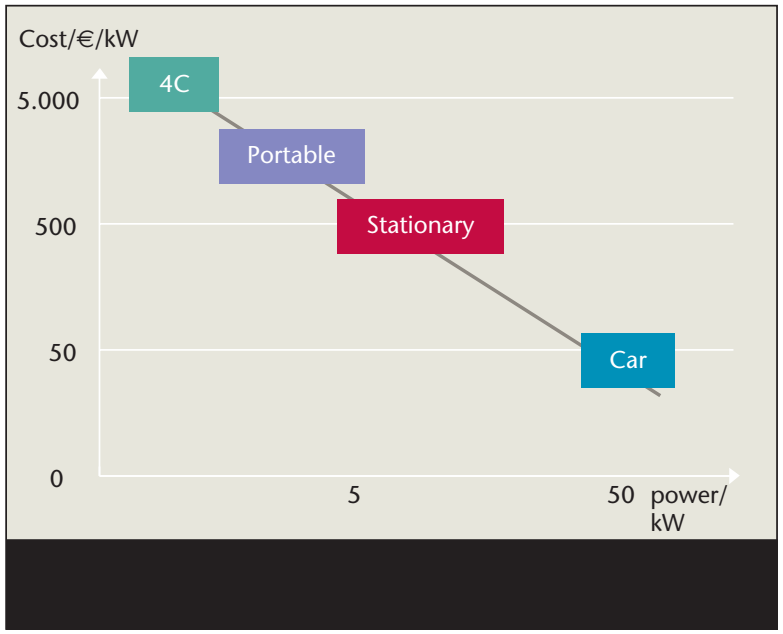




\section{5}

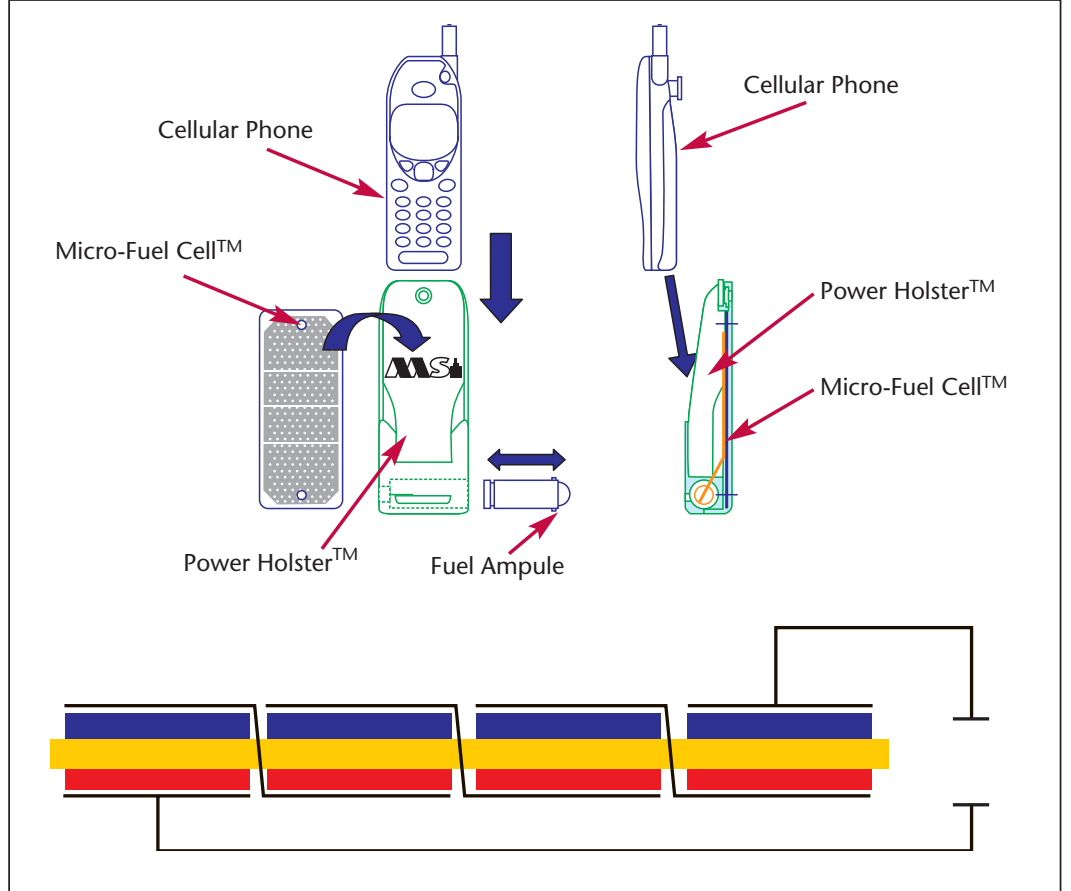

Figure 26: This "power holster" for a mobile phone uses DMFCs to charge the phone battery (source: Manhattan Scientifics). cell system volume. For device-integrated fuel cell systems, volume is clearly even more important than reliability, lifetime and costs.

It is therefore important to reduce the size of the fuel cell stack, the fuel storage system and auxiliary components such as valves, sensors, control units and liquid/gas separators. For this reason, air or oxygen should be supplied to the fuel cell without the need for active air movements such as fans. Water management is perhaps the most complicated problem for miniature PEMFCs and DMFCs, because it includes fuel concentration control, membrane humidification, water recovery and recirculation. Whereas it is possible to operate a fuel cell passively without any peripheral device, substantial improvements are expected from engineering modeling.

In principle there are two ways to construct small fuel cells. One is to take a standard fuel cell and miniaturise it; the other is to use micro-fabrication techniques, in which the various components - membranes, electrodes and catalyst - are "printed" directly onto ceramic or silicon wafers, or more recently flexible polymer sheets. The power conditioning for the low-power device-integrated applications is unlike analog equipment that draws a steady current; the mobile phone, for instance, requires short, large current spikes. Therefore, a hybrid configuration of fuel cells with a small battery or a super capacitor may be necessary.

The following examples show a device-integrated fuel cell and a methanol micro-reformer.

Figure 26 shows a "power holster" fitted with DMFCs which charge the phone when it is in the holster. The array contains ten fuel cells in a package measuring 120 $\mathrm{x} 46 \times 0.5 \mathrm{~mm}$ and generating around $1 \mathrm{~W}$. The cells are formed from paper-thin plastic sheets intended for rollfed mass production. They are mounted side by side, but are connected in series to provide the necessary voltage. Initial tests achieved a specific energy of $356 \mathrm{Wh} / \mathrm{kg}$ from a single fuel ampoule, and $28 \mathrm{~g}$ of fuel was enough to supply more than twice the energy contained in a 900mAh Li-ion battery.

The relatively low specific power available from DMFCs at ambient temperature and the difficulty of storing

Figure 27: Integrated methanol micro-reformer and chemical heater (Motorola)

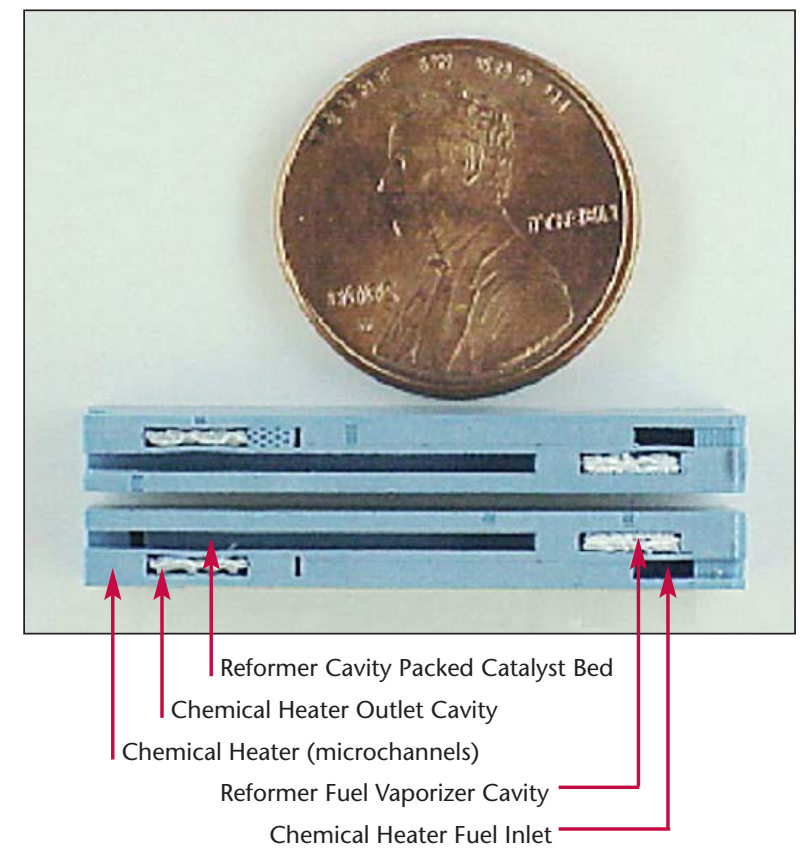



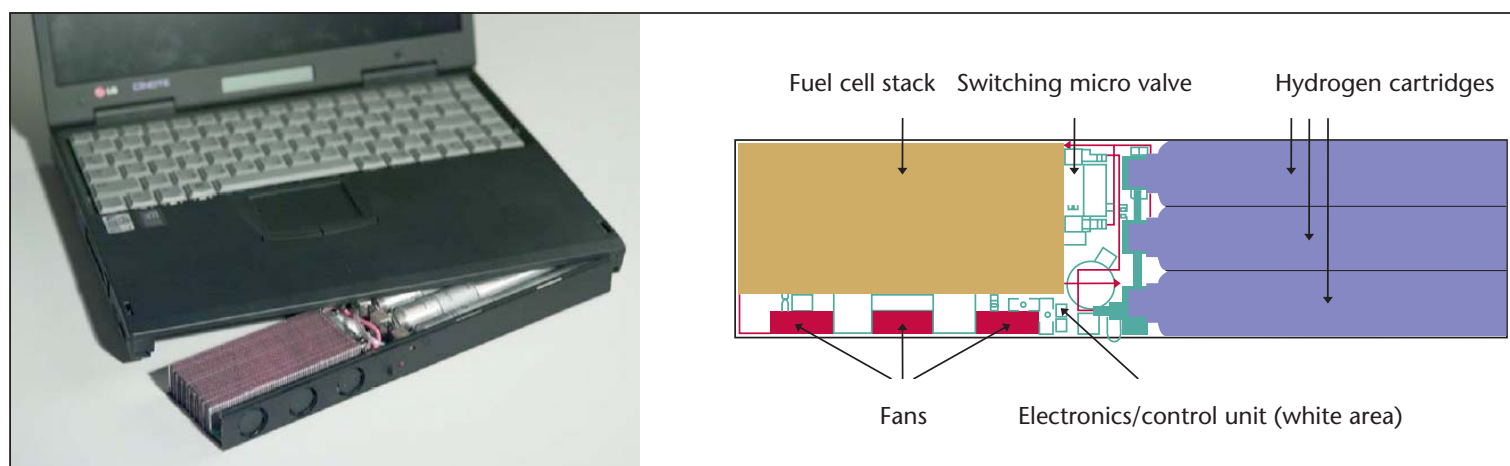

Figure 28: A notebook computer (LG CiNOTE 7400) with an integrated H$_{2}$-PEMFC system (LG; ISE Freiburg).

hydrogen have led to work on "micro-reformers" that can produce hydrogen to feed conventional PEMFCs. One such methanol micro-reformer developed by Motorola measures just $35 \times 15 \times 4 \mathrm{~mm}$. Its methanol conversion efficiency is greater than $95 \%$. The operating temperature of around $230^{\circ} \mathrm{C}$ is achieved by oxidising liquid methanol over a bed of activated platinum catalyst.

\section{Device-integrated systems for higher powers (20-100 W)}

Devices such as notebook computers, power tools, camcorders, digital cameras and toys may consume more than $20 \mathrm{~W}$, and power requirements are increasing all the time as manufacturers add new functions. These applications too require special miniaturised fuel cells.

Fuel cells have lower electrical efficiencies (around 50\%) than the batteries they replace (around 80\%). Since any energy that is not converted to electricity ends up as heat, fuel cells in this power range can suffer from overheating.

Overcoming the problem of excess heat requires intelligent thermal design. Metal hydrides require heat to release their stored hydrogen, so this may be a way to use surplus heat from the fuel cell. Also, compact and efficient thermal barriers are required.

Other important R\&D issues in fuel cell systems for consumer electronics are safety and effluent management. Fuels such as methanol, which is toxic and flammable, need to be contained safely. Exhaust components including methanol, formic acid (from DMFCs) and carbon monoxide (from PEMFCs) must be eliminated.

Replacement fuel cartridges will need to be standardised. Having to buy different refuelling systems for each device will seriously hinder market introduction.

The first of two example applications of higher-powered device-integrated fuel cells is a notebook computer powered by a PEMFC with metal hydride hydrogen storage [2].

This state-of-the-art system provides about $55 \mathrm{~W} / 1$ or 95
$\mathrm{W} / \mathrm{kg}$ [2], with an energy density of about $120-140 \mathrm{Wh} / \mathrm{l}$. The fuel cell system measures $275 \times 62 \times 22 \mathrm{~mm}$ and weighs $170 \mathrm{~g}$. The operating voltage of the 27 -cell stack is in the range 10-20 V and needs a DC/DC converter to increase it to the computer's operating voltage of $24 \mathrm{~V}$.

\section{Portable power generators ( $500 \mathrm{~W}-5 \mathrm{~kW}$ )}

Back-up power generators and auxiliary power units (APUs) in the range $500 \mathrm{~W}-5 \mathrm{~kW}$ could reach the market relatively quickly, because cost and lifetime for these units are less important than for other high-volume applications. Reliability and rapid start-up at ambient conditions are critical, especially for uninterruptible power supplies (UPSs), which need to be on-line within $20 \mathrm{~ms}$. Fuel cells for these applications also need to tolerate highly dynamic electrical loads.

Low-power units will use mainly DMFCs, while PEMFCs will cover the high end of the power range. For APUs with high load systems and long operating times, reformers will be essential. The fuel could be LPG, methanol, diesel, kerosene or gasoline.

Prototype back-up power generator systems based on fuel cells are already available for around $€ 10 / \mathrm{W}$, but the target for mass-produced compact units is $€ 2 / \mathrm{W}$. System lifetime is currently below $1,000 \mathrm{~h}$ and needs to be increased to $2,000 \mathrm{~h}$ or more. Power densities are in the range $10-100 \mathrm{~W} / 1$. The units can operate at temperatures from $-20^{\circ} \mathrm{C}$ to $50^{\circ} \mathrm{C}$, and at high relative humidities.

Most existing systems incorporate a small battery to provide power for start-up. Hybrid systems incorporating a larger battery alongside the fuel cell could help to reduce size and costs.

The following section shows an example of a high-power fuel cell module.

The NEXA ${ }^{\mathrm{TM}}$ from Ballard Power Systems is the first commercially-available $\mathrm{H}_{2}$-PEMFC power module. Table 12 shows its technical specifications.

Future opportunities for fuel cell systems in this power range include military applications, unattended marine systems and light traction. The military application is especially interesting because in this area an early market 


\section{5}

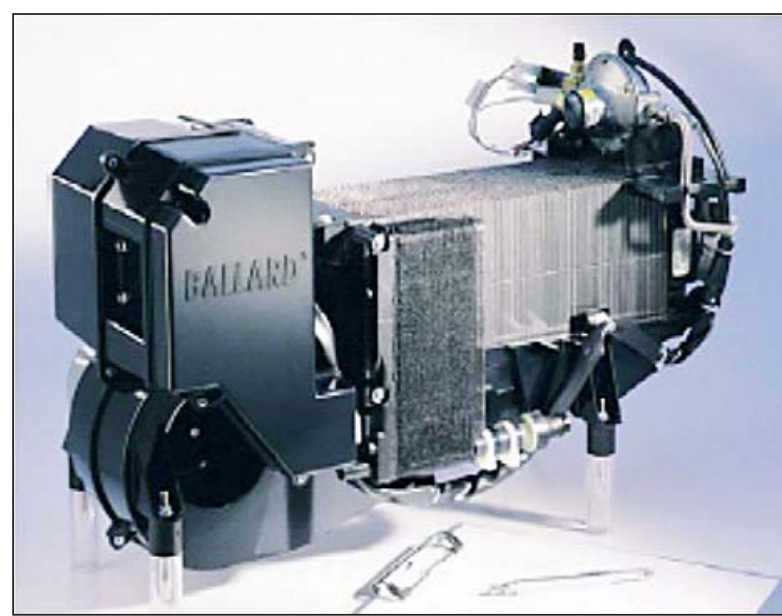

Figure 29: NEXATM 1.2-kW H2-PEMFC module (Ballard Power Systems).

\begin{tabular}{|lll|}
\hline \multirow{2}{*}{ Performance } & Rated net output & $1200 \mathrm{~W}$ \\
& Current & $46 \mathrm{~A}$ \\
& $\begin{array}{l}\text { DC voltage } \\
\text { Operating lifetime }\end{array}$ & $26 \mathrm{~V}$ \\
& & 1500 hours \\
Fuel & Composition & $99.99 \%$ dry H2 \\
Operating & Ambient temperature & $3-30^{\circ} \mathrm{C}$ \\
environment & Relative humidity & $0-95 \% \mathrm{RH}$ \\
Physical & Length $\mathrm{x}$ width $\times$ height & $56 \times 25 \times 33 \mathrm{~cm}$ \\
& Weight & $13 \mathrm{~kg}$ \\
& & \\
\hline
\end{tabular}

Table 12: Operating data for the Ballard NEXA ${ }^{\mathrm{TM}}$.

entrance even at today's costs is probable. For military use a power supply is necessary that emits a minimum of heat and noise.

Fuel cells are also an excellent replacement for batteries wherever access for charging is difficult, such as marine buoys, lighthouses and remote weather stations. In some cases the fuel cells could act as a backup for solar panels in seasonal systems. In this way the PV module area could be strongly reduced and therefore the costs can become acceptable. Light traction comprises fuel cells for bikes, scooters, internal transporters, wheelchairs, maintenance robots, golf cars, etc. The power range is dependent on the application $100 \mathrm{~W}-5 \mathrm{~kW}$. The advantage of the FC driven light traction is the higher cruising range in relation to battery driven vehicles.

\section{R\&D tasks}

The R\&D tasks for portable applications are relatively broad, covering PEMFCs, DMFCs, hydrogen storage systems and fuel processors.

\section{PEMFCs}

The following points cover PEMFCs not just for portable applications but also for transport and stationary uses. Catalysts need higher reactivity and lower platinum content. The oxygen electrode is a particular challenge here. Especially for REF-PEMFCs, the focus is on catalysts with high CO tolerance and on high-temperature technology that allows the development of CO-tolerant fuel cell systems.

Membrane costs need to be reduced, and there is scope for developing new types of membranes. Membranes requiring less or no humidification would make the system simpler, lighter and cheaper. Low-cost non-fluorinated membranes, for instance, offer the potential to achieve the target operating life of 2,000 hours for fuel cells in portable applications.

The need to increase the operating life of fuel cells is not confined to portable units. R\&D in this area concentrates on membrane materials, catalyst stability and the choice of optimal operating conditions.

\section{DMFCs}

The need to reduce the platinum loading of catalysts is especially important for DMFCs. Today's figures of $4 \mathrm{mg}$ $\mathrm{Pt} / \mathrm{cm}^{3}$ and $0.05 \mathrm{~W} / \mathrm{cm}^{3}$ result in a platinum cost alone of $€ 1,600$ per $\mathrm{kW}$ of capacity.

The activity of anode catalysts must increase, and the methanol sensitivity of cathode catalysts must be reduced in order to exclude mix potential formation of the oxygen reduction and the methanol oxidation.

Methanol crossover from one side of the membrane to the other reduces the efficiency of the system. New membranes with low methanol crossover need to be developed, although it is already possible to circumvent the problem by varying the methanol injection rate depending on the load.

Water management presents serious problems in DMFCs. The system could be simplified. Membranes should be developed which allow e.g. a water recycling through the membrane from the cathode to the anode side in order to simplify the system. The development of a passive system is a main target.

Concerns have also been expressed about the toxicity of methanol as a fuel. This has prompted some development work on direct ethanol fuel cells.

\section{$\mathrm{H}_{2}$-PEMFCs and DMFCs}

$\mathrm{H}_{2}$-PEMFCs and DMFCs require the development of catalysts with high activity at ambient temperatures, because high temperatures are not an option for most deviceintegrated fuel cells.

System development is very important, with greater functional integration used for reducing system complexity. Components such as mass flow controllers, sensors, pumps, blowers, gas/liquid separators, water management systems, temperature controllers and low- 
cost power conditioners need to be further developed, and miniaturised for portable applications.

The "manufacturability" of fuel cells needs to be improved, especially with regard to sealing methods.

The traditional bipolar construction of fuel cells creates a geometric form that is often inconvenient for device integration. Alternative designs such as monopolar cells or serially-connected cells in a planar configuration are therefore being developed.

\section{Fuels}

Fuel supply for fuel cells is a problem generally, but especially so for portable applications. The state of the art for portable units is to use cartridges containing hydrogen, as metal hydrides or compressed gas, or methanol. In each case the cartridges must be certified as safe under current chemical and transport regulations.

Intensive scientific effort is needed to develop existing hydride storage systems and discover new ones. Fuel cartridges for small portable applications may be regarded as disposable, so reversible storage is not absolutely necessary.

To extend the operating times of high-power portable fuel cells, compact reformers with simple gas purification systems are needed to run on a wide variety of fuels, including propane, butane and methanol.

\section{Conclusions}

Fuel cells for portable devices is becoming a niche, highvalue market area which has good opportunities for a fast introduction of fuel cell technology and the first consumer products in the electronic market can be expected within the coming year and is believed to grow rapidly thereafter. Danish industry is involved in the development of SOFC, PEMFC and DMFC fuel cells and the industry has in particular a strong position in system components and complete systems. This gives good opportunities for Danish companies for developing new products like for instance UPS, APU's and other portable devices. When combining the industry with the expertise existing in the Danish research institutes and Universities, it will be able to meet some of the R\&D tasks mentioned above, which will give the industry a competitive edge.

An important area for Danish Industry is system integration, where fuel cells and hydrogen technologies are implemented in electrical powered products. This is an area which is particular suited for small and medium sized enterprises and for start-ups. One example is in the medical sector - electrical wheelchairs with fuel cell technology as replacement for batteries giving longer driving range and faster re-charging. System integration is an area where Danish industry traditionally has a strong position and where innovative new applications of fuel cell technology can lead to new products. 


\subsection{Hydrogen infrastructure}

LARS HENRIK NIELSEN AND HANS LARSEN, RISØ NATIONAL LABORATORY; JAN JENSEN, DANISH GAS TECHNOLOGY CENTRE; AKSEL HAUGE PETERSEN, DONG.

\section{Introduction}

"Hydrogen infrastructure" refers to the physical links between sites where hydrogen is produced and where it is consumed. Infrastructure includes long-distance pipelines, transport by road, rail and water, large hydrogen storage facilities and filling stations.

Hydrogen as an energy carrier has the potential to replace almost all of the fuels in use today. Large demands for hydrogen are expected to emerge first in the transport sector, especially in road transport. Significant demand may also emerge in areas such as portable electronics, portable generators and uninterruptible power supplies (UPSs). Small-scale distributed CHP based on fuel cells may become a new source, as well as a user, of hydrogen.

Geographically these demands are dispersed. The infrastructure options may though be different according to the type, scale and quality requirements of the particular demands, and according to the specific hydrogen supply options. Generally, the supply side options may be both centralised large-scale and distributed or smaller-scale solutions.

This chapter describes the options for developing hydrogen supply infrastructures for road transport and other emerging technology areas. A central issue is the need for strategies to create hydrogen infrastructures that can grow gradually as demand increases. Hydrogen vehicles are expected to enter the market in 15-20 years.

\section{Drivers and visions}

An important driver for the introduction of hydrogen in the transport sector is serious concern about air pollution from road transport, especially in cities, and the health problems this generates. Direct hydrogen vehicles offer a solution, since hydrogen fuel cells produce virtually no emissions apart from water.

Another driver of growing importance is the security of future energy supplies for transport. At present this sector relies almost solely on oil. Hydrogen can be produced from virtually any energy resource, and thus is a good way to diversify energy production and increase security of supply.

But the hydrogen vision goes beyond transport. Hydrogen technology may penetrate into almost any energy cycle applied in society and provide sustainability, diversity, high efficiency and flexibility. Future energy supply systems based on hydrogen as an energy carrier could be configured for combined production of electricity, heat and hydrogen as a transport fuel. Such

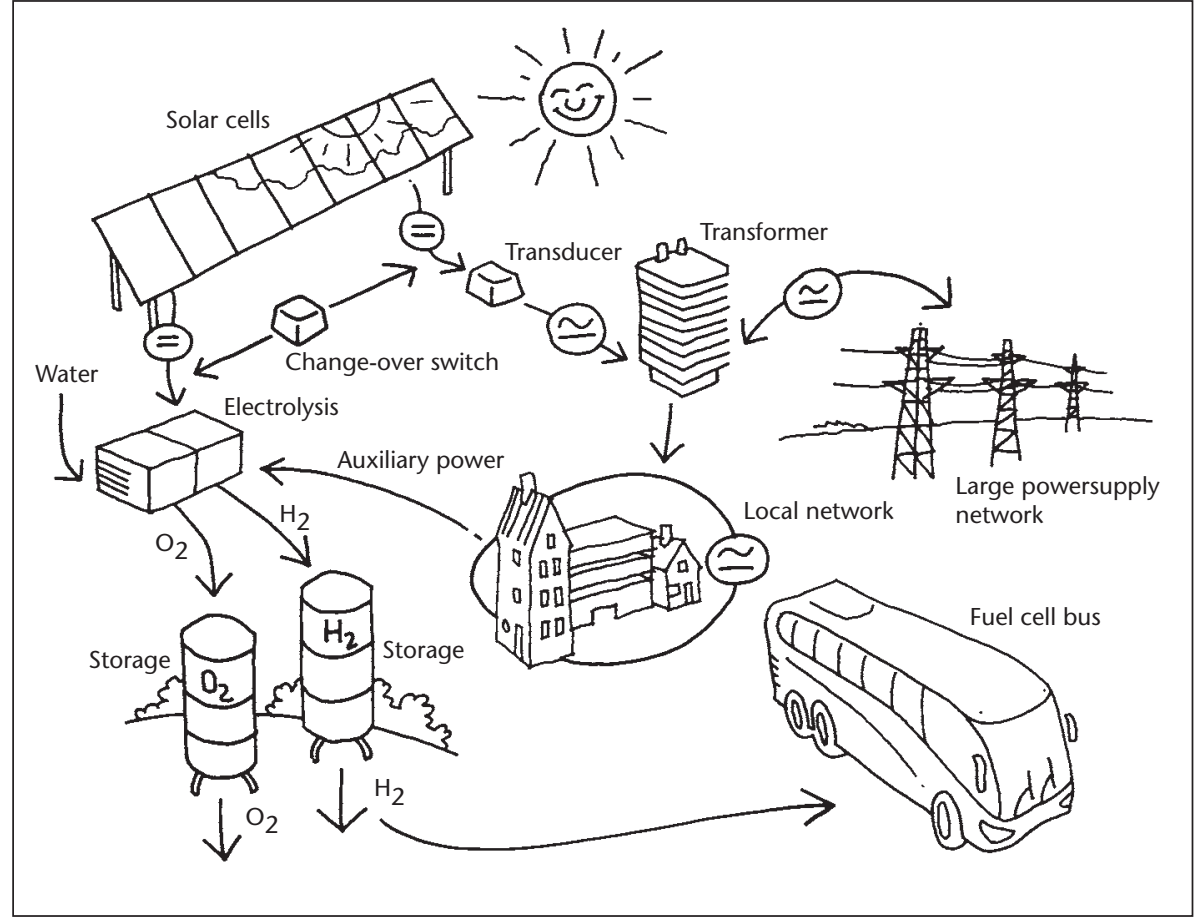


systems can achieve very high overall efficiencies, and due to the modular nature of fuel cell technologies they can be configured to be distributed, centralised or anywhere in between.

Robust hydrogen supply infrastructure solutions for road transport are needed urgently. Prototype hydrogenbased fuel cell vehicles are already being tested and demonstrated in Europe, Japan and the USA, and some major automotive manufacturers have announced that they will market fuel cell vehicles already by 2005 .

Large numbers of hydrogen vehicles, however, are not expected before 2015-20. Considerable efforts are being made to develop infrastructure solutions to support these vehicles, both through national R\&D and demonstration programmes and by the car industry. The accelerating development of hydrogen vehicles brings an urgent need for common codes, standards and regulations.

Filling stations for pressurised hydrogen gas are expected to be an essential part of an initial infrastructure. Hydrogen stored as a compressed gas at up to 700 bar already gives today's vehicles a range comparable to that of conventional vehicles, whereas infrastructures to support liquid hydrogen, metal hydride and other storage methods are not seen as viable at the moment. Road maps presenting the shorter-term aims and strategies for introduction of hydrogen for transport generally agree on the steps towards an extended hydrogen infrastructure. First, hydrogen filling stations will be built in large cities to supply bus fleets and other vehicles in regular operation within a limited area. A single filling station in a densely-populated area can serve a large number of users and maximize the environmental and health benefits of hydrogen. This is an optimal way to increase public awareness and acceptance of hydrogen technology.

Step two is to build filling stations on major roads linking cities and large towns that already have their own hydrogen filling stations. This allows existing fleets of hydrogen vehicles to increase their range, and will help to increase the size of the hydrogen vehicle market.

\section{Hydrogen infrastructure and future supply options}

The relevant hydrogen production options to supply the network of filling stations much depend on the local or regional conditions. In an initial stage the hydrogen production and supply may take advantage of the existing infrastructure for electricity and natural gas.

Via electrolytic production hydrogen may be generated and supplied at almost any location. The modularity of the electrolysis technologies means that both large and small-scale plants may be relevant. The individual hydrogen filling stations may be equipped with electrolysis units, e.g. for high-pressure electrolysis, compressor and storage facilities, and dispensers for high-pressure hydrogen. Even very small-scale residential dispenser units may be a future option based on electrolysis. Producing hydrogen via electrolysis means that attributes of the power production system in question e.g. primary energy inputs and $\mathrm{CO}_{2}$ characteristics, partly are transmitted to the transport sector. Fuel flexibility and system development options for the overall power system become options for transport as well.

Where natural gas is available, reforming is another supply option for hydrogen. Reformer plants could be situated near, or in, hydrogen filling stations. Economies of scale, however, may favour larger reformer plants, which in turn would require local pipelines to supply the filling stations.

Beyond the very initial stages of a hydrogen supply infrastructure build-up another option may be to distribute hydrogen mixed into the NG-grid in quantities up to about $15 \%$ volume, depending on pipeline material, pipeline pressure and end user technology. Hydrogen supplied from numerous sources may be distributed via mixed gas grid lines.

Hydrogen filling stations would be able to separate the hydrogen from the natural gas, purify and pressurise it for use in vehicles. Most other users would simply be able to burn the natural gas/hydrogen mixture without problems. The only difficulties would be with internal combustion engines running on natural gas. Denmark has many such engines in small CHP stations, and it has been shown that hydrogen levels above $1-2 \%$ in the gas can cause operational problems or reduced output. New engines developed for natural gas/hydrogen blends should not suffer from these problems.

Various other factors also limit the proportion of hydrogen than can be added to natural gas pipelines. The need to preserve the combustion quality of the gas (Wobbe index) would limit the hydrogen content to 25\% by volume, while restrictions on density would allow a maximum of $17 \%$ hydrogen. The most stringent limit is set by leakage and material compatibility. Above about $15 \%$ hydrogen, problems of leakage, corrosion, degradation of polyethylene pipe and embrittlement of steels are expected [8]. Tests and analyses of using the Danish NGgrid for transporting medium-pressure pure hydrogen has been carried out during 2003 [15]. Results of this test carried out during one year indicate that material changes may take place in the 4 bar distribution grid. Leakage measurements show that connections and sealings must be checked more frequently than for natural gas.

The energy content of hydrogen is only around onethird that of the same volume of natural gas. As a consequence, pipelines and underground storage caverns for hydrogen would have to be three times the size of their natural gas equivalents, at the same pressure, to cover the same energy demand. For safety reasons, hydrogen pipelines will also operate at lower pressures than natural 
gas pipelines (Chapter 6.2). Add in the fact that hydrogen is more demanding than natural gas in terms of materials of construction, and it is clear that pipelines for pure hydrogen will be more expensive than for natural gas.

Storage of gaseous hydrogen at high pressures is wellknown technology (Chapter 5.2). Hydrogen filling stations would require pressurised storage tanks holding hydrogen equivalent to roughly one day's sales. On a much larger scale, hydrogen can be stored underground in aquifers and cavities, in the same way as natural gas.

\section{Current hydrogen use and infrastructure}

Current world hydrogen production represents less than $1 \%$ of world energy production, or 73 Mtoe (2001) [13]. The industrial gas companies currently supply hydrogen for refineries and the industry in general as well as for space flight and hydrogen vehicle demonstrations [13] With 50 large hydrogen plants and 2,500 km of pipeline carrying high-purity hydrogen in the USA and Europe, the gas companies have expertise covering the entire hydrogen chain from production to industrial consumers.

Current hydrogen storage facilities include small- and medium-scale storage of liquid and gaseous hydrogen in industry, large-scale underground storage of gaseous hydrogen, and large-scale liquid hydrogen storage by NASA in the USA.

Hydrogen infrastructure can evolve gradually with conversion and production technologies, since most of the infrastructure developed for fossil-fuel-based hydrogen will also work with hydrogen from renewable and nuclear sources. Infrastructure development will begin with pilot projects and expand to local, regional, and ultimately national and international projects. The main infrastructure investment period is expected to be 2015 2035 [9].

\section{Hydrogen infrastructure and demonstration initiatives in the USA, Japan and Europe [3]}

The USA has recently been an outspoken advocate of the transition to hydrogen as a replacement for fossil fuels on the grounds of energy security and the environment. The US government has pledged $\$ 1.7$ billion over the next five years to develop hydrogen-powered fuel cells, hydrogen infrastructure and advanced automotive technologies. The US hydrogen vision envisages a transport system powered by hydrogen derived from a variety of domestic sources, as well as stationary fuel cell applications.

Japan's hydrogen effort focuses on R\&D to commercialise and popularise fuel cells, fuel cell vehicles and hydrogen infrastructure. The Japanese government has set ambitious targets for the penetration of hydrogen fuel cells, including 50,000 hydrogen vehicles by 2010, 5 million vehicles by 2020 and 15 million vehicles by 2030. The 2030 target also includes a nationwide hydrogen infrastructure with 8,500 filling stations. A programme covering 2003-2007 with a budget of about $¥ 31$ billion ( $€ 230$ million) has been planned.

EU countries are among the most active worldwide in developing the technologies and concepts that would underlie the transition to a hydrogen economy. The EU is seeking to promote greater co-operation, pooling of resources and harmonisation of efforts in this area, with the goals of reducing the negative environmental effects of energy use and improving the security of energy supply. The EU's long-term vision is to have an energy supply system based on renewable energy and fuel cells in place within 20-30 years, with hydrogen and electricity as prominent energy carriers.

In 2002 the European Commission established a High Level Group on Hydrogen and Fuel Cells (HLG), involving European stakeholders. The HLG aims to facilitate high-level strategic discussions for developing a European consensus on the introduction of hydrogen energy. In January 2004 the Commission launched the European Hydrogen and Fuel Cells Technology Platform. A third European initiative, a network called HyNet (the European Hydrogen Energy Thematic Network), was set up in 1999 by about 40 leading companies from a broad spectrum of industries and technologies. In May 2004 HyNet published a European Hydrogen Roadmap as part of the EU-funded HyWays project.

Other European hydrogen projects are CUTE and ECTOS, which will develop and operate 30 DaimlerChrysler Citaro fuel cell buses in ten European cities from 2003 onwards, with pressurised hydrogen as fuel. The EU has contributed $€ 21$ million to the projects.

Germany has been at the forefront of hydrogen fuel cell technology development and implementation worldwide, with various federal and numerous regional initiatives. There has been strong co-operation between public and private enterprises, with involvement from DaimlerChrysler, Opel, Ford, BMW and Ballard Power Systems among others. Particularly well known is the NEBUS passenger bus demonstration project. Another is the hydrogen service station at Munich airport. Furthermore an interesting initiative is the public/private Transport Energy Strategy (TES), which supports R\&D on hydrogen, methanol and natural gas as alternative fuels. Total public finance for hydrogen in Germany is approximately $€ 100$ million a year.

The government of Iceland has the vision to create the world's first hydrogen economy. Because most of the country's energy is derived from renewable (>70\%) and environment-friendly sources, the initial focus of Iceland's efforts is the transport sector. The plan to create a hydrogen economy involves co-operative R\&D through various public/private partnerships. The most significant, Icelandic New Energy (INE), was established as a joint venture to promote the use of hydrogen as a transport fuel. INE's main work is demonstration projects for buses, cars and fishing vessels. A demonstration 
project for passenger buses is already in progress (the ECTOS project, 2001-2005).

\section{The long-term vision for a hydrogen infra- structure}

The long-term vision is energy systems that are highly diversified, robust, environmentally benign and affordable. Fuel cells and electrolysers or reversible fuels cells, plus hydrogen grids and storage systems, are likely to be key technologies for balancing electricity grids. Hydrogen has the potential for being a link between the transport sector and the heat and power sectors. The flexibility of such system configurations can compensate for fluctuating power inputs, such as from wind power and solar cells, and thus promote the use of renewable energy for transport, heating and electricity.

Barriers to this vision include the need to improve the performance of hydrogen and hydrogen-related technologies to the point where they can compete in economic terms with existing energy technologies. In particular, this means improving the performance of fuel cells and mobile hydrogen storage technologies. The vision for getting started would involve the transport sector in particular and the build-up of a limited number of filling stations primarily for serving car fleets like taxies and buses in urban areas. In following stages of building up a hydrogen infrastructure, pipelines with hydrogen or natural gas mixed with hydrogen may be made available e.g. to selected blocks with flats and public buildings like schools, hospitals etc. According to [14] the share of hydrogen as a vehicle fuel in Europe would be $2 \%$ by 2015 and $5 \%$ by 2020 , and this would demand 10000 hydrogen filling stations in 2020. The technology to produce hydrogen from on site SMR (Steam Methane Reforming) is ready. The same applies for electrolytic hydrogen production.

The vision for the next 20-40 years is to make hydrogen fully competitive with conventional energy sources for both vehicles and individual dwellings. This will require extensive hydrogen distribution grids and a dense network of urban filling stations. 



\section{Hydrogen - Environmental and safety aspects}

On the face of it hydrogen seems to have low impact on the environment, but there are a number of uncertainties concerning the consequences of a large-scale shift towards a hydrogen economy.

Likewise hydrogen is probably no more hazardous than conventional fuels, but because of the many properties that make hydrogen distinct from conventional fuels, it is necessary to deal with the risk assessments for all the elements in the use and supply chain of hydrogen.

These fields are discussed in this chapter. 


\subsection{Hydrogen and the environment}

MARTIN SCHULTZ, MAX-PLANCK-INSTITUT FÜR METEOROLOGIE, GERMANY; FRANK MARKERT AND KIM PILEGAARD, RISø NATIONAL LABORATORY

\section{Introduction}

Hydrogen $\left(\mathrm{H}_{2}\right)$ is widely regarded as a key component in future energy systems because it is a sustainable, clean, and transportable energy carrier. It can be generated from pure water, and burned to produce nothing but water. Thus if hydrogen generated using clean and sustainable processes replaces fossil fuels as our main energy carrier, we will have significantly lower emissions of greenhouse gases, especially carbon dioxide $\left(\mathrm{CO}_{2}\right)$, and air pollutants, notably nitrogen oxides and volatile organic compounds.

This view is somewhat idealistic, however, as the technology for the clean and sustainable production of hydrogen is still in the pioneering phase. A great deal of effort will have to be made to build up sufficient hydrogen production capacity from sustainable energy sources such as wind power and solar cells.

The production and distribution of hydrogen inevitably involves energy losses. If the energy source is a fossil fuel, the energy losses and pollution involved in producing and distributing hydrogen may turn out to be greater than those from direct use of the fuel via conventional technology. When considering the use of hydrogen in any application, it is therefore important to check the overall environmental balance and to compare this with alternatives such as the direct use of electricity from windmills or solar cells.

Initially at least, the production of hydrogen as described in Chapter 5.1 will be based largely on the chemical conversion of fossil fuels such as natural gas and coal. Such processes generate carbon dioxide emissions which may exceed those from the direct use of the fossil fuel in an internal combustion engine. When hydrogen is produced at a large centralised plant, however, it may be possible to capture the carbon dioxide and end up with a net reduction in greenhouse gas emissions. In terms of other air pollutants, reforming would almost certainly be preferable to the present situation.

The use of hydrogen as such is regarded as sustainable and would improve air quality in urban areas. Nevertheless, it is important to assess the overall impact of hydrogen on the environment. The environment is a complex, highly coupled, non-linear system which may react in unforeseen ways to changes in the status quo. Emissions of man-made compounds including CFCs, which destroy ozone and act as greenhouse gases, other halogenated compounds and of course carbon dioxide have already caused environmental problems. We do not want to repeat the same mistakes with hydrogen.

This chapter gives an overview, based on the scientific literature, of current knowledge of the consequences of hydrogen in the soil and in the atmosphere.

\section{Sources, sinks and concentrations of atmospheric hydrogen}

The (incomplete) combustion of fossil fuel and biomass in boilers and internal combustion engines generates hydrogen along with carbon monoxide and carbon dioxide. At present, this source accounts for about 40\% of all the hydrogen released into the atmosphere.

Another important source, accounting for an estimated $50 \%$ of atmospheric hydrogen emissions, is the atmospheric photochemical oxidation of methane $\left(\mathrm{CH}_{4}\right)$ and non-methane hydrocarbons (NMHCs). Emissions from volcanoes, oceans and nitrogen-fixing legumes account for the remaining $10 \%[10,4]$. These estimates are still very uncertain.

Movement of hydrogen into the upper atmosphere and then to space is negligible in terms of the global hydrogen budget. Instead, hydrogen is removed from the atmosphere largely through dry deposition at the surface and subsequent microbiological uptake in soils. The rate of uptake depends on microbial activity, soil texture and moisture content. This sink is largest in the northern hemisphere because of its larger landmass, and it is thought to account for about $75 \%$ of all hydrogen removal.

The remaining $25 \%$ of hydrogen is removed through oxidation by hydroxyl free radicals $(\mathrm{OH})$ in the atmosphere:

(R1) $\mathrm{H}_{2}+\mathrm{OH} \rightarrow \mathrm{H}+\mathrm{H}_{2} \mathrm{O}$

(R2) $\mathrm{H}+\mathrm{O}_{2}+\mathrm{M} \rightarrow \mathrm{HO}_{2}+\mathrm{M}$

The hydrogen peroxy radical $\left(\mathrm{HO}_{2}\right)$ produced in reaction (R2) continues to react with nitrogen oxide (NO), a key step in photochemical ozone formation (see R6 below), or it reacts with itself or other peroxy radicals, thereby terminating the photochemical oxidation chain.

Hydroxyl radicals are also the main initiating reactant in the atmospheric degradation of volatile organic compounds (VOCs), greenhouse gases such as methane $\left(\mathrm{CH}_{4}\right)$, and carbon monoxide:

$$
\text { (R3) } \mathrm{CO}+\mathrm{OH}+\mathrm{O}_{2} \rightarrow \mathrm{HO}_{2}+\mathrm{CO}_{2}
$$

Hydroxyl radicals are produced mainly through the photolysis of an ozone molecule $\left(\mathrm{O}_{3}\right)$ to produce an oxygen molecule $\left(\mathrm{O}_{2}\right)$ and an electronically excited "singlet" oxygen atom $(\mathrm{O})$, which then reacts with a 
molecule of water vapour $\left(\mathrm{H}_{2} \mathrm{O}\right)$ to produce two hydroxyl radicals:

$$
\begin{array}{ll}
\text { (R4) } & \mathrm{O}_{3}+\mathrm{h} v \rightarrow \mathrm{O}_{2}+\mathrm{O} \\
\text { (R5) } & \mathrm{O}+\mathrm{H}_{2} \mathrm{O} \rightarrow 2 \mathrm{OH}
\end{array}
$$

Ozone is produced mainly by the photolysis of nitrogen dioxide to yield low-energy triplet oxygen atoms $\left(\mathrm{O}\left({ }^{3} \mathrm{P}\right)\right)$, which then react with oxygen to produce ozone:

$$
\begin{array}{ll}
\text { (R6) } & \mathrm{NO}+\mathrm{HO}_{2} \rightarrow \mathrm{OH}+\mathrm{NO}_{2} \\
\text { (R7) } & \mathrm{NO}_{2}+\mathrm{h} v \rightarrow \mathrm{NO}+\mathrm{O}\left({ }^{3} \mathrm{P}\right) \\
\text { (R8) } & \mathrm{O}\left({ }^{3} \mathrm{P}\right)+\mathrm{O}_{2}+\mathrm{M} \rightarrow \mathrm{O}_{3}+\mathrm{M}
\end{array}
$$

"hv" denotes a photon of ultraviolet light. Ozone in the troposphere is also an important component of summer smog.

These atmospheric reactions, which are closely linked, are important because they determine the capacity of the atmosphere to neutralise pollutants. The concentration of hydroxyl radicals is particularly important, since it is these radicals that begin the whole oxidative degradation process, and the reactions involved (R1 and R3) are the slowest in the whole sequence. More hydrogen in the atmosphere will tend to lower the concentration of hydroxyl radicals and so inhibit the capacity of the atmosphere to oxidise greenhouse gases and other pollutants. On the other hand, in a hydrogen economy, emissions of other compounds (e.g. CO, $\mathrm{NMHC}$, and $\mathrm{NO}_{\mathrm{X}}$ ), which affect the hydroxyl radical concentration more effectively, will be reduced. The resulting effect is discussed in more detail below (section on oxidizing capacity).

Measurements from ground stations, balloons and research aircrafts typically find about $0.5 \mathrm{ppmv}$ (parts per million by volume) of hydrogen in the troposphere (the part of the atmosphere extending from the earth's surface up to about $10 \mathrm{~km}$ ), and 0.4-0.5 ppmv in the stratosphere (10-60 km altitude) [5]. No significant trend can be deduced from observations made after 1990, although earlier observations did indicate a positive trend.

The tropospheric hydrogen concentration exhibits a clear yearly cycle. In the northern hemisphere the amplitude of the variation is 0.04-0.08 ppmv, with a maximum in the spring. In the southern hemisphere the amplitude is 0.02-0.04 ppmv, with a maximum during summer in the northern hemisphere. These seasonal variations are caused largely by the build-up of $\mathrm{CH}_{4}$ and NMHC in the winter, followed by increased oxidation rates in the summer. Seasonal variations in the rate of dry deposition may also contribute to the cycle.

\section{Estimates of future emissions}

The future environmental consequences of a large-scale hydrogen economy will depend on how much hydrogen we use, how it is produced, how fast our use increases, the amount of fossil fuel emissions that can be saved, and the steps we take to control hydrogen emissions. The present atmospheric hydrogen concentration of 0.5 ppmv implies a total mass of about 175 million tonnes of hydrogen, of which around $20 \%$ is thought to be from the combustion of fossil fuels.

There has been considerable recent controversy in the scientific literature over how much hydrogen a globalscale hydrogen economy would release into the atmosphere. Estimates range from less than $0.1 \%$ of hydrogen consumption, for tightly-controlled industrial applications, to $10-20 \%$ for evaporation from liquid hydrogen tanks in poorly-designed automobiles. $3 \%$ would be a more realistic upper limit, however, simply because higher leakage rates would be neither economic nor safe. Assuming the complete replacement of today's energy system with a hydrogen chain, about 1400-1800 million tons $\mathrm{H}_{2}$ /year would be required. ${ }^{8}$ Correcting for the present emissions of 42-54 million tons $\mathrm{H}_{2} /$ year and

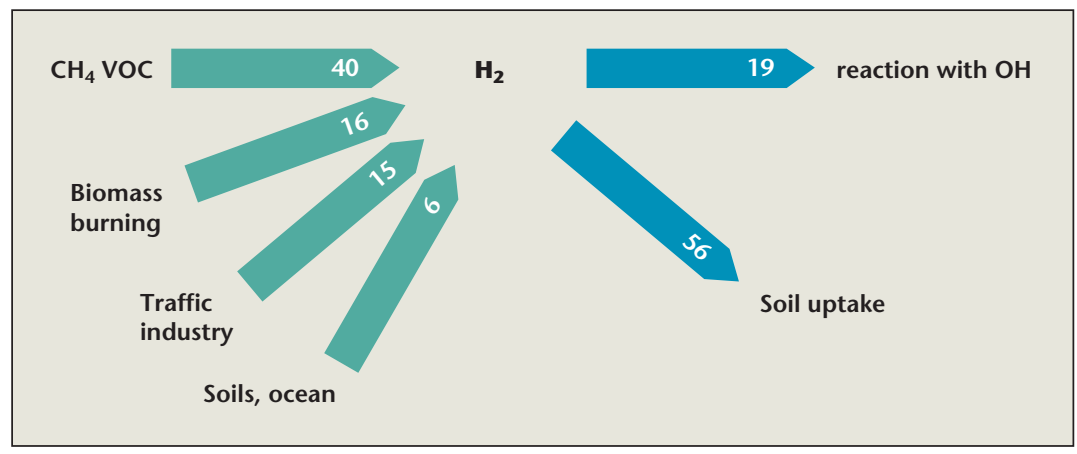

Figure 31: Sources and sinks for hydrogen in the atmosphere (million tonnes/year). The numbers are uncertain, especially for traffic and industry emissions $( \pm 10$ million tonnes/year) and soil deposition ( \pm 15 million tonnes/year).

8. Energy consumption $2001=404 \cdot 10^{18} \mathrm{~J}$ (EIA, 2003), energy density of hydrogen $=1.2 \cdot 10^{8} \mathrm{~J} / \mathrm{kg}$. Thus, an upper limit for the $1: 1$ replacement of today's energy demand would be given by 3340 million ton/year. However, one must factor in the efficiency gain when replacing an old technology with a new one (e.g. factor 2 for fuel cells over internal combustion engines), and conversion efficiency changes (e.g. coal to electricity versus steam reformation for hydrogen production). The value of 1400-1800 million ton/year given in the text is a conservative estimate based on different sources. 
assuming a $3 \%$ loss of $42-54$ million tons $\mathrm{H}_{2}$ /year the $\mathrm{H}_{2}$ emissions would increase by 17-49 million tons $\mathrm{H}_{2}$ /year (or 22\%-64\%), it is worthwhile to note that lower leak rates than $3 \%$ could even lead to a net reduction of hydrogen emissions.

Of course, a simple 1:1 replacement scenario of the present-day energy demand is overly simplistic, and considerable future efforts are needed to develop more reliable emission scenarios for hydrogen applications.

Our view is that these hydrogen emissions are probably much less important than the overall atmospheric emissions of $\mathrm{CO}_{2}, \mathrm{CO}$, and $\mathrm{NO}_{\mathrm{X}}$ from reformers and other hydrogen plants, and emissions of these gases will be reduced as conventional technologies are replaced by their hydrogen equivalents [13]. Of particular interest here are emissions of carbon dioxide and $\mathrm{NO}_{\mathrm{X}}$. Carbon dioxide is important because it is the biggest contributor to climate change. $\mathrm{NO}_{\mathrm{X}}$ levels drive the oxidising capacity of the atmosphere (essentially the $\mathrm{OH}$ concentration), and so regulate the lifetime of the greenhouse gas methane, and they control the amount of photochemical ozone formed in the troposphere. Table 13 lists current estimates of $\mathrm{NO}_{\mathrm{X}}$ sources [6].

Table 13: Global tropospheric $\mathrm{NO}_{\mathrm{x}}$ emissions estimates for 2000 [6].

\begin{tabular}{|ll|}
\hline $\mathrm{NO}_{\mathrm{x}}$ source & $\begin{array}{l}\text { Estimated budget } \\
\text { (million tonnes N/year) }\end{array}$ \\
\hline Fossil fuel combustion & $30-36$ \\
Aircraft & $0.5-0.8$ \\
Biomass combustion & $4-12$ \\
Soils & $4-7$ \\
Ammonia oxidation & $0.5-3.0$ \\
Lightning & $2-12$ \\
Transport from the stratosphere & $<0.5$ \\
& \\
\hline Total & 51.9 \\
\hline
\end{tabular}

As Table 13 shows, the burning of fossil fuels is by far the largest present-day source of $\mathrm{NO}_{\mathrm{X}}$. Emissions from fossil fuels are likely to increase in the future, despite successful regulations in Europe, North America and Japan. A largescale shift to hydrogen would eliminate or at least reduce a significant fraction of traffic-related $\mathrm{NO}_{\mathrm{X}}$ emissions. This would improve air quality, or at least help to slow the decline in air quality, over large regions of the world $[13,14]$.

\section{Possible impacts: a review of some articles}

The potential environmental impacts of a global hydrogen economy are:

- Increased hydrogen release would lower the oxidising capacity of the atmosphere, and so increase the lifetime of air pollutants and greenhouse gases such as methane, HCFCs and HFCs.
- Increased hydrogen release would lead to increased water vapour concentrations in the atmosphere, with potential consequences for cloud formation, stratospheric temperatures and stratospheric ozone loss.

- Increased hydrogen release could exceed the uptake capacity of hydrogen by micro-organisms in the soil, currently the main way in which hydrogen is removed from the atmosphere. The result would be that hydrogen concentrations in the atmosphere would increase quicker, which would reinforce the consequences described above.

- If hydrogen were to be generated using electricity derived from burning coal, $\mathrm{NO}_{\mathrm{X}}$ emissions could increase significantly. This would have serious effects on air pollution and the global tropospheric ozone budget.

- Generating hydrogen from fossil fuels could lead to increased emissions of carbon dioxide, which would accelerate global warming, unless the $\mathrm{CO}_{2}$ is captured and stored.

- Conversely, generating hydrogen from sustainable sources would reduce emissions of carbon monoxide and $\mathrm{NO}_{\mathrm{X}}$, with a consequent fall in tropospheric ozone levels. This would improve air quality in many regions of the world. Furthermore, $\mathrm{CO}_{2}$ emissions would be reduced, thereby slowing the global warming trend.

The following sections address each of these points and attempt to judge the likelihood that they will become topics of concern in the future.

\section{Changes in oxidising capacity}

Hydrogen acts as a significant sink for hydroxyl radicals, and increased atmospheric concentrations of hydrogen could lead to a decrease in $\mathrm{OH}$ concentration. This in turn could increase the atmospheric lifetime of greenhouse gases and other pollutants, with undesirable consequences for climate change and air quality [4].

While this argument is qualitatively correct, the anticipated changes in $\mathrm{OH}$ levels due to changes in the atmospheric hydrogen concentration are marginal. At present, hydrogen accounts for the destruction of less than $10 \%$ of all $\mathrm{OH}$ globally, so if hydrogen concentrations were to double (which seems unlikely, given the emissions estimates above) this would produce a change in $\mathrm{OH}$ concentrations of only a few percent.

However, significant changes in the oxidising capacity of the atmosphere could well arise from other emission changes associated with the shift towards hydrogen, most notably emissions of $\mathrm{NO}_{\mathrm{X}}$ [13]. There is still considerable uncertainty about the global $\mathrm{OH}$ budget and its historical trends [6]. Generally, scientists believe that the burning of fossil fuels has produced only small changes in the balance between $\mathrm{NO}_{\mathrm{X}}$ (which tends to increase $\mathrm{OH}$ ) and carbon monoxide (which tends to decrease $\mathrm{OH}$ ) since pre-industrial times, and that the global average 


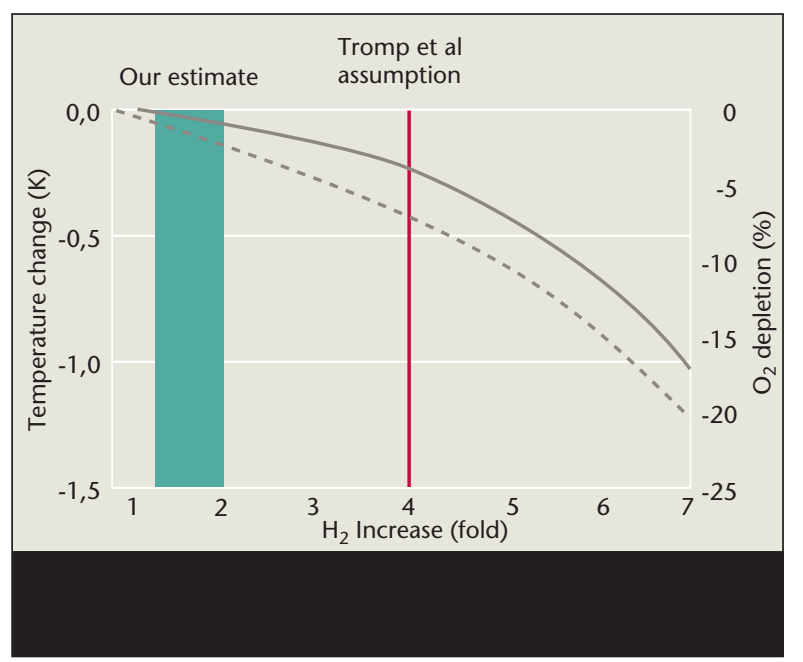

$\mathrm{OH}$ concentration has probably remained stable in about $10 \%$ over this time.

Significant future changes in either $\mathrm{NO}_{\mathrm{X}}$ or carbon monoxide emissions could have a much larger effect on $\mathrm{OH}$ levels. Such changes could happen in a hydrogen economy, but equally they could happen in a world of fossil fuels as a result of tightening emission controls. More research is clearly needed to produce reliable estimates based on probable emission scenarios.

\section{Changes in atmospheric water vapour}

The oxidation of hydrogen produces water vapour, which could have different consequences depending on where in the atmosphere it is released. One recent article suggests that increasing atmospheric hydrogen concentrations by a factor of four would increase the amount of water vapour in the stratosphere by up to $30 \%$ [15]. According to these researchers, this could decrease the lower stratospheric temperature at the polar vortex by about $0.2^{\circ} \mathrm{C}$, which in turn could trigger additional polar ozone losses of up to $8 \%$ (polar ozone depletion is very sensitive to small temperature changes [17]). Another model, however, showed a much weaker effect on stratospheric temperatures and ozone loss [16].

As discussed above, hydrogen levels are more likely to increase by $20 \%$ than by $400 \%$ in the coming decades. Even when we use the more pessimistic model [15], the consequences for stratospheric temperatures and ozone concentrations therefore are expected to be negligible (Figure 32).

Increased water vapour concentrations in the upper troposphere can be expected if air traffic increases as projected, especially if aircrafts begin to use hydrogen as fuel. At these altitudes, increased water vapour may cause cirrus clouds to form. This would increase or decrease heat radiation, depending on the height and thickness of the cloud, and might lead to either cooling or warming of the atmosphere.

It is difficult to establish reliable estimates of the poten-
Figure 32: Relative temperature changes in the lower stratosphere at $74^{\circ} \mathrm{N}$ (solid line) and the resulting maximum ozone depletion in the northern polar vortex (dashed line) as a function of increased atmospheric hydrogen concentrations relative to the today's actual hydrogen concentration of about 0.5 ppmv. The cause of the temperature change is the stratospheric water vapour resulting from the oxidation of hydrogen. The graph is taken from Tromp et al. [15], with additions.

tial water vapour release from aircrafts, and even harder to model the effects of extra water vapour on this highlysensitive region of the atmosphere. Emissions depend strongly on engine design, and the effects will be very different depending on the altitude, air temperature, exhaust temperature and background humidity.

If hydrogen combustion engines were used widely in aircrafts, another source of concern could be emissions of $\mathrm{NO}_{\mathrm{X}}$. Even under present-day conditions, $\mathrm{NO}_{\mathrm{X}}$ emissions are believed to significantly perturb the amount of ozone in the upper troposphere [6]. These processes in the upper troposphere and lower stratosphere region are still the subject of much research, and more measurements and better models are needed to assess them reliably.

\section{Soil uptake}

The uptake of atmospheric hydrogen by soil microorganisms or organic remnants is associated with large uncertainties. Studies using isotopically-labelled hydrogen suggest that soil uptake provides about $75 \%$ of the total hydrogen sink, but there is a large margin of error. Little is known about the detailed processes by which hydrogen is absorbed in the soil.

At the moment there is no sign that the process of hydrogen uptake in the soil is becoming saturated. Increased fossil fuel combustion has presumably increased atmospheric hydrogen concentrations significantly in the last century, but there has been no detectable increase since 1990. If hydrogen uptake in the soil were becoming saturated, we would expect the concentration of hydrogen in the atmosphere to have increased, even if hydroxyl radical concentration were increasing as well.

Since we do not expect the amount of hydrogen released to change very significantly in the next few decades, we currently have no reason to expect serious consequences from changes in the soil uptake rate. This is rather speculative, however, and further research is urgently required. 


\section{Carbon dioxide emissions}

In a recent study, today's surface traffic fuels were assumed to be replaced by hydrogen generated from renewable sources leading to a $20 \% \mathrm{CO}_{2}$ emission reduction [14]. However, as long as hydrogen is generated from fossil fuels, $\mathrm{CO}_{2}$ emissions from reforming can easily rival today's emissions from power plants and traffic. From the standpoint of avoiding $\mathrm{CO}_{2}$ emissions in the short to medium term, centralized facilities appear preferable, because this might allow efficient capturing and storing of the $\mathrm{CO}_{2}$ produced. ${ }^{9}$ In the long term, it is obvious that hydrogen generation has to be based on renewable sources to avoid the environmentally adverse effects of carbon dioxide.

\section{Air quality effects}

Probably the most immediate implication of a large-scale shift to hydrogen, especially in road transport, would be a significant drop in emissions of air pollutants $\left(\mathrm{NO}_{\mathrm{X}}\right.$, benzene and other VOCs) and an associated decrease in ground-level ozone concentrations.

In most regions of the world, ozone formation is limited by the amount of $\mathrm{NO}_{\mathrm{X}}$ in the atmosphere. However, many big cities emit such large amounts of $\mathrm{NO}_{\mathrm{X}}$ that ozone formation is limited instead by the availability of VOCs and carbon monoxide, which are produced by plants and soil bacteria as well as vehicles and industrial processes.

As a result, it is well known that lowering emission levels can actually increase ozone concentrations at first; only if the reduction is large enough will ozone concentrations decrease. This effect probably lies behind observations that though emissions of ozone precursors have decreased significantly in Europe over the past decade or so [1], summertime surface ozone concentrations have remained stable. All this means that the reduction of $\mathrm{NO}_{\mathrm{X}}$ and VOC emissions following the introduction of hydrogen vehicles could initially increase ozone levels in some areas. However, the reduced $\mathrm{NO}_{\mathrm{X}}$ and VOC concentrations will bring their own health benefits, and ozone levels downwind of the city will decrease. As a result, the damaging effects of ozone on crops and natural ecosystems will be reduced.
Simulations also show the positive trend for the air quality that drastic cuts in $\mathrm{NO}_{\mathrm{X}}$ emissions are especially effective in reducing peak ozone concentrations and the number of days on which air quality standards are exceeded [13].

Thus there is little reason to doubt that the widespread use of hydrogen should bring significant improvements of air quality. This would only be untrue if coal-fired power stations with little emission control were used to produce the hydrogen (in particular in developing countries, e.g. China). In this case $\mathrm{NO}_{\mathrm{X}}$ emissions might actually increase compared to today, with a further rise in tropospheric ozone concentrations.

\section{Conclusions}

While there are still large uncertainties about the current budget of atmospheric hydrogen and the consequences of a large-scale shift towards a hydrogen economy, present knowledge indicates that there are no major environmental risks associated with this energy carrier, and that it bears great potential for reducing air pollution world wide, provided that the following rules are followed:

- Hydrogen should not be produced using electricity generated by burning fossil fuels. Instead, natural gas or coal reformers should be used at first, and replaced by renewable energy sources as soon as possible. $\mathrm{CO}_{2}$ capture from reformers should be seriously considered.

- Hydrogen should be used predominantly on the ground rather than in aircrafts, and to achieve full benefits, fuel cells would be preferable against internal combustion engines.

- Leakage in the hydrogen energy chain should be limited to $1 \%$ wherever feasible, and global average leakage should not exceed 3\%.

Atmospheric hydrogen concentrations should be carefully monitored. Enough research should be carried out to obtain a better understanding of hydrogen sources and sinks, and to provide an early warning system in case we have overlooked something. 


\section{2 \\ Hydrogen safety}

NIJS JAN DUIJM, RIS $\varnothing$ NATIONAL LABORATORY; LIONEL PERETTE, INERIS

\section{Safety issues of hydrogen as an energy carrier}

Hydrogen's extreme flammability implies safety concerns with its introduction as an energy carrier, especially in mobile applications such as cars. Many people relate the hazards of hydrogen to the Hindenburg accident, but a more realistic scenario would be the accident that happened in Stockholm in 1983 (see box). Would the intensive use of hydrogen by consumers result in more, and more serious, accidents than the one in Stockholm?

On Thursday 3 March 1983 a truck was delivering various industrial gases to sites in the Stockholm area. As a rack of argon gas cylinders was being unloaded, hydrogen escaped from a rack of 18 interconnected cylinders; each had a volume of $50 \mathrm{I}$ and a working pressure of 200 bar. Recent analysis estimates that the resulting explosion involved about $4.5 \mathrm{~kg}$ of hydrogen. It injured 16 people, heavily damaged the facade of the nearest building, damaged ten vehicles and broke windows within a radius of $90 \mathrm{~m} \mathrm{[1]}$

Hydrogen has some properties that make it more dangerous than conventional fuels such as gasoline, LPG (liquefied petroleum gas) and natural gas. Hydrogen's lower flammability limit in air is higher than that of LPG or gasoline, but its flammable range is very large (4-75\% hydrogen in air). In the concentration range of $15-45 \%$, the ignition energy of hydrogen is one-tenth than that of gasoline. The "quenching gap" the smallest hole through which a flame can propagate - is considerably smaller for hydrogen than for the other fuels, which means that the requirements for flame arrestors and similar equipment must be higher.

Hydrogen has a number of other properties that might cause hazardous situations if not properly accounted for, such as:

- hydrogen is a strong reducing agent, and in contact with metal oxides (rust) the resulting reaction can produce heat;

- hydrogen damages or is otherwise unsuitable for use with many materials conventionally used for vessels, pipelines and fittings;

- in contrast to other compressed gases, lowering the pressure of hydrogen increases its temperature (in engineering terms, hydrogen has a negative Joule-Thomson coefficient at ambient temperature). When hydrogen is released from a high-pressure vessel, the resulting increase in temperature can contribute to ignition;

- hydrogen forms explosive mixtures with many other gases, including chlorine and other halogens;
- hydrogen diffuses easily through many conventional materials used for pipelines and vessels, and through gaps that are small enough to seal other gases safely; and

- the safety literature suggests that releases of hydrogen are more likely to cause explosions than releases of methane [2,3].

In contrast to LPG and gasoline vapour, hydrogen is extremely light and rises rapidly in air. In the open this is generally an advantage, but it can be dangerous in buildings that are not designed for hydrogen. Many countries' building codes, for instance, require garages to have ventilation openings near the ground to remove gasoline vapour, but there is often no high-level ventilation. Hydrogen released in such a building collects at roof level, and the resulting explosion can be extremely destructive.

Hydrogen has been used widely and on a large scale for more than a hundred years in a variety of industrial applications. Of course there have been incidents with hydrogen, as there have been with other hazardous materials including gasoline, LPG and natural gas. In general, though, experience shows that hydrogen can be handled safely in industrial applications as long as users stick to the appropriate standards, regulations and best practices.

But this experience does not cover the use of hydrogen at extremely high pressures (over 350 bar), as a cryogenic liquid and as hydrides - all technologies that are likely to be required in a hydrogen economy. Most importantly, there is no precedent for the safe handling of hydrogen by people who have not received specific training to a professional standard. At present, hydrogen is handled in industries where operators receive training and instructions concerning safety, and hydrogen installations are subject to professional safety management and inspection by safety authorities. It will be a challenge to develop technologies and systems that can be used by general consumers, where similar dedication to safety is hard to enforce.

\section{Regulations and standards}

Regulations and standards help to ensure sound and consistent approaches to safety. They are therefore important in promoting the safe use of hydrogen on a wider scale.

Regulations and standards have different purposes. Regulations reflect legal constraints translated into safety objectives. They are set by governments, usually based 


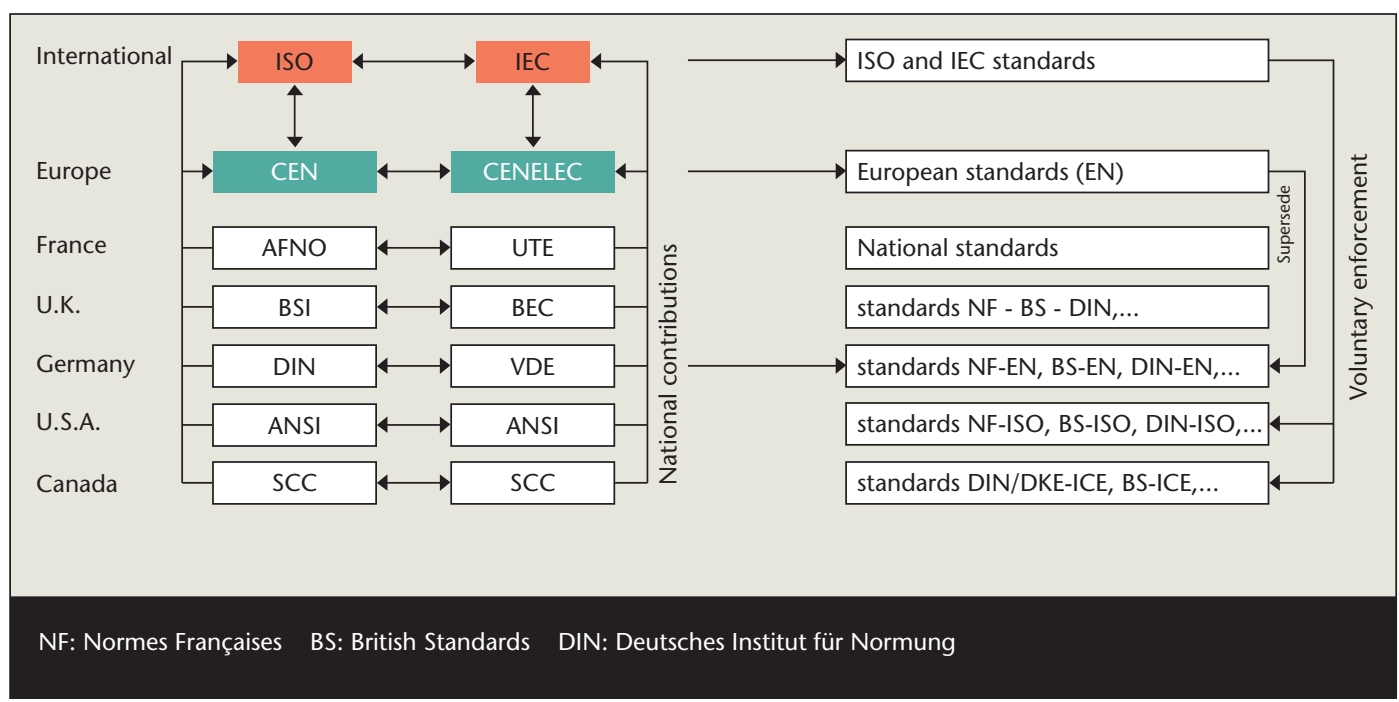

Figure 33: Standards bodies at international, European and national levels.

on European directives, to ensure the protection of citizens' health and fair trade. Regulations are mandatory. Standards set out the technical means by which safety objectives can be reached. They are built on consensus between companies in the industries concerned, and they are voluntary. Standards reassure stakeholders and end-users that safety matters have been considered. They provide a framework in which companies can carry out technical development, and companies can gain a commercial advantage by promoting the adoption of their own safety solutions as standards. Standardisation usually takes place at international or, for European companies, at European level.

In emerging technologies, standards always precede regulations. Creating new regulations takes time and requires considerable experience of the technology or product concerned. Poorly-drafted regulations can seriously hinder companies, but lack of regulations can equally be a problem for industry. Regulations help to make the business environment more predictable; without regulations there is always a risk that subsequent laws will force companies to abandon technologies or products in which they have already invested money. For this reason, companies and industry bodies actively push governments to design new regulations.

\section{Hydrogen regulations and standards: who is doing what? \\ Standards}

Standardisation work in hydrogen technologies is taking place mainly at international level. The International Organization for Standardization (ISO) and the International Electrotechnical Commission (IEC) are involved. International standards can eventually be converted into European standards, with or without modifications, which then supersede any national standards in Europe. At a European level, CENELEC (the European Committee for Electrotechnical Standardization) deals with the same range of subjects as the IEC, and CEN (the European Committee for Standardization) covers a similar area to that of ISO. National standardisation committees exist in IEC and ISO member countries. Figure 33 shows the relationships between ISO, IEC, CEN, CENELEC and various national organisations in Europe and north America.

IEC concerns itself with standards related to electric and electronic appliances. It therefore has a legitimate role in standards for fuel cells, including safety standards. IEC Technical Committee (TC) 105 is in charge of this work. More hydrogen-related subjects, including safety in hydrogen storage and distribution, are handled by ISO working groups. ISO TC 197 has been at work in this area since 1990. To avoid overlaps, information is exchanged between IEC and ISO, and TC 197 also has links to TC 22 (road vehicles), TC 58 (gas cylinders) and other ISO Technical Committees.

Most of the work of ISO TC 197 is dedicated to mobile applications. Canada, USA, and Germany are the most active countries in these working groups. IEC TC 105 has also been very active, even though it was established as late as in 1998. So far, ISO standards have been published on product specifications for hydrogen as a fuel (ISO 14687) and vehicle fuelling interfaces for liquid hydrogen (ISO 13984). Documents close to being published by both IEC and ISO cover basic safety considerations for hydrogen systems, fuel cells and airport fuelling applications. Work in progress covers vehicle storage for gaseous, liquid and hydride-absorbed hydrogen, fuelling systems and service stations, hydrogen generators and fuel cells. Safety is specifically addressed, for example in separate sections in the IEC documents.

At European level, CEN/CENELEC has created a technical committee known as Fuel Cell Gas Appliances to 
deal with domestic fuel cells with capacities of up to 70 $\mathrm{kW}$. This initiative follows demonstration projects involving small fuel cell systems, where neither appropriate regulations nor standards exist.

\section{Regulations}

European directives (the Machinery Directive, Electromagnetic Compatibility Directive, Gas Appliance Directive and others) apply to hydrogen systems whose manufacturers seek CE labelling. All these directives basically come down to risk assessment and safety features, and they apply to all self-contained products and systems, including portable and stationary fuel cells and hydrogen generators. CE labelling is compulsory for any product that is intended to be sold, rented or lent on the European market.

Large hydrogen plants such as steam methane reformers rely on the Major Hazards Directives and related national regulations.

Other European directives apply to cars. Existing directives do not cover neither gaseous nor cryogenic storage of hydrogen in cars. As with compressed natural gas (CNG) and LPG vehicles in the past, discussions are now taking place in Geneva under control of the dedicated working group UNECE WP29 (United Nations Economic Commission for Europe, Working Party 29). Current work is based on two draft documents for on-board hydrogen storage (gaseous and liquid), submitted by the European-funded European Integrated Hydrogen Project. (EIHP)

\section{Prospects for the safe use of hydrogen as an energy carrier}

Recent and future work on regulations and standards focuses on the safe use of hydrogen by untrained people. These regulations and standards are based on:

- experience learned from past incidents and accidents;

- a scientific approach; and

- public expectations.

So far, experience with new hydrogen technologies is scarce and is usually subject to commercial secrecy. Standards that are drawn up too early might miss crucial safety points. A substantial input from scientific researchers is therefore required. This scientific process should focus on:

- the long-term effect of hydrogen on materials used for piping, vessels and fittings under extreme conditions of pressure or temperature;

- requirements for equipment in potentially explosive hydrogen atmospheres;

- requirements for ventilation in car parks, garages, tunnels and other enclosed areas;
- the consequences of the diffusion of stored hydrogen, and ways to mitigate this;

- the consequences of accidental releases from storage and distribution systems, and ways to mitigate these;

- safety aspects of the behaviour of untrained consumers and their interaction with hydrogen technology, such as refuelling and vehicle maintenance.

The EIHP working group on safety concludes that overall hydrogen is no more hazardous, than conventional fuels [4]. However, says this group, the many ways in which hydrogen differs from conventional fuels make it necessary to perform detailed risk assessments for every stage in the hydrogen supply chain. A general requirement will be that hydrogen-based applications are always safer than the corresponding applications using conventional energy carriers.

Standards are based on consensus among companies who may be more interested in the technological and economic aspects than the science of safety. There must therefore be a dialog between standardisation working groups and safety experts, so that any doubts by the latter can be expressed and dealt with.

Safety was an integral activity of the EIHP [5], and this work will continue in a newly-created network of excellence entitled HYSAFE (Safe Use of Hydrogen as an Energy Carrier). HYSAFE brings together hydrogen safety experts from companies and research institutes across Europe, creating a meeting point for experts, standards working groups and national authorities. To promote its scientific and risk-based approach, HYSAFE plans to create a wide range of experimental and numerical tools which it can then use to investigate the safety of proposed standards.

The European Hydrogen and Fuel Cell platform and its dedicated working group on regulations and standards keeps an overview of the development of standards and identifies the need for new initiatives in this area.

\section{Conclusions and recommendations}

The international discussions now taking place will help to ensure adequate safety in the new hydrogen technologies. Early attention to safety issues, yet with care not to rush into premature technological pronouncements, and striving for international consensus all reinforce the idea that safety should be an integral part of hydrogen technology, and will help rather than hinder the growth of the hydrogen economy.

If these recommendations are followed there is no reason to believe that hydrogen will be riskier than conventional fuels. Accidents will happen, but careful planning will provide an acceptable level of safety and ensure that accidents such as the one in Stockholm remain rare. 



\section{Index}

ARGEMUC H2, 12

ATR, 26

BCC solid solution alloys, 35

Carbon nanotubes, 33

CEN, 64

CENELEC, 64

CEP, 11

chemisorption, 33

CHP plants, 40

Clean Energy Partnership, 11

CPO, 25, 26

CUTE, 12, 54

direct methanol fuel cells, 38, 47

DMFCs, 38, 47, 48, 49, 50, 51

DOE, 12,13

EFP, 17

EIHP, 65

energy vectors, 24

EU High Level Group for Hydrogen and Fuel Cells, 14

European Hydrogen Energy Thematic Network, 14

FreedomCAR partnership, 13

Fuel cells, 13, 14, 15, 17, 18, 19, 20, 21, 25, 26, 29, 37, 38, 40, 41, 42,47

gas turbines, $13,40,41,42$

GTs, 40

$\mathrm{HCCl}, 40$

High Level Group on Hydrogen and Fuel Cells, 6, 54

HLG, 13, 14, 54

Homogeneous charge compression ignition, 40

hydrogen infrastructure, 3, 5, 6, 7, 9, 10, 11, 12, 13, 14, 15, 45, 52, 53,54

Hydrogen infrastructure, 3, 4, 5, 6, 7, 10, 11, 12, 13, 14, 15, 45, 52, 53,

54,55

hydrogen-rich fuels, 5,37

HyNet, 3, 13, 14, 15, 54

HYSAFE, 18, 21, 65
ICEs, 42

IEA, 3, 13, 14

IEC, 47, 64

intermetallics, 34, 35

internal combustion engines, 12, 40, 42, 47, 59, 62

International Partnership for Hydrogen Energy Economy, 13

IPHE, 3, 6, 13, 14

Japan Hydrogen and Fuel Cell Demonstration Project, 12

LHV, 9

MCFC, 18, 37

MCFCs, 12, 13, 47

metal hydrides, 5, 10, 21, 33, 35, 36, 44, 49, 51

nanoporous materials, 10

New Hydrogen Project, 12

organometallic compounds, 10

PAFC, 37,38

PAFCs, $12,37,38$

PEMFC, 18, 37, 38, 39, 40, 41, 46, 49, 50, 51

PEMFCs, 10, 12, 13, 17, 21, 30, 37, 38, 42, 43, 44, 47, 48, 49, 50, 53, $54,57,58,59$

photobiological processes, 26

photofermentation, 27

physisorption, 33

portable electronic, 5, 47

POX, 25

PSO, 17

SECA, 12, 13

SOECs, 30

SOFC, 18, 19, 37, 38, 39, 40, 41, 51

SOFCs, 10, 12, 13, 17, 18, 21, 37, 38, 40, 41

Solid State Energy Conversion Alliance, 12

thermochemical cycles, 24

thermochemical processes, 28

uninterruptible power supplies, 38, 47, 49, 52

UPSs, $38,47,49,52$

WE-NET, 12 



\section{References for Chapter 3}

1. Bossel, Ulf (2004): The Hydrogen "illusion", Cogeneration and onsite power production, March-April 2004.

2. European Commission (1997): White Paper on renewable energy sources (COM(97)599).

3. European Commission (2001): Directive 2001/77 of September $27^{\text {th }} 2001$ on the Promotion of Electricity produced from Renewable Energy Sources in the internal electricity market.

4. European Commission (2003): Hydrogen Energy and Fuel Cells - A Vision of our Future, Final Report of the High Level Group, EUR 20719 EN.

5. HyNet (2004): Towards a European Hydrogen Energy Roadmap, prepared by the HyNet partners (www.HyNet.info).

6. IEA (2003): Comparative Review of National Programmes on Hydrogen and Fuel Cells R\&D, Hydrogen Co-ordination Group, IEA/CERT/ HCG(2003)1.

7. IEA (2004): Energy Technology: Facing the Climate Challenge Vol. One and Two (Draft for Comments), IEA/CERT(2004)01/ADD2

8. IPHE(2004): www.usea.org/iphe.

9. Iwai, Y. (2004): Japan's approach to commercialization of fuel cell/hydrogen technology. In Proc. 15 th World Hydrogen Energy Conf., Yokohama. 28PL-02, CD Rom, Hydrogen Energy Soc. Japan.

10. Sørensen, Bent et al. (2001): Hydrogen scenarios using fossil, nuclear or renewable energy, Roskilde University, DK-4000 Roskilde, Denmark.

11. Sørensen, Bent (2004a): Hydrogen and fuel cells, Elsevier Academic Press, Boston (expected December 04/Jan 05)

12. Sørensen, Bent (2004b): Renewable energy, $3^{\text {rd }}$ edition, Elsevier Academic Press, Boston (expected in June 04)

13. USDoE (2002): National hydrogen energy roadmap. Towards a more secure and cleaner energy future for America. United States Department of Energy, Washington DC.

14. USDoE (2003): International Energy Annual 2001. Energy Information Administration report DOE/EIA-0219(2001), US Department of Energy, Washington DC.

15. USDoE (2004): Hydrogen posture plan. An integrated research, development and demonstration plan. United States Department of Energy, Washington DC.

\section{References for Chapter 4}

1. Arnold, Erik \& Balázs, Katalina (1998). Methods in The Evaluation of Publicly Funded Basic Research. A Review for OECD. Technopolis. Available on www.technopolis.co.uk/reports.

2. Arundel, Anthony (2001). The relative effectiveness of patents and secrecy for appropriation. In Research Policy 30, 611-624.

3. Borup, Mads (2003). Research management between research and politics - strategy processes in national research programmes. In Research Management Processes under Rapid Change. Aarhus: The Danish Institute for Studies in Research and Research Policy.

4. Chorkendorff, Ib (2004). Fremtidens brintsamfund. Kvant 15 (1), 4 13
5. Foss Hansen, H. \& Holst Jørgensen, B. (1995). Styring af forskning. Kan forskningsindikatorer anvendes?. Copenhagen: Samfundslitteratur.

6. Hansson, Finn \& Holst Jørgensen, B. (eds.) (2002). Forskningens dilemmaer. En debatbog om ledelse og evaluering af forskning. Copenhagen: Samfundslitteratur.

7. Nørskov, J.K. \& Feidenhans'l, R. (Eds). (2004). Brintforskning i Danmark. Udfordringer og perspektiver. Unpublished white paper.

8. Regeringen (2003). Nye veje mellem forskning og erhverv - fra tanke til faktura. Copenhagen: Ministeriet for Videnskab, Teknologi og Udvikling.

9. Seymour, Richard.; Matthey, Johnson. (2004). Fuel Cell Market Survey: Patents, A Rich Vein of Knowledge. In Fuel Cell today. www.fuelcelltoday.com, 27 February 2004.

10. Videnskabsministeriet (2003a). Nye veje mellem forskning og erhverv - fra vilje til handling. København: Ministeriet for videnskab, teknologi og udvikling.

11. Videnskabsministeriet (2003b). Regeringens videnstrategi - viden i vækst. Baggrundsrapport. København: Ministeriet for videnskab, teknologi og udvikling.

\section{References for Chapter 5.1}

1. S. Lynum et al., in "How far are we from the Hydrogen Society?" Proceedings of Symposium on hydrogen - electrochemistry and energetics, Trondheim (NO), 16-18 Jun 1999, NTNU, Department of Materials Technology and Electrochemistry, Trondheim, 2000, p. 127-146, and 2. http://www.hyweb.de/index-e.html

2. Rostrup-Nielsen, J. R., Sehested, J., Nørskov, J.K., Adv. Catal., 47, 65 (2002).

3. Marion, C. P., and Slater, W. L., in Proc. $6^{\text {th }}$ World Petr. Congr., Frankfurt 1969, Vol. 3, p. 159

4. Ernst, W. S., Venables, S. C., Christensen, P. S., and Berthelsen, A. C., Hydrocarbon Process. 79, (3), 100-C (2000).

5. Bodke, A. S., Bharadwaj, S. S., and Schmidt, L. D., J. Catal. 179 138 (1998).

6. Basini, L., Aasberg-Petersen, K, Guarnoni, A., Aragno, A., and Østberg, M., Catal. Today 64, 9 (2001).

7. Dybkjær, I. and Christensen, T. S., Stud. Surf .Sci. Catal. 136, 435 (2001).

8. Rostrup-Nielsen, J. R. and Rostrup-Nielsen, T., Cattech (2002) (submitted).

9. Rostrup-Nielsen, J. R., Phys. Chem. Chem. Phys, 3, 283 (2001).

10. Rostrup-Nielsen, J. R. and Aasberg-Petersen, K. in Handbook of Fuel Cells - Fundamentals, Technology and Application (Eds. Vielstich, W., Gasteiger, H.A., Lamm, A.) Volume 3: Fuel Cell Technology and Applications. John Wiley \& Sons 2003.

11. Milne, T.A., Elam C. C. and Evans, R. J. 2002. Hydrogen from Biomass -State of the art and research challenges. Report for International Energy Agency. Agreement on the production and utilization of Hydrogen. Task 16, Hydrogen from Carbon-containing Materials. IEA/H $2 / T R-02 / 001.78$ p. 
12. Elam, C C, Padro, C E G, Sandrock, G. Luzzi, A, Lindblad, Hagen, E.F. 2003. Realising the hydrogen future: The International Energy Agencys effort to advance hydrogen energy technologies. Int. Journal. Hydrogen Energy. 28, 601-607.

13. Hallenbeck, P. C. and Benemannn J. R. 2002 International Journal of Hydrogen Energy 27, 1185-1193.

14. Babu S. P. 2002. Biomass gasification for hydrogen production process description and research needs. http://www.eere.energy.gov/hydrogenandfuelcells/hydrogen/iea/p dfs/gasification_report_sureshbabu.pdf.

15. Epstein, M. Spiewak I 1994. Review of the technology for solar gasification of carbonaceous materials. Proceedings of the 1994 ASME/JSME/JSES International solar energy conference, San Francisco, CA, pp. 79-91.

16. Savage, P.E, Gopalan, S., Mizan, T.I., Martino, C.J. Brock, E.E. (1995). Reactions at supercritical conditions: Applications and fundamentals. AIChE Journal. 41, 1723-1778.

17. Refs.: 1. P. Schmittinger, in "Electrochemical Hydrogen Technologies", ed. H. Wendt, Elsevier Amsterdam, 1990, p. 261-300; and 2. http://www.hyweb.de/index-e.html

18. J. Divisek and H. Wendt, in "Electrochemical Hydrogen Technologies", ed. H. Wendt, Elsevier Amsterdam, 1990, p.137-212.

19. H. Janßen, B. Emonts, H.-G. Groehn, H. Mai, R. Reichel, D. Stolten, „High-Pressure Electrolysis - The Key Technology for Efficient $\mathrm{H}_{2}$ Production", HYPOTHESIS IV, Proceedings Volume 1, 9.-14. September 2001, Stralsund, 172-177

20. Mogensen, M.; Bagger, C., in: Program and abstracts of 1998 Fuel cell seminar, Palm Springs, CA (USA), 16-19 Nov 1998. (Courtesy Associates Inc., Washington, DC, 1998) p. 96-99;

21. Jensen, S.H.; Høgh, J.V.T.; Barfod, R.; Mogensen, M., in: Energy technologies for Post Kyoto targets in the medium term. Proceedings. Risø international energy conference, Risø (DK), 19-21 May 2003. Sønderberg Petersen, L., Larsen, H. (eds.), Risø National Laboratory (DK). Systems Analysis Department; Risø National Laboratory (DK). Information Service Department. Risø-R-1405(EN) (2003) p. 204-215).

22. W. Dönitz et al. in "Electrochemical Hydrogen Technologies", ed. H. Wendt, Elsevier Amsterdam, 1990,p.213-259)

\section{References for Chapter 5.2}

1. http://www.e-sources.com/hydrogen/storage.htm

2. http://www.dynetek.com/

3. http://www.dti.gov.uk/renewable/hydrogen_casestudies.html tees valley

4. http://www.bellona.no/en/energy/hydrogen/report_62002/22979.html

5. http://www.wordiq.com/definition/Hydrogen

6. http://www.eere.energy.gov/hydrogenandfuelcells/pdfs/liquefaction_comp_pres_praxair.pdf

7. http://www.euweb.de/fuel-cell-bus/storage.htm

8. Schlapbach L., Zuettel A., Nature 414, 353 (2001)

9. Orimo S.-I., Majer G., Fukunaga T., Züttel A., Schlapbach L., Fujii $\mathrm{H} ., \mathrm{Hydrogen}$ in the mechanically prepared nanostructured graphite, Appl. Phys. Lett. 75, 3093 (1999)

10. Dillon A.C., Jones K. M., Bekkedahl T. A., Kiang C. H., Bethune D. S., Heben M. J., "Storage of hydrogen in single-walled carbon nanotubes", Nature 386:6623, 377-379 (1997).
11. Hirscher M., guest editor of the special issue "Hydrogen storage in nanoscale carbon and metals", Appl. Phys. A 72, 2 (2001); Hirscher M., Becher M., Haluska M., Dettlaff-Weglikowska U., Quintel A., Duesberg G. S., Choi Y. M., Downes P., Hulman M., Roth S., Stepanek I., Bernier P., "Hydrogen storage in sonicated carbon materials", Applied Physics A 72 (2001), pp. 129-132.

12. Züttel A., Nützenadel Ch., Sudan P., Mauron Ph., Emmenegger Ch., Rentsch S., L. Schlapbach L., Weidenkaff A., Kiyobayashi T., "Hydrogen sorption by carbon nanotubes and other carbon nanostructures", J. Alloys and Compounds 330, 676 (2002); Zuettel A, Sudan P., Mauron P., Wenger P, Appl. Phys. A 78, 941 (2004).

13. Schlapbach L., ed., "Hydrogen in Intermetallic Compounds I Electronic, Thermodynamic, and Crystallographic Properties, Preparation", Springer Series Topics in Applied Physics, Vol. 63 (1988), ISBN 3-540-18333-7; Schlapbach L., ed., "Hydrogen in Intermetallic Compounds II Surface and Dynamic Properties, Applications", Springer Series Topics in Applied Physics 67 (1992), ISBN 3-54054668-5

14. Sandrock G., Thomas G., "The IEA/DOC/SNL on-line hydride databases", Applied Physics A 72:2 153-155 (2001).

15. Zaluska, L. Zaluski, J.O. Stroem-Olsen, "Structure, catalysis and atomic reactions on the nano-scale: a systematic approach to metal hydrides for hydrogen storage", Appl. Phys. A 72:2, 157 (2001).

16. Yvon K., "Complex Transition Metal Hydrides", Chimia 52:10, 613619 (1998)

17. Liu F. J., Suda S., "A method for improving the long-term storability of hydriding alloys by air water exposure", Journal of Alloys and Compounds 231:1-2, 742-750 (1995).

18. Akiba E., Iba H., "Hydrogen absorption by Laves phase related BCC solid solution", Intermetallics 6:6, 461-470 (1998); Tsukahara M., Kamiya T., Takahashi K., Kawabata A., Sakurai S., Shi J., Takeshita H.T., Kuriyama N., Sakai T., "Hydrogen storage and electrode properties of V-based solid solution type alloys prepared by a thermic process", Journal of the Electrochemical Society 147:8, 2941-2944 (2000)

19. Inoue H., Miyauchi R.,Tanaka T., Choi W.-K., Shin-ya R., Murayama J.-i. and Iwakura Ch., "Effect of ball-milling with $\mathrm{Ni}$ and Raney $\mathrm{Ni}$ on surface structural characteristics of TiV2.1Ni0.3 alloy", Journal of Alloys and Compounds, Volume 325, Issues 1-2, 299-303(2001)

20. Zuettel A., Naturwissenschaften 91, 157 (2004).

21. Bogdanovic B., Schwickardi M., "Ti-doped alkali metal aluminium hydrides as potential novel reversible hydrogen storage materials", Journal of Alloys and Compounds 253, 1-9 (1997).

22. Weidenthaler C., Pommerin A., Felderhoff M., Bogdanovic B., Schueth F., Phys. Chem. Chem. Phys. 5, 5149 (2003)

\section{References for Chapter 5.3}

1. Assadi M., Hildebrandt A., Kemm M., Hermann F., Pålsson J., Ernebrandt S., "A general overview of solid oxide fuel cell hybrid systems", CIMAC 2004, Japan.

2. Pålsson J., Tunestål P., Hansen J., Assadi M., "Hybrid cycles based on solid oxide fuel cell and internal combustion engine (SOFC- $\mathrm{HCCl}$ ) for flexible operation", CIMAC 2004, Japan.

3. M. Kemm, A. Hildebrandt, M. Assadi, "Operation And Performance Limitations For Solid Oxide Fuel Cells And Gas Turbines in a Hybrid System", ASME TURBO EXPO 2004, Vienna, Austria. 
4. Hildebrandt, M.Genrup, M. Assadi, "Steady State and Transient Compressor Surge Characteristics within a Sofc-GT-Hybrid System", ASME Turbo EXPO 2004, Vienna, Austria.

5. Fredriksson Möller B., Arriagada J., Assadi M., Potts I., "Optimisation of an SOFC/GT system with $\mathrm{CO}_{2}$ Capture", Grove Fuel Cell Conference, 2003, UK.

6. Gabrielsson R., Torisson T., "Research and development for turbomachinery based electric generation in a sustainable energy system", ISRN LUMDN/MHP-03/3010-SE, Dept. of Heat and Power Eng., Lund Inst. of Technology, 2003.

7. Christiansen N., Kristensen S., Holm-Larsen H., Larsen P.H., Mogensen M., Hendriksen P.V., Linderoth S., "Status and Recent Advances in SOFC Development at Haldor Topsøe/Ris $\varnothing^{\prime}$, Proc. $6^{\text {th }}$ European Solid Oxide Fuel Cell Forum, 2004.

8. Hansen, J.B., "Fuels and Fuel Processing Options for Fuel Cells", Proc. Fuel Cell World, Lucerne, 2004.

\section{References for Chapter 5.5}

1. IEC TC 15 WG 8 , draft 2

2. D. Geppert, Gun-Tag Kim, "Brennstoffzellensysteme für LaptopComputer und andere elektronische Geräte", Proceedings f-cell 2002 meeting, Stuttgart (Germany)

\section{References for Chapter 5.6}

1. A National Vision of America's Transition to a Hydrogen Economy To 2030 and Beyond. United States Department of Energy. February 2002.

2. National Hydrogen Energy Roadmap. United States Department of Energy. November 2002

3. National Hydrogen Study. Australian Government. Department of Industry, Tourism and Resources. A report prepared by ACIL Tasman and Parson Brinckerhoff. 2003.

4. National hydrogen Program (WE-NET Project phase II: World Energy Network, International co-operation in research and development of clean energy system with particular emphasis on hydrogen.). Ministry of Economy Trade and Industry, METI / New Energy and Industrial Technology Development Organization (NEDO). Japan. Annual Report 2001.

5. Hydrogen Energy and Fuel Cells - a Vision of our Future. Summary Report. High Level Group for Hydrogen and Fuel Cells (Initiated in October 2002 by EC). European Commission. June 2003

6. Market Development of Alternative Fuels. Report of the Alternative Fuels Contact Group (EU contact group of stakeholders set up in 2002). December 2003.

7. Well-to-Wheels Analysis of Future Automotive Fuels and Powertrains in the European Context. Version 1b. Concawe (European Oil Industry); EUCAR (European car manufacturers); Joint Research Centre, Ispra. January 2004.

8. Scenarier for samlet udnyttelse af brint som energibærer i Danmarks fremtidige energisytem, RUC, DONG, Elkraft system, Risø, April 2001.

9. Hydrogen Posture Plan, An Integrated Research, Development, and Demonstration Plan, February 2004, United States Department of Energy.
10. The Future of the Hydrogen Economy: Bright or Bleak? Ulf Bossel; Baldur Eliasson; Gordon Taylor. Version of 15 April 2003 updated for distribution at the "003 Fuel Cell Seminar 3-7 November 2003.

11. Swedish Academy foresight for Sweden study, Energy Foresight Sweden in Europe", Royal Swedish Academy of Engineering Sciences, IVA, Stockholm, 2003.

12. Andersen, Paw, Celia Juhl, Lars Bo Pedersen, Asger N. Myken, Henrik Iskov: Brint som energibærer. Dansk Gasteknisk Center. 1999. ISBN 87-7795-172-7.

13. Future Business Opportunities for the Gas Industry in a Hydrogen Economy, Report of Study Group 7.4, 22nd World Gas Conference, June 1-5, 2003 Tokyo, Japan

14. The European Commision's Green Paper "Towards a European Strategy for the security of energy supply".

15. Brints anvendelighed for ren brintdistribution. Henrik Iskov. Dansk Gasteknisk Center 2004. ISBN 87-7795-253-7.

16. Towards a European Hydrogen Energy Roadmap. Executive Report. HyNet Co-ordination Office, Dr. Ulrich Bünger, L-B-Systemtechnik GmbH.12 May 2004.

17. Kaske, G.; Plenard, F.J. 1985. High-purity hydrogen distribution network for industrial use in Western Europe. Chemische Werke Hülls, Marl, F.R.G.; L'Air Liquide, Paris, France. Int. J. Hydrogen Energy, Vol. 10, No. 7, pp. 479-482

\section{References for Chapter 6.1}

1. Eurotrac, 2002

2. Finlayson-Pitts, Pitts, Jr.; Atomspheric Chemistry; 1986 p. 17 John Wiley \& sons ISBN 0-471-88227-5

3. GDCH - gesellschaft Deutscher Chemiker, Pressedienst 27/03 (20. August 2003) Ist Wasserstofftechnologie wirklich umweltverträglich? http://www.gdch.de/pubrelat/wpd2703.htm

4. Hauglastine, D.A. \& Ehhalt, D. H. A three-dimensional model of molecular hydrogen in the troposphere. Journal of Geophysical Research, 107, D17, 4330

5. Heiklen, Julian (1976) Atomspheric chemistry, Academic Press page $7 \& 28$

6. IPCC 2001, Climate Change 2001: The Scientific Basis; page 260 table 4.8; ISBN 0521014956

7. Kammen DM, Lipman TE, Assessing the future hydrogen economy, Science 302 (5643): 226-226 Oct. 102003

8. Lehman PA, Assessing the future hydrogen economy, Science 302 (5643): 227-228 Oct. 102003

9. Lovins $A B$, Assessing the future hydrogen economy, Science 302 (5643): 226-227 Oct. 102003

10. Novelli, P.C et al Molecular hydrogen in the troposphere: Global distribution and budget. Journal of Geophysical Research, 104, D23, 30, 427- 40,444, 1999

11. Pielke RA, Klein R, Maricle $G$, et al., Hydrogen cars and water vapour, Science 302 (5649): 1329-1329 Nov. 212003

12. Prather MJ, An environmental experiment with $\mathrm{H}_{2}$ ?, Science 302 (5645): 581-582 Oct. 242003

13. Schultz MG, Diehl T, Brasseur GP, et al. Air pollution and climateforcing impacts of a global hydrogen economy, Science 302 (5645): 624-627 Oct. 242003

14. Schultz, Feichter, and Leonardi, 2004 
15. Tracey K. Tromp, Run-Lie Shia, Mark Allen, John M. Eiler, Y. L. Yung, Potential Environmental Impact of a Hydrogen Economy on the Stratosphere, Science, Vol 300, Issue 5626, 1740-1742, 13 June 2003

16. Warwick et al., 2004

17. WMO2002

\section{References for Chapter 6.2}

1. A.G. Venetsanos, T. Huld, P. Adams, J.G. Bartzis, Source, dispersion and combustion modelling of an accidental release of hydrogen in an urban environment, Journal of Hazardous Materials 2003, No 105 p $1-25$
2. H. Iskov, Sikkerhedsforhold og myndighedsgodkendelse ved brintanvendelse til køretøjer (Safety aspects and authority approval of the use of hydrogen in vehicles, in Danish), Dansk Gasteknisk Center, Hørsholm, Denmark, 2000, 45 pages

3. L. Roth, U. Weller, Gefärliche Chemische Reaktionen, (Hazardous Chemical Reactions, in German) CD-ROM version 2000, Ecomed Verlagsgeselschaft AG \& Co, Landsberg, Germany, 1996)

4. J.L. Alcock, L.C. Shirvill, R.F. Cracknell, Compilation of Existing Safety Data on Hydrogen and Comparative Fuels, Deliverable Report, ElHP2, May 2001)

5. European Integrated Hydrogen Project - Phase 2, Final Technical Report, L-B-Systemtechnik GmbH, April 2004 

